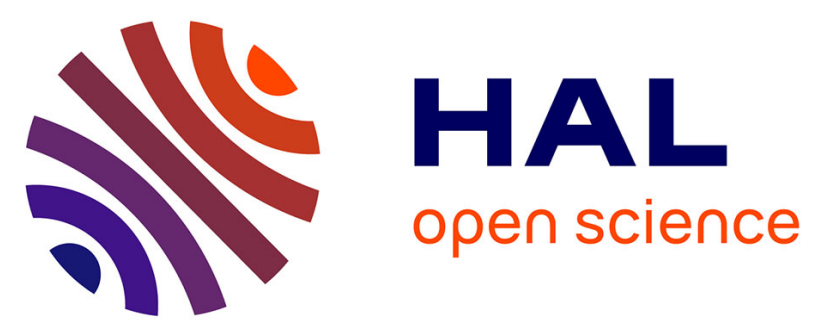

\title{
Development of a thermodynamic approach to assist the control of the precipitation of hydroxyapatites and associated calcium phosphates in open systems
}

Corentin Reynaud, Cyril Thomas, Sandra Casale, Sophie Nowak, Guylène Costentin

\section{To cite this version:}

Corentin Reynaud, Cyril Thomas, Sandra Casale, Sophie Nowak, Guylène Costentin. Development of a thermodynamic approach to assist the control of the precipitation of hydroxyapatites and associated calcium phosphates in open systems. CrystEngComm, 2021, 23 (27), pp.4857-4870. 10.1039/D1CE00482D . hal-03343001

\section{HAL Id: hal-03343001 https://hal.sorbonne-universite.fr/hal-03343001}

Submitted on 13 Sep 2021

HAL is a multi-disciplinary open access archive for the deposit and dissemination of scientific research documents, whether they are published or not. The documents may come from teaching and research institutions in France or abroad, or from public or private research centers.
L'archive ouverte pluridisciplinaire HAL, est destinée au dépôt et à la diffusion de documents scientifiques de niveau recherche, publiés ou non, émanant des établissements d'enseignement et de recherche français ou étrangers, des laboratoires publics ou privés. 


\title{
Development of a thermodynamic approach to assist the control of the precipitation of hydroxyapatites and associated calcium phosphates in open systems
}

\author{
Corentin Reynaud, ${ }^{1}$ Cyril Thomas, ${ }^{1}$ Sandra Casale, ${ }^{1}$ Sophie Nowak ${ }^{2}$ and Guylène Costentin ${ }^{1 *}$ \\ ${ }^{1}$ Sorbonne Université, CNRS, Laboratoire de Réactivité de Surface (LRS), 4 place Jussieu, \\ 75005 Paris, France \\ ${ }^{2}$ Plateforme Rayons X, UFR de Chimie, Université Paris Diderot, Paris, France \\ *E-mail: guylene.costentin@sorbonne-universite.fr
}

\begin{abstract}
The understanding of the precipitation mechanisms of calcium phosphates (CaPs) remains extremely challenging despite its fundamental interest for material sciences and its practical implications in medicine, paleosciences, and chemistry, especially for heterogeneous catalysis. The competitive precipitation of $\mathrm{CaPs}$, such as hydroxyapatite, octacalcium phosphate and dicalcium phosphate, has been shown experimentally to be strongly impacted by the $\mathrm{pH}$ of the precipitating medium. However, the thermodynamic validation of this observation, based on the solubility isotherms reported in the literature, could not be comprehensively substantiated. In the present study, we developed a thermodynamic prediction model adapted to the synthesis of CaPs in open systems (dropwise synthesis). By overcoming the theoretical limits of the solubility isotherms to explain their precipitation features, this new thermodynamic model makes it possible
\end{abstract}


to shed light on the influence of the common ion effect on the stability of these materials in aqueous solution. Finally, this work paves the way to a methodological approach that could be of broad interest in the field of the precipitation of inorganic materials when a continuous flow addition is used.

\section{INTRODUCTION}

Calcium phosphates $(\mathrm{CaPs})$ are materials of wide interest in many fields (medicine, ${ }^{1,2}$ geosciences, ${ }^{3,4}$ paleosciences, ${ }^{5-7}$ chemistry ${ }^{8-10} \ldots$ ) due, among other things, to their biocompatibility, and mechanical and surface properties. They present distinct $\mathrm{Ca} / \mathrm{P}$ ratios ranging from 1.00 to 1.67 and are likely to precipitate in aqueous solution under soft chemistry conditions. This is the case of hydroxyapatite $(\mathrm{HAp}, \mathrm{Ca} / \mathrm{P}=1.67)$ of generic formula $\mathrm{Ca}_{10}\left(\mathrm{PO}_{4}\right)_{6}(\mathrm{OH})_{2}$, amorphous calcium phosphate $(\mathrm{ACP}, \mathrm{Ca} / \mathrm{P}=1.50)$ that consists of $\mathrm{Ca}_{9}\left(\mathrm{PO}_{4}\right)_{6}$ units generally referred to as Posner's clusters, ${ }^{11}$ octacalcium phosphate $(\mathrm{OCP}, \mathrm{Ca} / \mathrm{P}=1.33)$ of generic formula $\mathrm{Ca}_{8}\left(\mathrm{HPO}_{4}\right)_{2}\left(\mathrm{PO}_{4}\right)_{4} \cdot 5 \mathrm{H}_{2} \mathrm{O}$, as well as dicalcium phosphate dihydrate (DCPD, $\mathrm{CaHPO}_{4} \cdot 2 \mathrm{H}_{2} \mathrm{O}$, $\mathrm{Ca} / \mathrm{P}=1.00)$ and dicalcium phosphate anhydrous $\left(\mathrm{DCPA}, \mathrm{CaHPO}_{4}, \mathrm{Ca} / \mathrm{P}=1.00\right)$. Hydroxyapatite is the main mineral constituent of bones and teeth, while ACP and OCP are proposed to be its in vivo precursors in the biomineralization mechanisms. ${ }^{12,13}$ Interestingly, owing to its great flexibility, the HAp structure exhibits peculiar affinity for both cationic and anionic substitutions. Together with its non-stoichiometric properties, often expressed as the modulation of the $\mathrm{Ca} / \mathrm{P}$ ratio, such a tunable composition impacts its bioactive, mechanical and surface properties, making this system attractive for dental treatments, ${ }^{14,15}$ osteointegration, ${ }^{16}$ heavy-metal waste water or soil remediation ${ }^{17,18}$ and heterogeneous catalysis applications. ${ }^{8-10,19}$ As these different minerals are likely to precipitate competitively in aqueous solution, the understanding of 
the precipitation mechanisms could make it possible to design highly selective syntheses in terms of crystalline phase composition, crystallographic defects incorporation and textural properties. Such insights into these in vitro mechanisms could also provide keys for the appreciation of in vivo mineralization processes, such as osteogenesis..$^{20,21}$ In addition, HAp materials have emerged as eco-friendly heterogeneous catalysts, ${ }^{17}$ both as a bulk tunable active phase and as a suitable support for the controlled surface deposition of highly-dispersed catalytic metallic centers, ${ }^{9}$ being of interest for both liquid solvent-free medium, ${ }^{10,22,23}$ and gas phase reactions. ${ }^{9,24}$ Given the significant impact of the preparation conditions on the texture and the composition (nonstoichiometric properties) of the apatitic compounds, ${ }^{8}$ there is a crucial need in the rationalization of the key synthesis parameters to be tuned to control the surface reactivity.

Hydroxyapatite is extensively prepared by co-precipitation routes, ${ }^{8,25}$ which are highly sensitive to the $\mathrm{pH}$ of the reaction medium that strongly influences the nature of the precipitated calcium phosphate(s). ${ }^{26}$ In particular, gel and $\mathrm{NH}_{3}$ vapor diffusion techniques were developed as biomimetic protocols to study, inter alia, the effects of matrix molecules on CaPs mineralization. ${ }^{27-30}$ Besides, numerous protocols reported to date for its preparation involve the dropwise addition of a phosphate source in a calcium one (or vice versa). As a result, the thermodynamic modelling of CaPs dissolution in closed systems (solubility isotherms), widely cited to explain the formation of HAp in alkaline and neutral media, and that of DCPA in an acidic one, appears to be inadequate to account for the thermodynamic precipitation predictions in such current open systems..$^{31,32}$

The present study aims at investigating how thermodynamics influences the precipitation reactions. To decorrelate the thermodynamic and kinetic aspects of CaPs precipitation, the present study focuses on their dropwise syntheses, under quite soft chemistry conditions (water as a 
solvent, moderate temperatures, long reaction times, and high concentration of precursors). The combination of a theoretical and an experimental approach made it possible to analyze the influence of various experimental parameters such as the $\mathrm{pH}$, the temperature, the final

concentration ratio $\left[\mathrm{Ca}^{2+}\right] /\left[\mathrm{H}_{x} \mathrm{PO}_{4}^{(3-x)-}\right]=\left[\mathrm{Ca}^{2+}\right] /[\mathrm{P}]$ introduced into the reactor as well as the order of introduction of the precursor ions on materials synthesized under thermodynamic control. It is rationalized how setting these experimental parameters can help control the HAp morphology in the absence of organic solvent or additive. ${ }^{33-35}$ From an industrial point of view, the establishment of such interconnection between the experimental parameters and the properties of the synthesized materials is of the utmost interest. ${ }^{36-38}$ The purpose of this study lies in the indepth analysis of the thermodynamic aspects of the competitive precipitation of CaPs, whereas the complementary kinetic aspects will be investigated in a forthcoming article. Synthesized $\mathrm{CaP}$ powders have been characterized by X-Ray diffraction (XRD), Raman spectroscopy, X-Ray fluorescence spectroscopy (XRF), scanning electron microscopy (SEM) and $\mathrm{N}_{2}$ sorption. The synthesis routes implemented at stationary $\mathrm{pH}$ to validate the thermodynamic model have made it possible to greatly modulate the $\mathrm{Ca} / \mathrm{P}$ ratio of the HAp material as well as its morphology and specific surface area (SSA), which is of particular interest in the context of applications in heterogeneous catalysis in order to establish structure-activity relationships. ${ }^{39}$

\section{MATERIALS AND METHODS}

Material synthesis. Calcium phosphates were prepared via a co-precipitation procedure using an automated reactor (Optimax 1001 synthesis workstation, Mettler Toledo) that allows controlling, inter alia, both $\mathrm{pH}$ and temperature profiles as well as the addition rate of the precursor solutions (Figure 1). ${ }^{40}$ Calcium and phosphate solutions were prepared by dissolving $12.81 \mathrm{mg}$ of 
$\mathrm{Ca}\left(\mathrm{NO}_{3}\right)_{2} \cdot 4 \mathrm{H}_{2} \mathrm{O}$ (Sigma Aldrich, purity $\geq 99.0 \%$ ) and $3.74 \mathrm{mg}$ of $\left(\mathrm{NH}_{4}\right)_{2} \mathrm{HPO}_{4}$ (Acros Organics, purity $\geq 99.0 \%$ ) in $250 \mathrm{~mL}$ of ultrapure water (resistivity of $18.2 \mathrm{M} \Omega \times \mathrm{cm}$ at $25^{\circ} \mathrm{C}$ ), respectively. Two synthesis routes, $\mathrm{Ca} \rightarrow \mathrm{P}$ and $\mathrm{P} \rightarrow \mathrm{Ca}$, were considered depending on the order of introduction of the precursor ions into the reactor. Both syntheses were carried out at $80{ }^{\circ} \mathrm{C}$ (unless stated otherwise) and at constant $\mathrm{pH}$ in the reactor of 9.0, 6.5 and 4.2. The typical procedure is detailed in the case of the $\mathrm{Ca} \rightarrow \mathrm{P}$ route performed at $80{ }^{\circ} \mathrm{C}$ and operating at steady $\mathrm{pH}$ of 9.0. The phosphate solution ([P] $\left.]_{0}=0.13 \mathrm{~mol} / \mathrm{L}, 200 \mathrm{~mL}\right)$ was first adjusted to $\mathrm{pH} 10.0$ by the addition of a small volume of concentrated ammonia (Sigma Aldrich, $28 \%$ ) before being poured into the reactor and maintained under an inert atmosphere $\left(\mathrm{N}_{2}\right)$. This phosphate solution was then gradually heated up to $80{ }^{\circ} \mathrm{C}\left(5{ }^{\circ} \mathrm{C} / \mathrm{min}\right)$ under mechanical stirring $(400 \mathrm{rpm})$. The temperature of the reaction medium is known to influence the acid-base equilibrium governing the $\mathrm{pH}$. The $\mathrm{pH}$ of the phosphate solution was found to decrease as the temperature increased ( $\mathrm{S} 1$ and Figure S1A) and was adjusted to a value of 9.0 by adding concentrated ammonia drop by drop (Figure S1B). Depending on the targeted final ratio $\left[\mathrm{Ca}^{2+}\right] /[\mathrm{P}]$ of 1.67 or 1.50 , an appropriate volume of the calcium solution $\left(\left[\mathrm{Ca}^{2+}\right]_{0}=0.22 \mathrm{~mol} / \mathrm{L}\right)$, beforehand degassed by bubbling $\mathrm{N}_{2}$ for 15 minutes and adjusted to $\mathrm{pH} 10.0$ by the addition of concentrated ammonia, was poured at a controlled speed $(2.2 \mathrm{~mL} / \mathrm{min})$ into the reactor. During this step, the $\mathrm{pH}$ was kept constant with the automated addition of suitable volumes of concentrated ammonia. Note that the $\mathrm{pH}$ of the medium in the reactor is easier to maintain constant by the system during a $\mathrm{Ca} \rightarrow \mathrm{P}$ rather than a $\mathrm{P} \rightarrow$ Ca synthesis because of the higher buffering capacity of the phosphate solution compared to that of the calcium one (Figure S1C). In some cases, once the addition step was completed, a $2 \mathrm{~h}$ maturation step at $80^{\circ} \mathrm{C}$ and $\mathrm{pH} 9.0$ was eventually performed. The reactor temperature was then cooled down to $20^{\circ} \mathrm{C}$ within a few minutes. In most cases, the white precipitate was recovered by 
centrifugation (8500 rpm) and washed three times with distilled water to mainly remove ammonia, and ammonium and nitrate ions. The wet sample was then recovered on a watch glass and dried at room temperature for 12 hours before being finely ground in an agate mortar. In the case of syntheses at $\mathrm{pH} 4.2$, as discussed in section II - 1.2., the precipitates were rapidly recovered by Büchner filtration and washed promptly with distilled water.

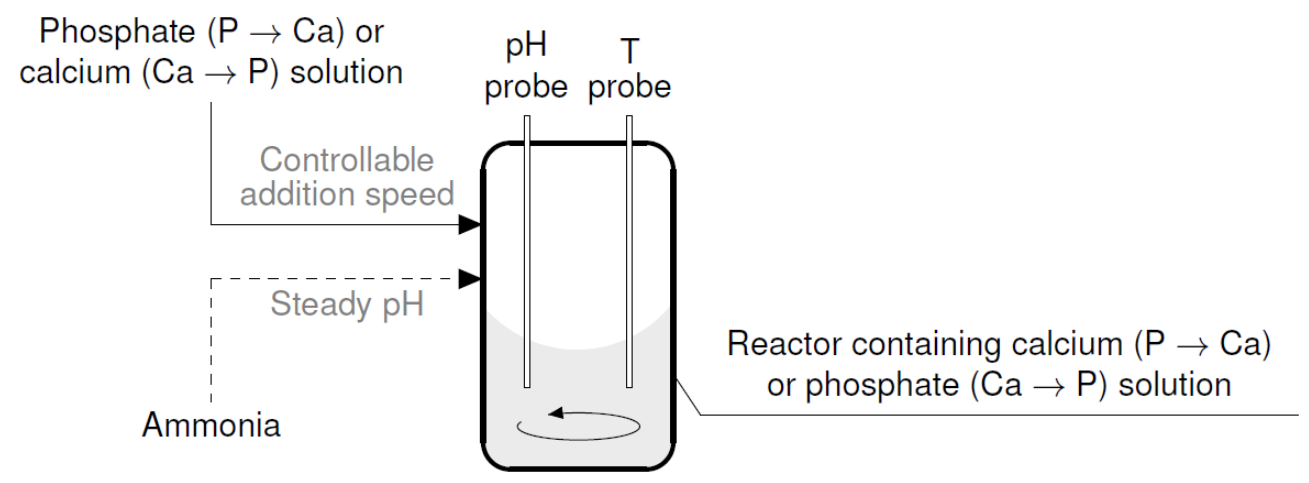

Figure 1. Schematic representation of the automated reactor used for the precipitation of calcium phosphates.

X-ray diffraction. Laboratory X-ray diffraction patterns were recorded with a Brucker D8 Advance diffractometer equipped with a copper source $\left(\lambda_{\mathrm{Cu}-K_{\alpha 1}}=1.54056 \AA\right.$ and $\lambda_{\mathrm{Cu}-K_{\alpha 2}}=$ $1.54439 \AA$ ) and a LynxEye detector. XRD patterns were recorded by $0.02^{\circ}$ steps in the $2 \theta$ range of 8-90 ${ }^{\circ}$ for high-angle diffraction. For low-angle XRD, a blade was added to the experimental set-up to prevent the detector from directly receiving the incident X-ray beam and patterns were recorded by $0.02^{\circ}$ steps in the $2 \theta$ range of $1-6^{\circ}$. The indexation of the XRD lines of the CaP phases is reported in S2 (Table S2A).

Raman spectroscopy. Raman spectra were collected with a Kaiser Optical system equipped with a charge couple detector (CCD) and a laser with $\lambda=785 \mathrm{~nm}(P=12$ or $25 \mathrm{~mW}$, resolution $=4 \mathrm{~cm}^{-1}$, accumulation time $=30 \mathrm{~s}, 30$ scans per spectrum). Poorly crystalline powders were 
analyzed with a laser power of $25 \mathrm{~mW}$ instead of $12 \mathrm{~mW}$ to improve the signal-to-noise ratio, without any noticeable observation of material degradation. Assignment of the Raman bands of the CaP phases is provided in S2 (Table S2B).

Scanning electron microscopy. Scanning Electron Microscopy with Field Emission Gun (SEM-FEG) was used for morphological investigation of the materials. High resolution images were obtained with a Hitachi SU-70 microscope. The samples were fixed on an alumina SEM support with a carbon adhesive tape and were observed without any metal coating. Secondary electron detector (SE-Lower) was used to observe the samples. The low accelerating voltage was $1 \mathrm{kV}$ to prevent charging effects of the insulating CaPs and the working distance was around 10 to $15 \mathrm{~mm}$.

N2 sorption. Specific surface area measurements were carried out on a BELSORP-max instrument (BEL Japan) at $77 \mathrm{~K}$ after evacuation of the samples at $140{ }^{\circ} \mathrm{C}$ for $12 \mathrm{~h}$ under vacuum. This parameter was estimated by using the BET method in the $0.05<p / p^{0}<0.30$ domain.

X-ray fluorescence spectroscopy. $\mathrm{Ca} / \mathrm{P}$ bulk ratio of the prepared $\mathrm{CaPs}$ was determined following a quantitative XRF protocol. In order to avoid matrix and grain size effects, all samples were melted into "beads" and analyzed with a X-ray fluorimeter Epsilon 3xl (Panalytical) equipped with an Ag X-ray tube operating under He atmosphere, with two conditions: $12 \mathrm{kV}-25$ $\mu \mathrm{A}$ during $120 \mathrm{~s}$ for the analysis of calcium and $10 \mathrm{kV}-30 \mu \mathrm{A}$ during $120 \mathrm{~s}$ for that of phosphorus. The bead was prepared by mixing approximately $0.114 \mathrm{~g}$ of sample, $1.231 \mathrm{~g}$ of fluxing agent $\left(\mathrm{LiBO}_{2} / \mathrm{Li}_{2} \mathrm{~B}_{4} \mathrm{O}_{7}\right)$ and $0.019 \mathrm{~g}$ of non-wetting agent $(\mathrm{LiBr})$ in a platinum crucible. The mixture was heated to $1050{ }^{\circ} \mathrm{C}$ for 25 minutes in a fusion instrument (LeNeo fluxer, Claisse). Calibration curves were obtained from beads of mechanical mixtures of the precursors $\mathrm{Ca}\left(\mathrm{NO}_{3}\right)_{2} \cdot 4 \mathrm{H}_{2} \mathrm{O}$ and 
$\left(\mathrm{NH}_{4}\right)_{2} \mathrm{HPO}_{4}$ used for the material synthesis (Figure $\mathrm{S} 3$ ). Their relative proportions were chosen in order to prepare reference samples with a $\mathrm{Ca} / \mathrm{P}$ ratio framing those of calcium phosphates, although with this methodology, the response is perfectly linear over the entire concentration range.

\section{RESULTS AND DISCUSSIONS}

The solubility of CaPs has been found to be strongly dependent on the $\mathrm{pH}$ of the aqueous medium. Being very weakly soluble in basic media, these minerals solubilize to a significant extent in acidic ones (S4). ${ }^{41,42}$ Such an increase in the solubility of CaPs at low $\mathrm{pH}$ is accounted for by the speciation diagram of the phosphate species in solution (Figures S4A and S4B). As the $\mathrm{pH}$ decreases, the protonation of the $\mathrm{PO}_{4}^{3-}$ and $\mathrm{HPO}_{4}^{2-}$ groups of CaPs, into $\mathrm{HPO}_{4}^{2-}, \mathrm{H}_{2} \mathrm{PO}_{4}^{-}$and $\mathrm{H}_{3} \mathrm{PO}_{4}$ species, leads to a shift of the dissolution-precipitation equilibria towards the dissolution of the

CaPs (Table 1, S4). These observations, formalized by the solubility isotherms, ${ }^{31,32}$ are often reported to explain the formation of DCPA and HAp under acidic and neutral/basic conditions,

respectively. ${ }^{34,43}$ However, due to the different $\mathrm{Ca} / \mathrm{P}$ ratios exhibited by $\mathrm{CaPs}$, the comparison of their solubility isotherms cannot be used as a basis for the comprehensive understanding of their competitive precipitation. 
Table 1. Ca/P molar ratio of calcium phosphates, dissolution-precipitation equilibria and associated solubility product $K_{s, a p p}^{C a P}$ at 37 and $80^{\circ} \mathrm{C}$. Acid-base equilibria and associated acidity constant $K_{a i}$ and $K_{w}$ at 37 and $80^{\circ} \mathrm{C}$.

\begin{tabular}{|c|c|c|c|}
\hline $\mathrm{Ca} / \mathrm{P}$ & Dissolution-precipitation equilibrium ${ }^{(a)}$ & $K_{S, \text { app }}^{C a P}\left(37^{\circ} \mathrm{C}\right)$ & $K_{s, a p p}^{C a P}\left(80^{\circ} \mathrm{C}\right)$ \\
\hline 1.67 & $\mathrm{HAp}_{(\mathrm{s})}=5 \mathrm{Ca}_{(\mathrm{aq})}^{2+}+3 \mathrm{PO}_{4(\mathrm{aq})}^{3-}+\mathrm{HO}_{(\mathrm{aq})}^{-}$ & $10^{-58.6}$ & $10^{-59.6}$ \\
\hline 1.50 & $\mathrm{ACP}_{(\mathrm{s})}=3 \mathrm{Ca}_{(\mathrm{aq})}^{2+}+2 \mathrm{PO}_{4(\mathrm{aq})}^{3-}$ & $10^{-29.5}$ & $10^{-31.0}$ \\
\hline 1.33 & $\mathrm{OCP}_{(\mathrm{s})}=4 \mathrm{Ca}_{(\mathrm{aq})}^{2+}+3 \mathrm{PO}_{4(\mathrm{aq})}^{3-}+\mathrm{H}_{3} \mathrm{O}_{(\mathrm{aq})}^{+}+\frac{3}{2} \mathrm{H}_{2} \mathrm{O}_{(\mathrm{l})}$ & $10^{-48.7}$ & $10^{-49.5}-10^{-52.5}$ \\
\hline 1.00 & $\mathrm{DCPD}_{(\mathrm{s})}=\mathrm{Ca}_{(\mathrm{aq})}^{2+}+\mathrm{HPO}_{4(\mathrm{aq})}^{2-}+2 \mathrm{H}_{2} \mathrm{O}_{(\mathrm{l})}$ & $10^{-6.56}$ & $10^{-7.00}$ \\
\hline \multirow[t]{2}{*}{1.00} & $\mathrm{DCPA}_{(\mathrm{s})}=\mathrm{Ca}_{(\mathrm{aq})}^{2+}+\mathrm{HPO}_{4(\mathrm{aq})}^{2-}$ & $10^{-7.03}$ & $10^{-7.40}$ \\
\hline & Acid-base equilibrium ${ }^{(b)}$ & $K_{a}\left(37^{\circ} \mathrm{C}\right)$ & $K_{a}\left(80^{\circ} \mathrm{C}\right)$ \\
\hline & $\mathrm{H}_{3} \mathrm{PO}_{4(\mathrm{aq})}+\mathrm{H}_{2} \mathrm{O}_{(\mathrm{l})}=\mathrm{H}_{2} \mathrm{PO}_{4(\mathrm{aq})}^{-}+\mathrm{H}_{3} \mathrm{O}_{(\mathrm{aq})}^{+}$ & $K_{a 1}=10^{-2.20}$ & $10^{-2.37}$ \\
\hline & $\mathrm{H}_{2} \mathrm{PO}_{4(\mathrm{aq})}^{-}+\mathrm{H}_{2} \mathrm{O}_{(\mathrm{l})}=\mathrm{HPO}_{4(\mathrm{aq})}^{2-}+\mathrm{H}_{3} \mathrm{O}_{(\mathrm{aq})}^{+}$ & $K_{a 2}=10^{-7.17}$ & $10^{-7.09}$ \\
\hline & $\mathrm{HPO}_{4(\mathrm{aq})}^{2-}+\mathrm{H}_{2} \mathrm{O}_{(\mathrm{l})}=\mathrm{PO}_{4(\mathrm{aq})}^{3-}+\mathrm{H}_{3} \mathrm{O}_{(\mathrm{aq})}^{+}$ & $K_{a 3}=10^{-12.3}$ & $10^{-11.9}$ \\
\hline & $2 \mathrm{H}_{2} \mathrm{O}_{(\mathrm{l})}=\mathrm{H}_{3} \mathrm{O}_{(\mathrm{aq})}^{+}+\mathrm{HO}_{(\mathrm{aq})}^{-}$ & $K_{w}=10^{-13.6}$ & $10^{-12.6}$ \\
\hline
\end{tabular}

(a) Data on CaPs dissolution-precipitation equilibria were taken and/or extrapolated from the literature. ${ }^{44-47}$ Note that, for $\mathrm{ACP}$, the thermodynamic data used in this study are those associated with the $\beta-\mathrm{Ca}_{3}\left(\mathrm{PO}_{4}\right)_{2}$ mineral having a close structure. $^{48}$

(b) Data on the acid-base equilibria involving phosphate species at $80{ }^{\circ} \mathrm{C}$ were extrapolated from the study of Rard and Wolery, ${ }^{49}$ using the Ellingham approximation. ${ }^{50}$

\section{Thermodynamic modelling of the precipitation of calcium phosphates in open systems}

In the present study, CaPs were synthesized using an automated reactor (Figure 1) allowing for the differentiation of two synthesis routes $(\mathrm{Ca} \rightarrow \mathrm{P}$ and $\mathrm{P} \rightarrow \mathrm{Ca}$ ) with the gradual addition of a solution (containing $\mathrm{Ca}^{2+}$ or $\mathrm{PO}_{4}^{3-}$ ions) into the reactor containing that of the other precursor (see Materials and Methods). During the addition step, the two synthesis routes involved different common ion effect ${ }^{51}$ and successive disruptions of equilibrium whose thermodynamic influence is 
reported in this paper. This experimental system has the major advantage of allowing the precipitation to proceed at constant $\mathrm{pH}$ during the addition step, which is not possible with those developed for vapor and gel diffusion syntheses involving a $\mathrm{pH}$ gradient out of thermodynamic equilibrium. ${ }^{21,27,30}$ This study thus describes a methodology based on aqueous solution chemistry principles to provide an in-depth understanding of the competitive precipitation of CaPs in open systems (dropwise synthesis). On the basis of thermodynamic modelling, the influence of various parameters such as the $\mathrm{pH}$ and the order of introduction of the precursor ions could be investigated.

\section{I - 1. Thermodynamic differentiation in the $\mathrm{Ca} \rightarrow \mathrm{P}$ and $\mathrm{P} \rightarrow$ Ca routes: a common ion effect}

The impact of the order of introduction of the precursors on the precipitation processes and the structural properties of the final product was investigated. The present methodology consists first in predicting which $\mathrm{CaP}$ material is the thermodynamic product at the beginning of the addition step (Figure 2).

A precipitate forms spontaneously in a solution at a given temperature $T$ if this solution becomes rich enough in precursor ions to satisfy the supersaturation criterion $S \geq 1$, also expressed as $Q \geq$ $K_{S}$ (thermodynamic driving force, S5), where $Q$ is the quotient of the precipitation reaction characteristic of the considered solution and $K_{S}$ is the solubility constant of the phase prone to precipitate at $T$. In that respect, at the beginning of the addition stage in the $\mathrm{Ca} \rightarrow \mathrm{P}$ synthesis, the minimum concentration of calcium ions $\left[\mathrm{Ca}^{2+}\right]_{\min }$, to be introduced into the reactor containing the phosphate solution, to precipitate the HAp mineral should verify the equation:

$$
Q=a\left(\mathrm{Ca}^{2+}\right)_{\min }^{5} a\left(\mathrm{PO}_{4}^{3-}\right)_{r}^{3} a\left(\mathrm{HO}^{-}\right)_{r}=\gamma_{2 \pm}^{5} \gamma_{3 \pm}^{3} \gamma_{ \pm} \frac{\left[\mathrm{Ca}^{2+}\right]_{\min }^{5}\left[\mathrm{PO}_{4}^{3-}\right]_{r}^{3}\left[\mathrm{HO}^{-}\right]_{r}}{\left(c^{\circ}\right)^{9}}=K_{s}^{H A p}
$$


with $\gamma_{ \pm}, \gamma_{2 \pm}$ and $\gamma_{3 \pm}$ the activity coefficients associated with $\mathrm{HO}^{-}, \mathrm{Ca}^{2+}$ and $\mathrm{PO}_{4}^{3-}$ ions calculated from the Davies equation deriving from the Debye-Hückel theory, $\left[\mathrm{HO}^{-}\right]_{r}$ and $\left[\mathrm{PO}_{4}^{3-}\right]_{r}$ the initial concentrations of hydroxide and phosphate ions present in the reactor and $c^{\circ}$ the standard concentration of $1 \mathrm{~mol} / \mathrm{L}$. The HAp material spontaneously precipitates if the concentration $\left[\mathrm{Ca}^{2+}\right]_{\min }$ introduced into the reactor is:

$$
\left[\mathrm{Ca}^{2+}\right]_{\min }=\frac{1}{\gamma_{2 \pm}}\left(\frac{K_{s}^{\mathrm{HAp}}\left(c^{\circ}\right)^{9}}{\gamma_{3 \pm}^{3}\left[\mathrm{PO}_{4}^{3-}\right]_{r}^{3} \gamma_{ \pm}\left[\mathrm{HO}^{-}\right]_{r}}\right)^{\frac{1}{5}}
$$

The $\left[\mathrm{HO}^{-}\right]_{r},\left[\mathrm{PO}_{4}^{3-}\right]_{r}, \gamma_{ \pm}, \gamma_{2 \pm}$ and $\gamma_{3 \pm}$ parameters depend on the $\mathrm{pH}$ of the solution, which is maintained constant in the reactor in the present study. Eq. 2 indicates that the more alkaline the medium, the lower the minimum concentration of calcium ions to be introduced for precipitating the HAp material, as also illustrated in Figure 2 A.

Similarly, at the beginning of the $\mathrm{P} \rightarrow$ Ca synthesis, the minimum concentration of phosphate species $[\mathrm{P}]_{\min }=\left[\mathrm{H}_{3} \mathrm{PO}_{4}\right]_{\text {min }}+\left[\mathrm{H}_{2} \mathrm{PO}_{4}^{-}\right]_{\text {min }}+\left[\mathrm{HPO}_{4}^{2-}\right]_{\text {min }}+\left[\mathrm{PO}_{4}^{3-}\right]_{\text {min }}$ to be introduced into the reactor to precipitate HAp has to verify:

$$
Q=a\left(\mathrm{Ca}^{2+}\right)_{r}^{5} a\left(\mathrm{PO}_{4}^{3-}\right)_{m i n}^{3} a\left(\mathrm{OH}^{-}\right)_{r}=\gamma_{2 \pm}^{5} \gamma_{3 \pm}^{3} \gamma_{ \pm} \frac{\left[\mathrm{Ca}^{2+}\right]_{r}^{5}\left[\mathrm{PO}_{4}^{3-}\right]_{m i n}^{3}\left[\mathrm{OH}^{-}\right]_{r}}{\left(c^{\circ}\right)^{9}}=K_{s}^{H A p}
$$

Hence, the HAp mineral precipitates spontaneously if the concentration in phosphate species introduced into the reactor is at least:

$$
[\mathrm{P}]_{\min }=\frac{1}{n \gamma_{3 \pm}}\left(\frac{K_{s}^{H A p}\left(c^{\circ}\right)^{9}}{\gamma_{2 \pm}^{5}\left[\mathrm{Ca}^{2+}\right]_{r}^{5} \gamma_{ \pm}\left[\mathrm{OH}^{-}\right]_{r}}\right)^{\frac{1}{3}}
$$


with $n$ the molar fraction in phosphate ions.

The same thermodynamic approach was applied to predict the conditions for the precipitation of all of the CaPs materials (S5). The $\mathrm{pH}$ dependence of the corresponding calculated $\left[\mathrm{Ca}^{2+}\right]_{\min }$ and $[\mathrm{P}]_{\min }$ concentrations is plotted in Figure 2 for a reaction temperature of $80{ }^{\circ} \mathrm{C}$. Under given conditions, the most stable $\mathrm{CaP}$ material is the one requiring the lowest precursor concentration to spontaneously precipitate. The HAp crystalline phase, constituted of phosphate groups, appears to be the thermodynamically-predicted material to be formed at the beginning of the $\mathrm{Ca} \rightarrow \mathrm{P}$ (Figure $2 \mathrm{~A}$ ) and $\mathrm{P} \rightarrow \mathrm{Ca}$ (Figure $2 \mathrm{~B}$ ) synthesis routes carried out in basic, neutral or slightly acidic media. During the addition step proceeding in a more acidic media, the DCPA material, consisting of hydrogen phosphate groups, is predicted to be the most stable material initially formed in aqueous solution at $80{ }^{\circ} \mathrm{C}$. Interestingly, the modelling of the competitive CaPs precipitation predicts thermodynamic differentiation at the beginning of the $\mathrm{Ca} \rightarrow \mathrm{P}$ and $\mathrm{P} \rightarrow$ Ca synthesis routes as the DCPA/HAp stability frontier is shifted by 1.5 units of $\mathrm{pH}$, decreasing from 5.3 to 3.8, respectively (Figure 2 A, B). Such an influence of the order of introduction of the precursors under acidic conditions has never been reported in earlier literature studies to the best of our knowledge. 

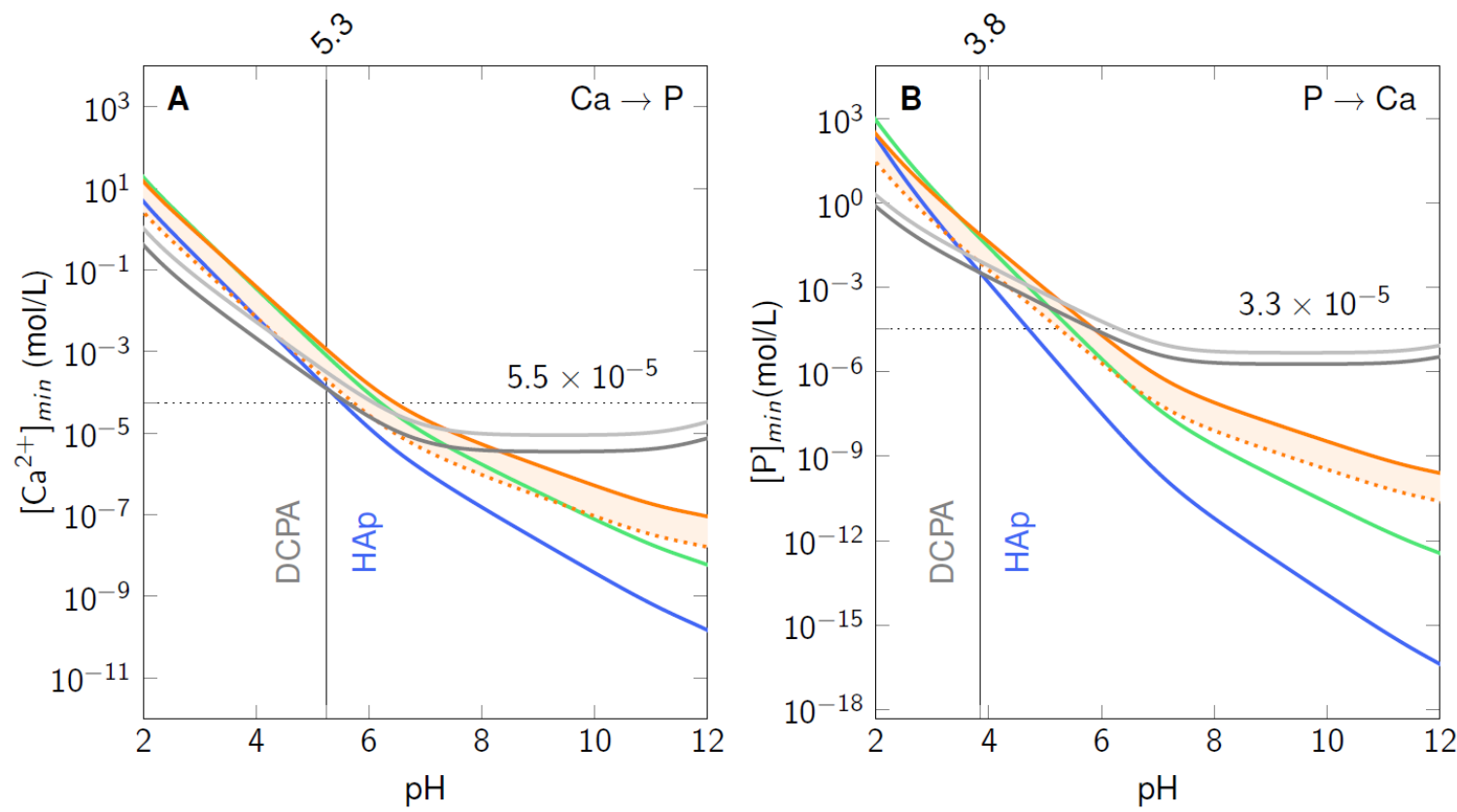

Figure 2. Thermodynamic traces predicting the minimum concentration in precursor to be initially introduced into the reactor for both $\mathrm{Ca} \rightarrow \mathrm{P}(\mathbf{A})$ and $\mathrm{P} \rightarrow \mathrm{Ca}(\mathbf{B})$ routes in order to precipitate the different calcium phosphates: HAp (blue), ACP (green), OCP (orange), DCPD (light grey) and DCPA (dark grey) at $80{ }^{\circ} \mathrm{C}$ (modelling parameters: $[\mathrm{P}]_{r}=0.13 \mathrm{~mol} / \mathrm{L}$, and $\left[\mathrm{Ca}^{2+}\right]_{r}=0.22$ $\mathrm{mol} / \mathrm{L}$ ). For OCP, due to the important uncertainty on its solubility product at $80{ }^{\circ} \mathrm{C}$ (Table 1 ), the corresponding domain is highlighted in orange. Specified concentrations of $\left[\mathrm{Ca}^{2+}\right]=5.5 \times 10^{-5}$ $\mathrm{mol} / \mathrm{L}$ and $[\mathrm{P}]=3.3 \times 10^{-5} \mathrm{~mol} / \mathrm{L}$ are those estimated in the reactor after one drop of the corresponding precursor is added (see Materials and Methods). $\left[\mathrm{Ca}^{2+}\right]_{\min }$ or $[\mathrm{P}]_{\min }$ are the minimum concentrations in calcium ions or phosphate species to be introduced into the reactor containing the phosphate or the calcium solution to precipitate the $\mathrm{CaP}$ minerals, respectively.

\section{I - 2. Influence of the temperature}

The influence of the temperature on the formation of CaPs in aqueous solution was studied by plotting the thermodynamic traces $\left[\mathrm{Ca}^{2+}\right]_{\min }=f(\mathrm{pH})$ and $[\mathrm{P}]_{\min }=f(\mathrm{pH})$ calculated at $37{ }^{\circ} \mathrm{C}$ (Figure S5A) and $80{ }^{\circ} \mathrm{C}$ (Figure $2 \mathrm{~A}, \mathbf{B}$ ). It appears that the reaction temperature has very little influence on the stability of the calcium phosphates, and the HAp and DCPA materials remain the thermodynamic products as a function of the $\mathrm{pH}$ at physiological temperature (Figure S5A). A decrease in temperature from 80 to $37^{\circ} \mathrm{C}$ leads to a slight increase in the $K_{S}^{C a P}$ values (Table 1), 
which translates in the need for the addition of slightly higher amounts of precursor ions to spontaneously precipitate both HAp and DCPA minerals (Eq. 2, Eq. 4 and Figure 3). In line with the conclusions of Vereecke and Lemaitre, ${ }^{32}$ a lower reaction temperature is found to be favourable to the thermodynamic stability of the DCPA material over a moderately wider range of $\mathrm{pH}$ with an increase in this parameter by about 0.5 unit for both synthesis routes.
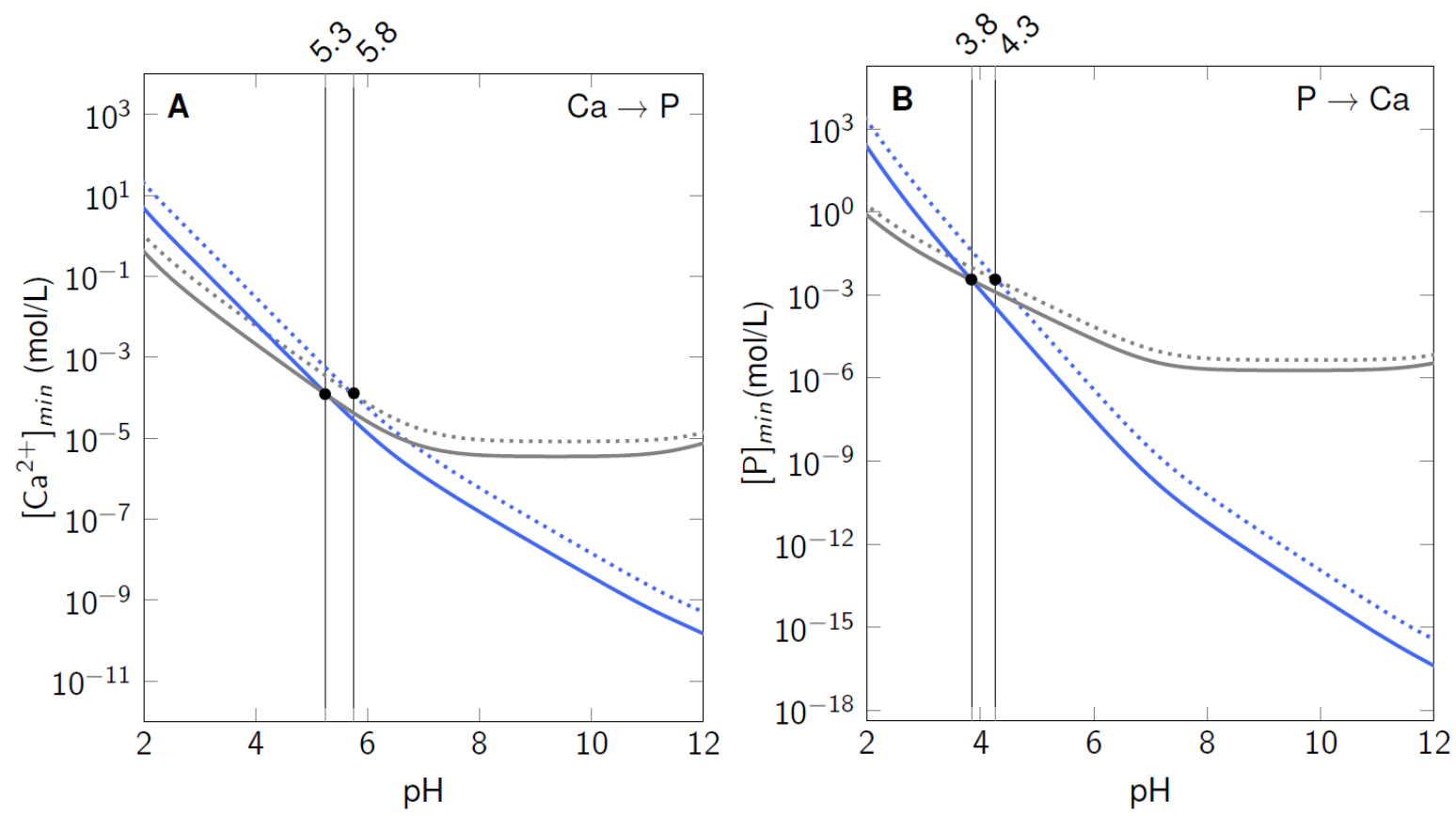

Figure 3. Influence of temperature on the competitive precipitation of HAp (blue) and DCPA (dark grey) at the beginning of the $\mathrm{Ca} \rightarrow \mathrm{P}(\mathbf{A})$ and $\mathrm{P} \rightarrow \mathrm{Ca}(\mathbf{B})$ synthesis routes. The DCPA/HAp stability frontiers at 80 (solid lines) and $37{ }^{\circ} \mathrm{C}$ (dotted lines) are indicated by vertical lines and black dots. $\left[\mathrm{Ca}^{2+}\right]_{\min }$ or $[\mathrm{P}]_{\min }$ are the minimum concentrations in calcium ions or phosphate species to be introduced into the reactor containing the phosphate or the calcium solution to precipitate the HAp (blue) and DCPA (dark grey) minerals, respectively. 
I - 3. Successive disruptions of equilibrium during the addition step: influence of the $\left[\mathrm{Ca}^{2+}\right] /[\mathbf{P}]$ ratio

At a given $\mathrm{pH}$, the competitive precipitation of $\mathrm{CaPs}$ in $\mathrm{P}$-rich ( $\mathrm{Ca} \rightarrow \mathrm{P}$ route) or Ca-rich $(\mathrm{P} \rightarrow$ Ca route) solutions has to deal with different CaPs stabilities (Figure 2). In particular, the HAp mineral is thermodynamically stable over a wider range of $\mathrm{pH}$ when it precipitated in a Ca-rich solution (Figure 2 B) rather than in a P-rich one (Figure 2 A) in agreement with its high intrinsic $\mathrm{Ca} / \mathrm{P}$ ratio making it the most calcium enriched $\mathrm{CaP}$ mineral (Table 1).

During the addition step, the $\left[\mathrm{Ca}^{2+}\right]_{r}$ and $[\mathrm{P}]_{r}$ concentrations in the reactor decrease due to both the precipitation of $\mathrm{CaPs}$ and the dilution of the reaction medium. The $\mathrm{pH}$ stability frontier between HAp and DCPA appears to be more or less shifted during that step, depending on the selected synthesis route (Figure 4). Such a pH shift can be calculated using the same methodology as that used for the prediction of the DCPA/HAp stability frontier at the beginning of the reaction by considering the corresponding decrease in the $\left[\mathrm{Ca}^{2+}\right]_{r}$ and $[\mathrm{P}]_{r}$ concentrations in the reactor, in other words, by taking into account the progress of the precipitation reaction. Considering the $\mathrm{Ca} \rightarrow \mathrm{P}$ route at $80{ }^{\circ} \mathrm{C}$, the $\mathrm{pH}$ stability frontier between the HAp and DCPA materials, initially at pH 5.3 (Figure $2 \mathbf{A}$ ), progressively shifts to lower $\mathrm{pH}$ as the addition step progresses and the $[\mathrm{P}]_{r}$ concentration decreases in the reactor (Figure 4, dashed line). Within this synthesis route, the stability domains of HAp and DCPA are on the right-hand side (Figure 4, region III) and the lefthand side (Figure 4, regions I and II) of the dashed trace, respectively. A reverse tendency is observed for the $\mathrm{P} \rightarrow \mathrm{Ca}$ route regarding the impact of the addition step on the position of the stability frontier moving to higher $\mathrm{pH}$ during the progress of the precipitation reaction (Figure 4, solid line). Regions I and III in Figure 4 define experimental conditions boundaries for which the 
order of introduction of the precursor ions has no influence on the nature of the predicted thermodynamic product, i.e. DCPA (region I) or HAp (region III). In contrast, a thermodynamic differentiation should occur in region II for which HAp is predicted to thermodynamically precipitate first in the $\mathrm{P} \rightarrow$ Ca route (right-hand side of the solid line), whereas DCPA is expected as the thermodynamic product at the beginning of the $\mathrm{Ca} \rightarrow \mathrm{P}$ route (left-hand side of the dashed line). The present identification of such a thermodynamic differentiation represents an important breakthrough compared to the earlier thermodynamic modelling reported in the literature to date that was traditionally based upon the solubility isotherms. ${ }^{31,32}$ The thermodynamic differentiation between both synthesis routes is observed from $\mathrm{pH} 3.8$ to 5.3 at the beginning of the reaction and gradually diminishes with the precipitation progress until disappearing at the end of the addition step, when the targeted final $\left[\mathrm{Ca}^{2+}\right] /[\mathrm{P}]$ ratio is achieved in the reactor (Figure $2 \mathbf{A}, \mathbf{B}$ and Figure 4). When the precipitation is performed in region II of Figure 4, the nature of the precipitated nuclei is expected to transform from DCPA to HAp (hydrolysis, region II $\rightarrow$ region III) or from HAp to DCPA (dehydration, region II $\rightarrow$ region I) for the $\mathrm{Ca} \rightarrow \mathrm{P}$ and $\mathrm{P} \rightarrow$ Ca routes, respectively. 


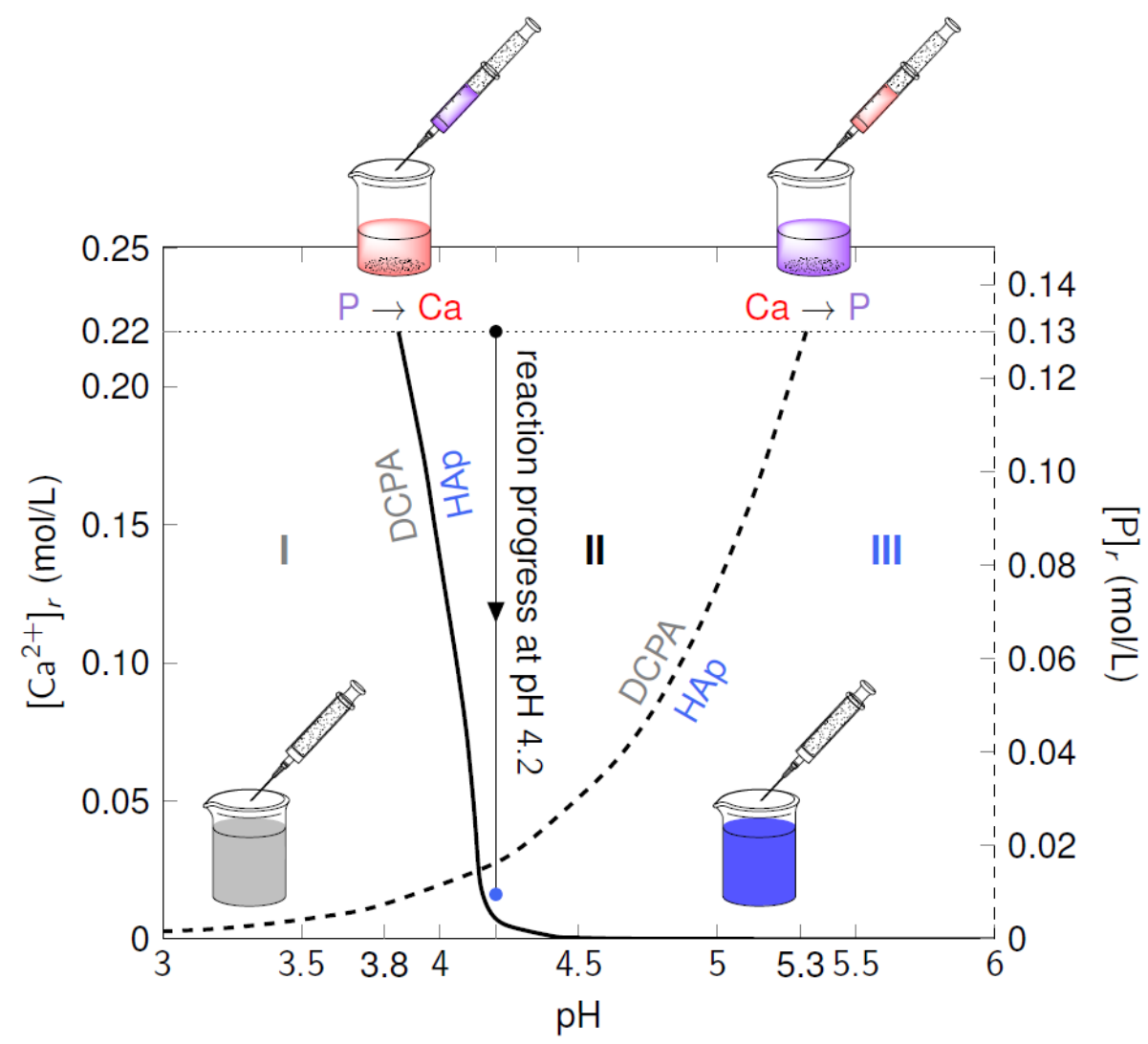

Figure 4. Evolution of the DCPA/HAp stability frontier during the addition stage for the $\mathrm{P} \rightarrow \mathrm{Ca}$ (solid line) and $\mathrm{Ca} \rightarrow \mathrm{P}$ (dashed line) synthesis routes at $80{ }^{\circ} \mathrm{C}$. Regions I and III correspond to the stability regions of DCPA and HAp for both synthesis routes, respectively. Region II is the thermodynamic differentiation region between the $\mathrm{Ca} \rightarrow \mathrm{P}$ and the $\mathrm{P} \rightarrow \mathrm{Ca}$ synthesis routes for which DCPA and HAp are respectively the most stable crystalline phases at the beginning of the addition step. Note the presence of a fourth region that is thermodynamically not accessible under the operating conditions used in the present study. The black and blue dots indicate respectively the beginning and the end of the addition step of syntheses carried out at constant pH 4.2 (vertical arrow), assuming that the thermodynamic equilibria are achieved as soon as the droplet is added. The horizontal dashed line highlights the calcium and phosphate species concentrations of the starting solutions in the reactor at the beginning of the syntheses. Note that the $\left[\mathrm{Ca}^{2+}\right]_{r}$ and $[\mathrm{P}]_{r}$ concentrations are different from 0 at the end of the addition stage at pH 4.2 because of the important solubility of hydroxyapatite under those conditions (Figure S5B).

According to the model proposed in the present study, in the case of thermodynamicallycontrolled experiments, OCP and DCPD materials are not expected to precipitate in aqueous solution by varying the order of introduction of the precursors, i.e. by playing with the common 
ion effect. The formation of these minerals could thus result from non-thermodynamicallycontrolled conditions, as detailed in a forthcoming paper, or from the modification of the experimental conditions. As the dissociative power of the solvent greatly affects the solubility of ionic solids such as DCPD, ${ }^{52}$ the use of hydroalcoholic or organic media appears, for instance, as an alternative solution to make the OCP and DCPD materials stable in solution. However, the lack of thermodynamic data on the solubility of CaPs in such environments makes the understanding of the CaPs competitive precipitation difficult.

\section{Experimental validation of the predictive thermodynamic model of the competitive precipitation of CaPs}

CaPs were precipitated at constant $\mathrm{pH}$ and under thermodynamic control (Table 2 and S1 Synthesis $p H$ profile) to assess of the reliability of the predictive capabilities of the thermodynamic model adapted for open systems (Section I). Based on this model, three stationary $\mathrm{pH}$ conditions were considered regarding both synthesis routes. At pH 6.5 and 9.0, the HAp material is expected to be the thermodynamic product regardless of the synthesis route (Figure 4, region III). In region II of Figure 4, a thermodynamic differentiation is anticipated with the precipitation of the DCPA and HAp minerals in the $\mathrm{Ca} \rightarrow \mathrm{P}$ and $\mathrm{P} \rightarrow$ Ca routes, respectively. To promote a thermodynamic control, the precipitation reactions were carried out at a moderate temperature of $80{ }^{\circ} \mathrm{C}$ and over a relatively long period of time (addition rate: $2.2 \mathrm{~mL} / \mathrm{min}$, addition stage $\approx 1 \mathrm{~h} 30$, optional additional maturation step of $2 \mathrm{~h}$ ). As the present study may also have an impact in the field of biomineralization, two syntheses were performed at the physiological temperature of $37^{\circ} \mathrm{C}$. The influence of the final $\left[\mathrm{Ca}^{2+}\right] /[\mathrm{P}]$ ratio of precursor ions introduced into the reactor was 
investigated at $\mathrm{pH} 6.5$ in the $\mathrm{Ca} \rightarrow \mathrm{P}$ route as the formation of HAp exhibiting a $\mathrm{Ca} / \mathrm{P}$ ratio lower than 1.67 is expected under acidic conditions. ${ }^{53,54}$

Table 2. Experimental conditions applied in the synthesis of calcium phosphates, crystalline phases identified by XRD, Ca/P molar ratios determined by XRF and specific surface areas (SSA) of synthesized materials. All of the experiments were performed with an addition rate of the corresponding precursor solution of $2.2 \mathrm{~mL} / \mathrm{min}$.

\begin{tabular}{|c|c|c|c|c|c|c|c|}
\hline $\begin{array}{c}\text { Sample } \\
\text { reference }\end{array}$ & pH & $\begin{array}{c}\text { Synthesis } \\
\text { route }\end{array}$ & $\begin{array}{c}\text { Final } \\
{\left[\mathrm{Ca}^{2+}\right] /[\mathbf{P}]}\end{array}$ & $\begin{array}{c}\text { Maturation } \\
\text { time (h) }\end{array}$ & $\begin{array}{c}\text { Crystalline } \\
\text { phase }\end{array}$ & $\mathrm{Ca} / \mathrm{P}$ & $\begin{array}{c}\text { SSA } \\
\left(\mathrm{m}^{2} / \mathrm{g}\right)\end{array}$ \\
\hline 1 & \multirow{4}{*}{9.0} & \multirow{2}{*}{$\mathrm{P} \rightarrow \mathrm{Ca}$} & 1.67 & 2 & HAp & 1.72 & 39 \\
\hline 2 & & & 1.67 & - & HAp & 1.71 & 38 \\
\hline 3 & & \multirow{2}{*}{$\mathrm{Ca} \rightarrow \mathrm{P}$} & 1.67 & - & HAp & 1.66 & 102 \\
\hline $4\left(37^{\circ} \mathrm{C}\right)$ & & & 1.67 & 2 & HAp & 1.65 & 195 \\
\hline 5 & \multirow{4}{*}{6.5} & \multirow{2}{*}{$\mathrm{P} \rightarrow \mathrm{Ca}$} & 1.67 & - & HAp & 1.63 & 15 \\
\hline $6\left(37^{\circ} \mathrm{C}\right)$ & & & 1.67 & - & HAp & 1.52 & 122 \\
\hline 7 & & \multirow{2}{*}{$\mathrm{Ca} \rightarrow \mathrm{P}$} & 1.67 & - & HAp & 1.53 & 44 \\
\hline 8 & & & 1.50 & - & HAp & 1.53 & 43 \\
\hline 9 & \multirow{5}{*}{4.2} & \multirow{3}{*}{$\mathrm{P} \rightarrow \mathrm{Ca}$} & 1.50 & 2 at $\mathrm{pH} 7.0$ & HAp & 1.57 & 53 \\
\hline 10 & & & 1.50 & 2 & HAp/OCP & 1.44 & 45 \\
\hline 11 & & & 1.67 & - & HAp/OCP & 1.43 & 55 \\
\hline 12 & & \multirow{2}{*}{$\mathrm{Ca} \rightarrow \mathrm{P}$} & 1.67 & - & DCPA & 1.04 & $<2$ \\
\hline 13 & & & 1.67 & 15 & HAp/DCPA & - & - \\
\hline
\end{tabular}

\section{II - 1. Nature and properties of the CaPs synthesized under thermodynamic control}

\section{II - 1.1. Samples prepared at pH 6.5 and 9.0 (Figure 4, region III)}

Hydroxyapatite precipitation. The predictive model accounts for HAp precipitation at stationary pH 6.5 and 9.0 without any thermodynamic differentiation (Figure 4, region III). In accordance with this prediction, all of the samples prepared at such $\mathrm{pH}$ (Table 2, samples 1 to 8 ) exhibit XRD patterns that perfectly match that of the pure HAp crystalline phase (Figure $5 \mathrm{~A}, \mathbf{B}$, S6 and Table S2A). However, the crystallinity of the HAp phase appears to be surprisingly impacted by the order of introduction of the precursor ions. A close examination of the full width 
at half maximum of the diffraction lines provides evidences for a slight loss in HAp crystallinity for the samples obtained following the $\mathrm{Ca} \rightarrow \mathrm{P}$ route compared to those prepared by the $\mathrm{P} \rightarrow \mathrm{Ca}$ pathway (Figure $5 \mathbf{A}, \mathbf{B}$, sample $7 v$ sample 5, and sample $3 v s$ sample 2). This loss can be inferred to a lowering in the size of the crystallites, as supported by the significant changes in the specific surface area (Table 2). Indeed, by simply switching the order of introduction of the ion precursors from $\mathrm{P} \rightarrow \mathrm{Ca}$ to $\mathrm{Ca} \rightarrow \mathrm{P}$, the SSA increases from 38 (sample 2) to $102 \mathrm{~m}^{2} / \mathrm{g}$ (sample 3 ) for materials prepared at pH 9.0 and from 15 (sample 5) to $44 \mathrm{~m}^{2} / \mathrm{g}$ (sample 7) for those synthesized at pH 6.5 (Table 2). Similarly, the particularly wide diffraction lines observed for samples 4 and 6 , formed at physiological temperature (Figure $5 \mathbf{A}, \mathbf{B}$ ), is attributed to barely crystallized particles. Consequently, an increase in the precipitation temperature from 37 up to $80^{\circ} \mathrm{C}$ results in a decrease in the SSA of the materials ranging from 195 to $102 \mathrm{~m}^{2} / \mathrm{g}$ for those obtained following the $\mathrm{Ca} \rightarrow \mathrm{P}$ route at pH 9.0 (Table 2, samples 4 and 3) and from 122 to $15 \mathrm{~m}^{2} / \mathrm{g}$ for those prepared with the $\mathrm{P} \rightarrow$ Ca route at $\mathrm{pH} 6.5$ (Table 2, samples 6 and 5). Thus, for the same synthesis duration, the use of a higher reaction temperature promotes a thermodynamic control of the precipitation process that logically tends to bring the system to a stable state more rapidly, i.e. more crystallized in the case of HAp precipitation. ${ }^{55}$

Hydroxyapatite stoichiometry. The HAp materials prepared at $\mathrm{pH} 6.5$ and 9.0 exhibit different $\mathrm{Ca} / \mathrm{P}$ ratios ranging from 1.52 to 1.72 (Table 2, samples 1 to 8 ). Both the $\mathrm{pH}$ and the order of introduction of the precursor ions are shown to influence this ratio with the formation of substoichiometric materials $(\mathrm{Ca} / \mathrm{P}<1.67)$ at $\mathrm{pH}$ 6.5. A simplified formula $\mathrm{Ca}_{10-x}\left(\mathrm{HPO}_{4}\right)_{x}\left(\mathrm{PO}_{4}\right)_{6-x}(\mathrm{OH})_{2-x} \cdot n \mathrm{H}_{2} \mathrm{O}$ was reported for such minerals, also referred to as calcium-deficient hydroxyapatite (CDHAp, $x=0-1$ and $\mathrm{Ca} / \mathrm{P}=1.67-1.50) .{ }^{56}$ The presence of hydrogen phosphate groups $\mathrm{HPO}_{4}^{2-}$ as crystallographic defects is responsible for the Raman bands 
at 879,920 and $1011 \mathrm{~cm}^{-1}$ assigned to $[\mathrm{P}-\mathrm{OH}]$ and $v_{1}\left(\mathrm{HPO}_{4}\right)$ stretching modes (Table $\left.\mathrm{S} 2 \mathrm{~B}\right)$. The related bands are clearly observed for the HAp materials prepared at pH 6.5 (Table 2 and Figure $5 \mathrm{D}$ ), under which the $\mathrm{CaHPO}_{4(\mathrm{aq})}$ species in solution, is the predominant ion pair in the reactor compared to $\mathrm{CaH}_{2} \mathrm{PO}_{4(\mathrm{aq})}^{+}$and $\mathrm{CaPO}_{4(\mathrm{aq})}^{-} \cdot{ }^{57,58} \mathrm{As}$ expected, a lowering in the $\mathrm{Ca} / \mathrm{P}$ ratio is correlated with an increase in the intensity of these Raman contributions and makes it possible to identify the formation of CDHAp at pH 6.5. On the contrary, such defects are extremely limited in HAp precipitated at pH 9.0 (Figure 5 C), as such an alkaline $\mathrm{pH}$ favours the stability of $\mathrm{CaPO}_{4(\mathrm{aq})}^{-}$species in solution compared to that of $\mathrm{CaHPO}_{4(\mathrm{aq})}$ and $\mathrm{CaH}_{2} \mathrm{PO}_{4(\mathrm{aq})}^{+} \cdot{ }^{58}$ Interestingly, at $\mathrm{pH}$ 6.5, the $\mathrm{P} \rightarrow$ Ca route (Table 2, sample 5) appears to be less favourable to the incorporation of such $\mathrm{HPO}_{4}^{2-}$ defects (Ca/P ratio closer to 1.67) in the HAp structure than the $\mathrm{Ca} \rightarrow \mathrm{P}$ route (Table 2, sample 7), suggesting differences in the corresponding precipitation pathways. Given the substoichiometry observed for the samples prepared at $\mathrm{pH} 6.5$, the influence of the final $\left[\mathrm{Ca}^{2+}\right] /[\mathrm{P}]$ ratio of precursors ions introduced into the reactor during the addition step was investigated by decreasing its value from 1.67 (sample 7) to 1.50 (sample 8). Neither the XRD patterns nor the Raman spectra and the XRF quantification show any distinguishable structural modification between these two HAp samples (Figure 5 B, D and Table S2), which demonstrates that the final $\left[\mathrm{Ca}^{2+}\right] /[\mathrm{P}]$ ratio in the reactor does not drive the stoichiometry of the formed HAp materials. In contrast, the relative intensity between the diffraction lines at 32.20 and $32.90^{\circ}$, associated with the (112) and (300) diffraction planes, of samples 7 and 8 is different from that observed for the sample prepared by the $\mathrm{P} \rightarrow$ Ca route at the same $\mathrm{pH}$ (Figure 5 B and Table 2, sample 5). The existence of distinct microstructures, leading to different preferred orientations when preparing samples for XRD analysis, could be at the origin of this observation. ${ }^{59}$ The higher 
SSA of samples 7 and 8 compared to that of sample 5 (Table 2), also suggests differences in textural properties between these samples as shown in section II - 2 .
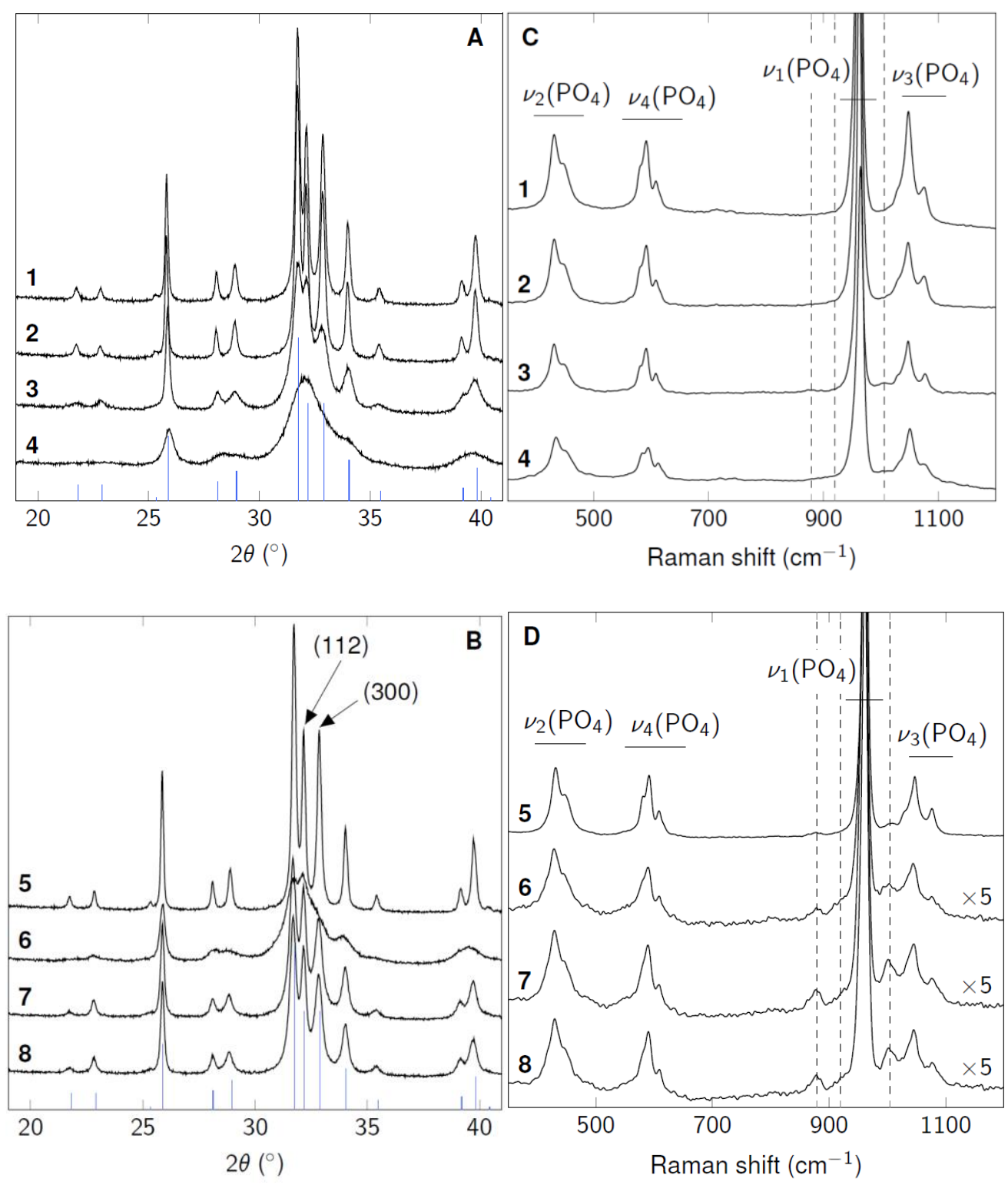

Figure 5. Structural characterizations of the samples synthesized at $\mathrm{pH} 9.0$ and 6.5 (Figure 4, region III). Diffraction patterns of samples 1, 2, 3 and 4 prepared at pH 9.0 (A) and samples 5, 6, 7 and 8 prepared at $\mathrm{pH} 6.5(\mathbf{B})$. The corresponding positions of the diffraction lines expected for HAp are reported in blue (ICDD reference card $n^{\circ}$ 00-009-0432). Raman spectra of samples 1, 2, 3 and 4 synthesized at pH 9.0 (C) and samples 5, 6, 7 and 8 precipitated at pH 6.5 (D). In $\mathbf{C}$ and D, Raman contributions at 879,920 and $1011 \mathrm{~cm}^{-1}$, characteristic of the presence of hydrogen phosphate groups in the samples (Table S2B), are indicated by vertical dashed lines. 


\section{II - 1.2. Samples prepared at pH 4. 2 (Figure 4, region II)}

The proposed model predicts a DCPA/HAp thermodynamic differentiation region in between pH 3.8 and 5.3 (Figure 4, region II). In this region, the order of introduction of the precursor ions is expected to impact the thermodynamic nature of the formed nuclei depending on the progress of the precipitation reaction. To validate the existence of such a differentiation region, samples 11 and 12 were synthesized at pH 4.2 (Table 2). The recovered precipitates were rapidly filtered on Büchner and washed promptly with distilled water to avoid denaturing the isolated CaPs materials (S7). The crystalline phase composition of these samples is found to be different, as shown by the comparison of their XRD patterns and Raman spectra (Figure 6), demonstrating the importance of a different common ion effect taking place during the addition steps of the $\mathrm{Ca} \rightarrow \mathrm{P}$ (phosphate type) and $\mathrm{P} \rightarrow \mathrm{Ca}$ (calcium type) synthesis routes. In agreement with the thermodynamic predictions (Figure 4), the $\mathrm{Ca} \rightarrow \mathrm{P}$ route leads to the formation of DCPA, as supported by the corresponding diffraction pattern (Figure $6 \mathbf{A}$, sample 12) and the presence of the characteristic vibrational bands at 903 and $988 \mathrm{~cm}^{-1}$ attributed to $v_{1}\left(\mathrm{HPO}_{4}\right)$ and $v(\mathrm{P}-\mathrm{OH})$ vibration modes of hydrogen phosphate groups present in this mineral, respectively (Figure $6 \mathbf{C}$ and Table S2B). Under such experimental conditions, DCPA is the thermodynamic product during a large part of the addition step as the phosphate type common ion effect is favourable to the stabilization of this material having the lowest $\mathrm{Ca} / \mathrm{P}$ ratio of the CaPs (Figure 4, region II). At the end of the addition step, when the common ion effect switches to calcium-type, HAp becomes the thermodynamic product (Figure 4, region III). Nevertheless, in sample 12, no trace of HAp could be observed experimentally under the present conditions due to the unfavourable kinetics of DCPA hydrolysis into HAp under acidic conditions ${ }^{60}$, as indicated in Eq. 5:

$$
\mathrm{Ca}_{6}\left(\mathrm{HPO}_{4}\right)_{6(\mathrm{~s})}+(4-x) \mathrm{Ca}_{(\mathrm{aq})}^{2+}+(8-2 x) \mathrm{HO}_{(\mathrm{aq})}^{-}+n \mathrm{H}_{2} \mathrm{O}_{(\mathrm{l})}=
$$




$$
\mathrm{Ca}_{10-x}\left(\mathrm{HPO}_{4}\right)_{x}\left(\mathrm{PO}_{4}\right)_{6-x}(\mathrm{OH})_{2-x} \cdot n \mathrm{H}_{2} \mathrm{O}_{(\mathrm{s})}
$$

Such a conclusion is supported by the experiment for which the precipitate was matured during 15 h (Table 2, sample 13). This maturation time allowed the system to approach its state of equilibrium (Figure 4, blue dot) by partial hydrolysis of the DCPA to HAp (S8). The presence of DCPA as a unique material in sample 12 indicates that the stable DCPA crystals formed at the beginning of the addition step could be preserved in a metastable way at the end of the addition step, as the establishment of the final equilibrium state is not reached rapidly due to hydrolysis kinetic limitations (dissolution-reprecipitation mechanism). This shows that thermodynamic control is not achieved at the end of the addition step at pH 4.2 in the $\mathrm{Ca} \rightarrow \mathrm{P}$ route. In contrast, during the $\mathrm{P} \rightarrow \mathrm{Ca}$ route at $\mathrm{pH} 4.2$, HAp is predicted to be formed over the whole experiment (Figure 4, region II). The XRD pattern of sample 11 did not show the presence of DCPA but mainly that of HAp (Figure 6 B). In addition, low-angle diffraction lines are observed at 4.72, 9.44 and $9.77^{\circ}$ (Figure $6 \mathbf{B}$ ) that are not indexed to the HAp crystalline structure (ICDD reference card $n^{\circ}$ 00-009-0432). Despite close crystallographic structures between the HAp and OCP minerals, these three low-angle diffraction lines are characteristic of the (001), (020), and (110) diffraction planes of OCP, respectively, whereas that at $10.8^{\circ}$ corresponds to the (100) plane of the HAp structure (Figure $6 \mathbf{B}$ and Table S1A). The presence of OCP is also confirmed by Raman spectroscopy as shown in the magnification of the $v_{1}\left(\mathrm{PO}_{4}\right)$ spectral region reported in the inset of Figure 6 D. Compared to the Raman spectrum of sample 9, composed of the pure CDHAp phase, sample 11 exhibits a slight shift of the maximum of the $v_{1}\left(\mathrm{PO}_{4}\right)$ vibrational band to lower wavenumbers and a shoulder at higher wavenumbers, which are both characteristic of the presence of OCP in mixture with CDHAp. ${ }^{21}$ In line with such a composition, sample 11 exhibits a Ca/P ratio of 1.43 (Table 2), lying between those of OCP (1.33) and CDHAp (1.67-1.50). If the HAp 
mineral was predicted as the thermodynamic product precipitating in the $\mathrm{P} \rightarrow$ Ca route at $\mathrm{pH} 4.2$ (Figure 4, region II), this is not the case for OCP, which has been reported to form in non-basic media in earlier studies. ${ }^{26,61}$

The present results put particular emphasis on the importance of the introduction order of the precursor ions on the nature of the precipitated materials at $\mathrm{pH}$ 4.2. To a large extent, the observed differences can be explained reliably from the thermodynamic methodology developed in this study apart from the formation of the OCP phase which is discussed in the section II - 2. The proposed thermodynamic model appears to be more appropriate to account for the competitive precipitation of $\mathrm{CaPs}$ under realistic experimental conditions (dropwise synthesis) compared to the earlier approach based on the solubility isotherms. ${ }^{31,32}$ 

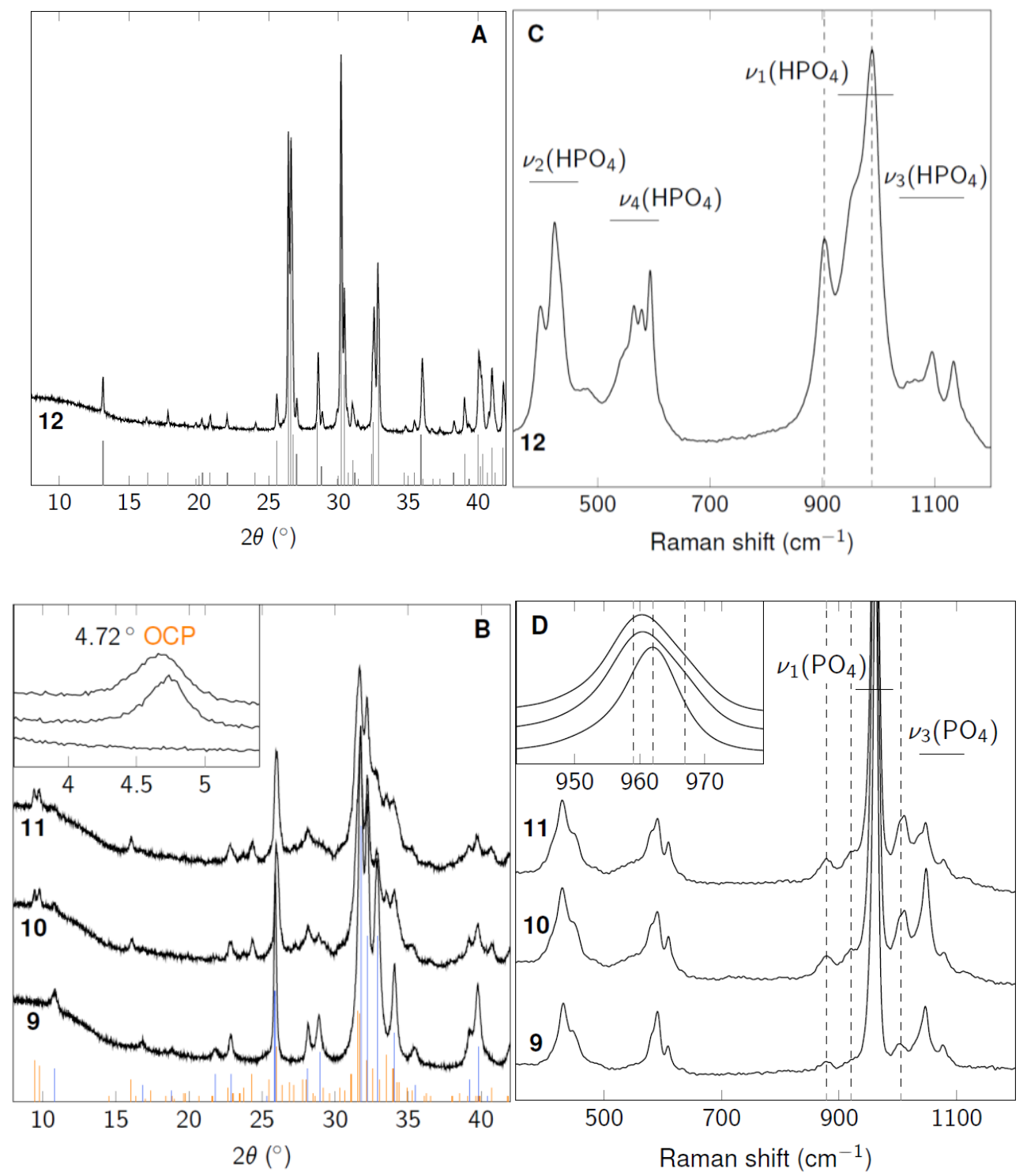

Figure 6. Structural characterization of the samples synthesized at pH 4.2 (Figure 4, region II). Diffraction patterns of sample 12 obtained via the $\mathrm{Ca} \rightarrow \mathrm{P}$ route $(\mathbf{A})$ and samples 9,10 and 11 precipitated following the $\mathrm{P} \rightarrow$ Ca route with corresponding low-angle pattern in the inset $(\mathbf{B})$. The position of the diffraction lines expected for DCPA (ICDD reference card $n^{\circ}$ 00-009-0080), HAp (ICDD reference card $n^{\circ}$ 00-009-0432) and OCP (ICDD reference card $n^{\circ} 00-026-1056$ ) are reported in grey, blue and orange, respectively. Raman spectra of sample 12 (C) and samples 9, 10 and 11 with magnification between 940 and $980 \mathrm{~cm}^{-1}$ in the inset (D). Vertical dashed lines highlight the Raman shifts at 903 and $988 \mathrm{~cm}^{-1}\left(v_{1}\left(\mathrm{HPO}_{4}\right)\right.$ and $v(\mathrm{P}-\mathrm{OH})$ vibration modes in hydrogen phosphate groups of DCPA), at 879,920 and $1011 \mathrm{~cm}^{-1}$ (characteristic of the presence of hydrogen phosphate groups in both HAp and OCP), at 959 and $967 \mathrm{~cm}^{-1}$ (typical of OCP) and at $962 \mathrm{~cm}^{-1}$ (typical of HAp) (Table S2B). 


\section{II - 2. Morphologies, Oswald ripening control and incorporation of defects as a function of pH: towards the limits of the predictive precipitation thermodynamic model}

The quite soft chemistry conditions used in the present study result in HAp materials with very different particle sizes and surface areas ranging from 15 to $195 \mathrm{~m}^{2} / \mathrm{g}$ (Table 2). This may be of particular interest in the field of heterogeneous catalysis, which is known to be surface dependent. $^{8,62}$ In addition to these differences, SEM characterization of the prepared samples showed the existence of two distinct morphologies associated with rod-like and platelet/ribbonlike crystallites (Figure 7 and Figure S9). Given the hexagonal symmetry of HAp, the typical rodlike morphology with a hexagonal section (S10), observed for the materials prepared with the $\mathrm{P} \rightarrow$ Ca route at pH 6.5 (Figure 7, sample 5) and 9.0 (Figure 7, sample 2), was expected, even though the $\mathrm{pH}$ of the precipitation medium still strongly influences the particle size distribution and the associated SSA of the prepared samples (Table 2). The order of introduction of the precursor ions into the reactor is found to play a key role in controlling the HAp morphology. At $\mathrm{pH} 6.5$, the $\mathrm{P} \rightarrow$ Ca route led to rod-like crystallites (Figure 7, sample 5) and the $\mathrm{Ca} \rightarrow \mathrm{P}$ route to platelet/ribbonlike ones (Figure 7, sample 7). The platelet/ribbon morphology obtained in a slightly acidic medium has already been reported in earlier studies using (i) additives that modified both the ionic precursors speciation and the growth processes, (ii) electrochemical (energy consuming) protocols or (iii) biomimetic synthesis operated at physiological $\mathrm{pH}$ and temperature. ${ }^{63-65}$ As another common feature with the biomimetic materials, the HAp platelet-like materials were found to be calcium-deficient with a Ca/P ratio of 1.53 (Table 2, samples 7 and 8) due to the presence of hydrogen phosphate groups (Figure 5 D). Samples 7, 8, 9 and 10, showing platelet/ribbon-like particles (Figures 7 and 8), exhibit specific surface areas (43-53 $\mathrm{m}^{2} / \mathrm{g}$, Table 2) comparable to those measured for the rod-like crystallites of samples 1 and 2 (Table 2, Figure 7). The origin of 
such differences in shape and particle size of the precipitated CaPs likely result from different reaction pathways related to their kinetics of nucleation/growth/solid-solid phase transformation, which will be detailed in a forthcoming paper. It remains possible to play on the thermodynamic processes to tune the HAp morphology by setting up a maturation step at stationary $\mathrm{pH}$ (see Materials and Methods). Due to the dropwise synthesis mode, the precipitates formed during the addition step do not remain in the reactor for the same duration, leading to a heterogeneous crystallite size distribution. The maturation step should favour the Oswald ripening process, which accounts for the change of an inhomogeneous structure over time, i.e. the dissolution of small crystallites and the growth of larger ones due to the redeposition of dissolved species. ${ }^{66}$ Yet this phenomenon is disfavoured in an alkaline medium as $\mathrm{CaP}$ crystallites were shown to be poorly soluble in such an environment (Figures S4A and S4B). At pH 9.0, the addition of a 2-hour maturation step in the $\mathrm{P} \rightarrow$ Ca route (sample 1) did not lead to significant changes in the HAp crystallite size as attested by the similar SSA of samples 1 and $2\left(38-39 \mathrm{~m}^{2} / \mathrm{g}\right.$, Table 2$)$. In contrast, the addition of such a maturation step at the end of the $\mathrm{P} \rightarrow$ Ca protocol for the syntheses carried out at $\mathrm{pH} 4.2$ was found to bring an increase in the size of the crystallites and a decrease in the SSA of the prepared materials by about $18 \%$ (Figure $6 \mathbf{B}$ and Table 2, sample 11: $55 \mathrm{~m}^{2} / \mathrm{g}$, sample 10: $45 \mathrm{~m}^{2} / \mathrm{g}$ ). Such a finding is in accordance with the high apparent solubility of both HAp and OCP in these acidic conditions (Figure S4A). 

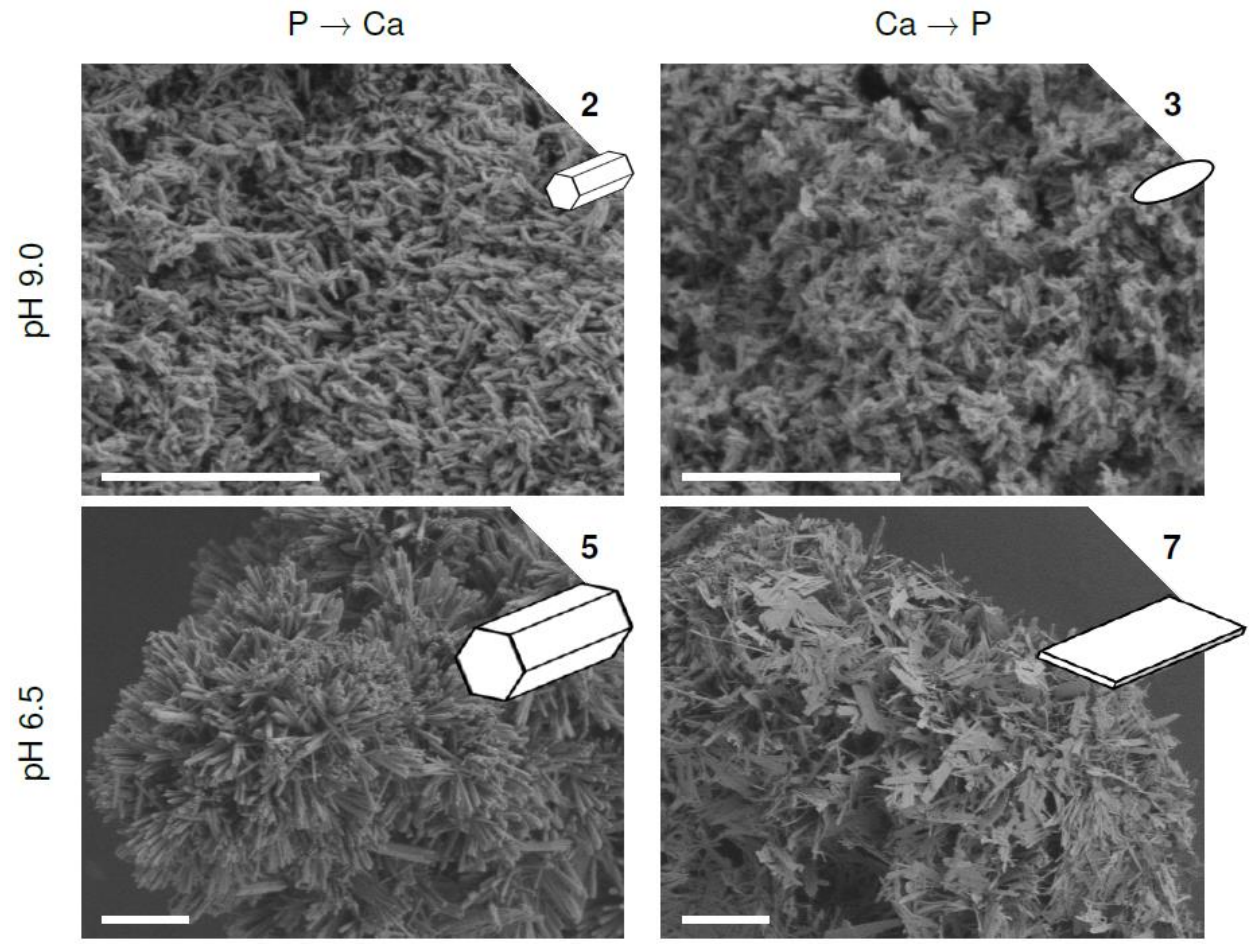

Figure 7. Impact of the $\mathrm{P} \rightarrow \mathrm{Ca}$ or $\mathrm{Ca} \rightarrow \mathrm{P}$ route on the morphology (rod-like or platelet/ribbonlike, respectively) of the HAp crystallites prepared at pH 9.0 (samples 2 and 3) or 6.5 (samples 5 and 7) as investigated by scanning electron microscopy. The numbers indicated on the top right corners of the images refer to as the sample references listed in Table 2. Scale bars: $2 \mu \mathrm{m}$.

Based on these results, a $\mathrm{P} \rightarrow \mathrm{Ca}$ synthesis was carried out at $\mathrm{pH} 4.2$ and the resulting particles were matured in a neutral medium (Table 2, sample 9). Such a maturation step is expected to be favourable to the hydrolysis of OCP to CDHAp:

$$
\begin{gathered}
\mathrm{Ca}_{8}\left(\mathrm{HPO}_{4}\right)_{2}\left(\mathrm{PO}_{4}\right)_{4} \cdot 5 \mathrm{H}_{2} \mathrm{O}_{(\mathrm{s})}+(2-x) \mathrm{Ca}_{(\mathrm{aq})}^{2+}+(4-2 x) \mathrm{HO}_{(\mathrm{aq})}^{-}= \\
\mathrm{Ca}_{10-x}\left(\mathrm{HPO}_{4}\right)_{x}\left(\mathrm{PO}_{4}\right)_{6-x}(\mathrm{OH})_{2-x} \cdot n \mathrm{H}_{2} \mathrm{O}_{(\mathrm{s})}+(7-x-n) \mathrm{H}_{2} \mathrm{O}_{(\mathrm{l})}
\end{gathered}
$$

but to be unfavourable to the Oswald ripening process. ${ }^{67,68}$ This protocol allowed the preparation of a pure CDHAp material (Figure $6 \mathbf{B}, \mathbf{D}$ ) for which the characteristic SSA of about $53 \mathrm{~m}^{2} / \mathrm{g}$ and the platelet/ribbon-like morphology of the OCP/HAp mixture obtained at pH 4.2 and $80{ }^{\circ} \mathrm{C}$ without maturation step (Table 2, sample 11 and Figure 8) were preserved. The conservation of 
the OCP platelet/ribbon-like morphology during the OCP hydrolysis into CDHAp indicates the involvement of a solid-solid phase transformation, controlled by diffusion, as proposed by Tseng et al. ${ }^{67}$
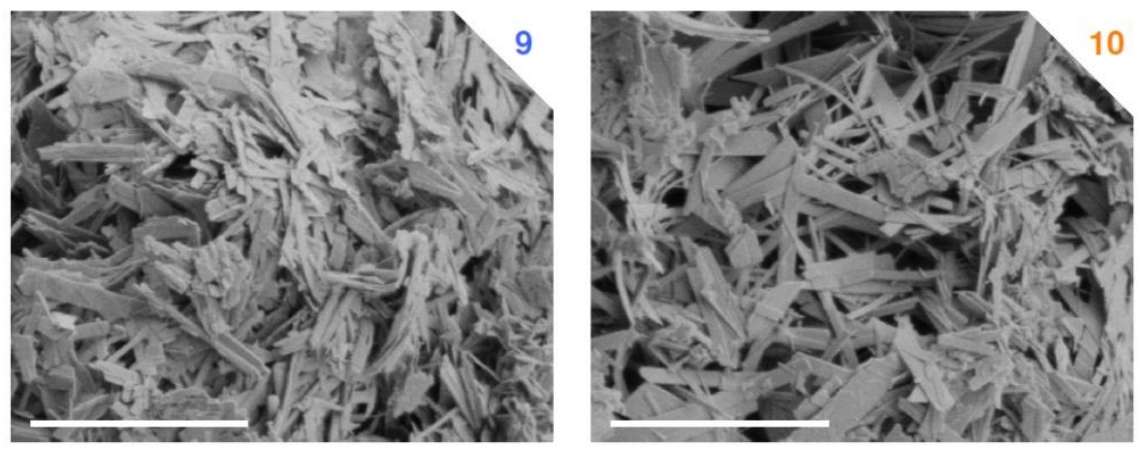

Figure 8. Preservation of the morphology of OCP crystallites during their hydrolysis to HAp. Scanning electron microscopy images of samples 9 (HAp) and 10 (partially hydrolysed OCP into CDHAp) presenting crystallites with a platelet/ribbon-like morphology obtained via the $\mathrm{P} \rightarrow \mathrm{Ca}$ route at $\mathrm{pH} 4.2$ and matured for 2 hours at $\mathrm{pH} 7.0$ and 4.2, respectively. The numbers indicated on the top right corners of the images refer to as the sample references listed in Table 2. Scale bars: $2 \mu \mathrm{m}$.

The present study therefore allowed the development of syntheses to tune (1) the morphology of the HAp material and (2) the incorporation of defects (hydrogen phosphate groups) into its crystalline structure. Surprisingly, not only the $\mathrm{pH}$ but also the order of introduction of the precursor ions into the reactor $(\mathrm{P} \rightarrow \mathrm{Ca}$ or $\mathrm{Ca} \rightarrow \mathrm{P})$ have a major impact on these two features. In particular, the order of introduction of the precursor ions exhibits the more pronounced influence on the final HAp morphology, while earlier literature studies in the field attributed the observed changes in the morphology of the $\mathrm{CaP}$ particles prepared under hydrothermal or physiological conditions to $\mathrm{pH}$ only. ${ }^{34,65,69}$ However, it must be stressed that the complete rationalization of the mineralisation processes of CaPs cannot be done exclusively on the basis of the proposed thermodynamic model. This model allows for the prediction of a final state of equilibrium from a 
given initial state only and in no case of the reaction pathway leading to it indeed. Nevertheless, these pathways may also influence the final morphology of the thermodynamically-predicted CaPs and the incorporation of crystallographic defects. Finally, the present study also reveals that the formation of DCPA and HAp materials could involve reaction intermediates such as OCP, as supported by its identification in some of the experiments whose operating conditions did not allow for a complete thermodynamic control (Table 2, samples 10 and 11).

\section{CONCLUSION}

The results of the present study provide unique insights into the precipitation of CaPs at the thermodynamic level. The dropwise synthesis, involving successive equilibrium disruptions, allows to differentiate two synthesis routes $(\mathrm{P} \rightarrow \mathrm{Ca}$ and $\mathrm{Ca} \rightarrow \mathrm{P}$ ), which led to the precipitation of materials with distinct structural properties. In particular, the synthesis procedures detailed in the present work constitute robust and simple protocols to obtain HAp particles with a wide variety of morphologies and quantity of hydrogen phosphate defects under soft chemistry conditions. The proposed thermodynamic model takes the influence of the $\mathrm{pH}$, the temperature and the order of introduction of the precursors into account to understand the competitive precipitation of $\mathrm{CaPs}$ in open systems. DCPA was found to be obtained regardless of the route considered when operating at a $\mathrm{pH}$ lower than 3.8, whereas HAp is preferentially formed at a $\mathrm{pH}$ higher than 5.3. In between $\mathrm{pH} 3.8$ and 5.3, a thermodynamic differentiation region was identified theoretically and validated experimentally. This differentiation phenomenon sheds light on the importance of the common ion effect on the comparative stability of the DCPA and HAp crystalline phases. In the HAp pHstability region, the use of the $\mathrm{P} \rightarrow$ Ca route and/or basic conditions favour the precipitation of weakly defective materials, while the $\mathrm{Ca} \rightarrow \mathrm{P}$ pathway and/or more acidic conditions favor the 
incorporation of hydrogen phosphate defects. At a given $\mathrm{pH}$, the order of introduction of the precursor ions appears from the present study to be a major parameter to control the morphology of the HAp from platelets/ribbons to rods. The present work can therefore be used as a basis to help researchers select the appropriate synthesis procedure to prepare the targeted HAp materials of proper surface area (Table 2) and morphology (Figures 7 and 8). The developed approach could be adapted to the study of the competitive precipitation of other materials of major interest such as clays ${ }^{69}$ and magnesium silicates, ${ }^{70}$ which are widely used as purifying agents or in the cosmetic field.

Under particular conditions, the proposed thermodynamic model was not able, however, to account for (i) the formation of OCP and (ii) the formation of singular platelet/ribbon-like crystallites with various defectiveness. These apparent discrepancies, likely related to kinetic aspects, will be discussed in a forthcoming article. It is anticipated that the combination of thermodynamic and kinetic approaches will further allow to propose complementary detailed precipitation mechanisms accounting for the possibility to obtain numerous HAp morphologies by modulating the $\mathrm{pH}$ and above all, the synthesis route used.

\section{ASSOCIATED CONTENT}

Supporting information on the synthesis and characterization of materials as well as mathematical details on the developed thermodynamic model are available free of charge via the Internet at

$\mathrm{S} 1-\mathrm{pH}$ control

S2 - Indexation of the XRD lines and Raman bands of CaPs

S3 - XRF calibration traces 
S4 - Apparent solubility of CaPs

S5 - Precipitation conditions of CaPs for the $\mathrm{Ca} \rightarrow \mathrm{P}$ and $\mathrm{P} \rightarrow$ Ca synthesis routes

S6 - Low-angle diffractograms of HAp samples prepared at $\mathrm{pH} 6.5$

S7 - DCPA hydrolysis into CDHAp during the washing step

S8 - Sample 13

S9 - High magnification images of rod-like and platelet/ribbon-like crystallites

S10 - Hexagonal section of samples 2 and 5

\section{AUTHOR CONTRIBUTIONS}

Study conception and design: COSTENTIN, REYNAUD and THOMAS

Acquisition of data: CASALE, NOWAK and REYNAUD

Analysis and interpretation of data: COSTENTIN, REYNAUD and THOMAS

Drafting of manuscript: REYNAUD

Critical revision: COSTENTIN and THOMAS

Conflicts of interest

There are no conflicts to declare.

\section{ACKNOWLEDGMENT}

CR gratefully acknowledges Sorbonne Université for financial support (PhD Grant n 3415/2019).

The authors thank Jean-Marc Krafft (LRS) for his support in Raman spectroscopy data acquisition.

The authors would like to thank the IMPC (Institut des Matériaux de Paris Centre, Fédération de Recherche 2482) through the "plateforme de microscopie électronique" and the "plateforme de diffraction X”. 


\section{REFERENCES}

(1) Kankilic, B.; Dede, E. C.; Korkusuz, P.; Timuçin, M.; Korkusuz, F. Apatites for Orthopedic Applications. In Clinical Applications of Biomaterials: State-of-the-Art Progress, Trends, and Novel Approaches; Kaur, G., Ed.; Springer International Publishing: Cham, 2017; pp $65-90$.

(2) Dorozhkin, S. V.; Epple, M. Biological and Medical Significance of Calcium Phosphates. Angew. Chem. Int. Ed. 2002, 41, 3130-3146.

(3) Boyce, J. W.; Liu, Y.; Rossman, G. R.; Guan, Y.; Eiler, J. M.; Stolper, E. M.; Taylor, L. A. Lunar Apatite with Terrestrial Volatile Abundances. Nature 2010, 466, 466-469.

(4) Mao, M.; Rukhlov, A. S.; Rowins, S. M.; Spence, J.; Coogan, L. A. Apatite Trace Element Compositions: A Robust New Tool for Mineral Exploration. Econ. Geol. 2016, 111, 11871222.

(5) Aufort, J.; Gervais, C.; Ségalen, L.; Labourdette, N.; Coelho-Diogo, C.; Baptiste, B.; Beyssac, O.; Amiot, R.; Lécuyer, C.; Balan, E. Atomic Scale Transformation of Bone in Controlled Aqueous Alteration Experiments. Palaeogeogr. Palaeoclimatol. Palaeoecol. 2019, 526, 80-95.

(6) Cohen, P. A.; Strauss, J. V.; Rooney, A. D.; Sharma, M.; Tosca, N. Controlled Hydroxyapatite Biomineralization in an $\sim 810$ Million-Year-Old Unicellular Eukaryote. Sci. Adv. 2017, 3-6.

(7) Zazzo, A.; Saliège, J.-F. Radiocarbon Dating of Biological Apatites: A Review. Palaeogeogr. Palaeoclimatol. Palaeoecol. 2011, 310, 52-61.

(8) Fihri, A.; Len, C.; Varma, R. S.; Solhy, A. Hydroxyapatite: A Review of Syntheses, Structure and Applications in Heterogeneous Catalysis. Coord. Chem. Rev. 2017, 347, 48-76.

(9) Akri, M.; Zhao, S.; Li, X.; Zang, K.; Lee, A. F.; Isaacs, M. A.; Xi, W.; Gangarajula, Y.; Luo, J.; Ren, Y.; Cui, Y.-T.; Li, L.; Su, Y.; Pan, X.; Wen, W.; Pan, Y.; Wilson, K.; Li, L.; Qiao, 
B.; Ishii, H.; Liao, Y.-F.; Wang, A.; Wang, X.; Zhang, T. Atomically Dispersed Nickel as Coke-Resistant Active Sites for Methane Dry Reforming. Nat. Commun. 2019, 10 (1), 5181.

(10) Sebti, S.; Tahir, R.; Nazih, R.; Saber, A.; Boulaajaj, S. Hydroxyapatite as a New Solid Support for the Knoevenagel Reaction in Heterogeneous Media without Solvent. Appl. Catal. Gen. 2002, 228 (1), 155-159.

(11) Betts, F.; Posner, A. S. An X-Ray Radial Distribution Study of Amorphous Calcium Phosphate. Mater. Res. Bull. 1974, 9, 353-360.

(12) Brown, W. E.; Eidelman, N.; Tomazic, B. Octacalcium Phosphate as a Precursor in Biomineral Formation. Adv. Dent. Res. 1987, 1, 306-313.

(13) Nudelman, F.; Pieterse, K.; George, A.; Bomans, P. H. H.; Friedrich, H.; Brylka, L. J.; Hilbers, P. A. J.; de With, G.; Sommerdijk, N. A. J. M. The Role of Collagen in Bone Apatite Formation in the Presence of Hydroxyapatite Nucleation Inhibitors. Nat. Mater. 2010, 9 , 1004-1009.

(14) Pajor, K.; Pajchel, L.; Kolmas, J. Hydroxyapatite and Fluorapatite in Conservative Dentistry and Oral Implantology—A Review. Materials 2019, 12, 2683.

(15) Moreno, E. C.; Kresak, M.; Zahradnik, R. T. Physicochemical Aspects of Fluoride-Apatite Systems Relevant to the Study of Dental Caries. Caries Res. 1977, 11, 142-171.

(16) Germaini, M.-M.; Detsch, R.; Grünewald, A.; Magnaudeix, A.; Lalloue, F.; Boccaccini, A. R.; Champion, E. Osteoblast and Osteoclast Responses to A/B Type Carbonate-Substituted Hydroxyapatite Ceramics for Bone Regeneration. Biomed. Mater. Bristol Engl. 2017, 12, 035008 .

(17) Ibrahim, M.; Labaki, M.; Giraudon, J.-M.; Lamonier, J.-F. Hydroxyapatite, a Multifunctional Material for Air, Water and Soil Pollution Control: A Review. J. Hazard. Mater. 2020, 383, 121139.

(18) Reichert, J.; Binner, J. G. P. An Evaluation of Hydroxyapatite-Based Filters for Removal of Heavy Metal Ions from Aqueous Solutions. J. Mater. Sci. 1996, 31, 1231-1241. 
(19) Petit, S.; Thomas, C.; Millot, Y.; Krafft, J.-M.; Laberty-Robert, C.; Costentin, G. Activation of C-H Bond of Propane by Strong Basic Sites Generated by Bulk Proton Conduction on VModified Hydroxyapatites for the Formation of Propene. ChemCatChem 2020, 12, 25062521.

(20) Damien, E.; Revell, P. A. Coralline Hydroxyapatite Bone Graft Substitute: A Review of Experimental Studies and Biomedical Applications. J. Appl. Biomater. Biomech. JABB 2004, 2, 65-73.

(21) Robin, M.; Euw, S. V.; Renaudin, G.; Gomes, S.; Krafft, J.-M.; Nassif, N.; Azaïs, T.; Costentin, G. Insights into OCP Identification and Quantification in the Context of Apatite Biomineralization. CrystEngComm 2020, 22 (16), 2728-2742.

(22) Pillai, M. K.; Singh, S.; Jonnalagadda, S. B. Solvent-Free Knoevenagel Condensation over Cobalt Hydroxyapatite. Synth. Commun. 2010, 40 (24), 3710-3715.

(23) Ichihara, J.; Yamaguchi, S.; Nomoto, T.; Nakayama, H.; Iteya, K.; Naitoh, N.; Sasaki, Y. Keggin-Type Polyacid Clusters on Apatite: Characteristic Catalytic Activities in SolventFree Oxidation. Tetrahedron Lett. 2002, 43 (46), 8231-8234.

(24) Tsuchida, T.; Sakuma, S.; Takeguchi, T.; Ueda, W. Direct Synthesis of n-Butanol from Ethanol over Nonstoichiometric Hydroxyapatite. Ind. Eng. Chem. Res. 2006, 45 (25), 86348642.

(25) Haider, A.; Haider, S.; Han, S. S.; Kang, I.-K. Recent Advances in the Synthesis, Functionalization and Biomedical Applications of Hydroxyapatite: A Review. RSC Adv. 2017, 7 (13), 7442-7458.

(26) De Rooij, J. F.; Heughebaert, J. C.; Nancollas, G. H. A pH Study of Calcium Phosphate Seeded Precipitation. J. Colloid Interface Sci. 1984, 100 (2), 350-358.

(27) Gebrehiwet, T.; Guo, L.; Fox, D.; Huang, H.; Fujita, Y.; Smith, R.; Henriksen, J.; Redden, G. Precipitation of Calcium Carbonate and Calcium Phosphate under Diffusion Controlled Mixing. Appl. Geochem. 2014, 46, 43-56. 
(28) Iafisco, M.; Marchetti, M.; Gómez Morales, J.; Hernández-Hernández, M. A.; García Ruiz, J. M.; Roveri, N. Silica Gel Template for Calcium Phosphates Crystallization. Cryst. Growth Des. 2009, 9 (11), 4912-4921.

(29) Gómez-Morales, J.; Delgado-López, J. M.; Iafisco, M.; Hernández-Hernández, A.; Prat, M. Amino Acidic Control of Calcium Phosphate Precipitation by Using the Vapor Diffusion Method in Microdroplets. Cryst. Growth Des. 2011, 11 (11), 4802-4809.

(30) Nassif, N.; Martineau, F.; Syzgantseva, O.; Gobeaux, F.; Willinger, M.; Coradin, T.; Cassaignon, S.; Azaïs, T.; Giraud-Guille, M. In Vivo Inspired Conditions to Synthesize Biomimetic Hydroxyapatite. Chem. Mater. 2010, 22, 3653-3663.

(31) General Chemistry of the Calcium Orthophosphates. In Studies in Inorganic Chemistry; Elliott, J. C., Ed; Structure and Chemistry of the Apatites and Other Calcium Orthophosphates; Elsevier, 1994; Vol. 18, pp 1-62.

(32) Vereecke, G.; Lemaître, J. Calculation of the Solubility Diagrams in the System $\mathrm{Ca}(\mathrm{OH})_{2}-$ $\mathrm{H}_{3} \mathrm{PO}_{4}-\mathrm{KOH}-\mathrm{HNO}_{3}-\mathrm{CO}_{2}-\mathrm{H}_{2} \mathrm{O}$. J. Cryst. Growth 1990, 104 (4), 820-832.

(33) Hentrich, D.; Tauer, K.; Espanol, M.; Ginebra, M.-P.; Taubert, A. EDTA and NTA Effectively Tune the Mineralization of Calcium Phosphate from Bulk Aqueous Solution. Biomimetics 2017, 2 (4), 24.

(34) Suchanek, K.; Bartkowiak, A.; Perzanowski, M.; Marszałek, M. From Monetite Plate to Hydroxyapatite Nanofibers by Monoethanolamine Assisted Hydrothermal Approach. Sci. Rep. 2018, 8, 15408.

(35) Nazeer, M. A.; Yilgor, E.; Yagci, M. B.; Unal, U.; Yilgor, I. Effect of Reaction Solvent on Hydroxyapatite Synthesis in Sol-Gel Process. R. Soc. Open Sci. 2017, 4 (12), 171098.

(36) Evans, J. W.; De Jonghe, L. C. Production of Powders. In The Production and Processing of Inorganic Materials; Evans, J. W., De Jonghe, L. C., Eds.; Springer International Publishing: Cham, 2016; pp 355-382. 
(37) Segovia, L. C. A.; Agudelo, J. I. D.; Glisoni, R. J.; Acha, C.; Zan, M. M. D.; Rintoul, I. A Multiparametric Model for the Industrialization of Co-Precipitation Synthesis of NanoCommodities. Nanotechnology 2020, 31 (18), 185604.

(38) Balonis, M.; Ma, X.; Kakoulli, I. Phase Relations in the Calcium Carbonate/Ammonium Phosphate System under Aqueous Conditions and $25^{\circ}$ C. J. Am. Ceram. Soc. 2020, 103 (6), 3837-3850.

(39) Grasselli, R. K.; Sleight, A. W. Structure-Activity and Selectivity Relationships in Heterogeneous Catalysis; Elsevier, 1991.

(40) Ben Osman, M.; Krafft, J. M.; Millot, Y.; Averseng, F.; Yoshioka, T.; Kubo, J.; Costentin, G. Molecular Understanding of the Bulk Composition of Crystalline Nonstoichiometric Hydroxyapatites: Application to the Rationalization of Structure-Reactivity Relationships. Eur. J. Inorg. Chem. 2016, 2709-2720.

(41) Wang, L.; Nancollas, G. H. Calcium Orthophosphates: Crystallization and Dissolution. Chem. Rev. 2008, 108 (11), 4628-4669.

(42) Pan, H.-B.; Darvell, B. W. Calcium Phosphate Solubility: The Need for Re-Evaluation. Cryst. Growth Des. 2009, 9 (2), 639-645.

(43) Chen, S.; Krumova, M.; Cölfen, H.; Sturm, E. V. Synthesis of Fiber-like Monetite without Organic Additives and Its Transformation to Hydroxyapatite. Chem. Mater. 2019, 31 (5), 1543-1551.

(44) McDowell, H.; Gregory, T. M.; Brown, W. E. Solubility of $\mathrm{Ca}_{5}\left(\mathrm{PO}_{4}\right)_{3} \mathrm{OH}$ in the System $\mathrm{Ca}(\mathrm{OH})_{2}-\mathrm{H}_{3} \mathrm{PO}_{4}-\mathrm{H}_{2} \mathrm{O}$ at $5,15,25$, and $37{ }^{\circ} \mathrm{C}$. J. Res. Natl. Bur. Stand. Sect. Phys. Chem. 1977, 81A, 273-281.

(45) Tung, M. S.; Eidelman, N.; Sieck, B.; Brown, W. E. Octacalcium Phosphate Solubility Product from 4 to $37^{\circ}$ C. J. Res. Natl. Bur. Stand. 1988, 93 (5), 613-624.

(46) Gregory, T. M.; Moreno, E. C.; Brown, W. E. Solubility of $\mathrm{CaHPO}_{4} \cdot 2 \mathrm{H}_{2} \mathrm{O}$ in the System $\mathrm{Ca}(\mathrm{OH})_{2}-\mathrm{H}_{3} \mathrm{PO}_{4}-\mathrm{H}_{2} \mathrm{O}$ at $5,15,25$, and $37.5^{\circ} \mathrm{C}$. J. Res. Natl. Bur. Stand. 1970, 74A, 461475. 
(47) Sutter, J. R.; McDowell, H.; Brown, W. E. Solubility Study of Calcium Hydrogen Phosphate. Ion-Pair Formation. Inorg. Chem. 1971, 10 (8), 1638-1643.

(48) Gregory, T. M.; Moreno, E. C.; Patel, J. M.; Brown, W. E. Solubility of $\beta-\mathrm{Ca}_{3}\left(\mathrm{PO}_{4}\right)_{2}$ in the System $\mathrm{Ca}(\mathrm{OH})_{2}-\mathrm{H}_{3} \mathrm{PO}_{4}-\mathrm{H}_{2} \mathrm{O}$ at 5, 15, 25, and $37{ }^{\circ} \mathrm{C}$. J. Res. Natl. Bur. Stand. Sect. Phys. Chem. 1974, 78 A (6), 667-674.

(49) Rard, J. A.; Wolery, T. J. The Standard Chemical-Thermodynamic Properties of Phosphorus and Some of Its Key Compounds and Aqueous Species: An Evaluation of Differences between the Previous Recommendations of NBS/NIST and CODATA. J. Solut. Chem. 2007, 36 (11), 1585-1599.

(50) Ellingham, H. J. T. Reducibility of Oxides and Sulphides in Metallurgical Processes. J. Soc. Chem. Ind. 1944, 63, 125-133.

(51) Gamsjäger, H.; Lorimer, J. W.; Scharlin, P.; Shaw, D. G. Glossary of Terms Related to Solubility (IUPAC Recommendations 2008). Pure Appl. Chem. 2008, 80 (2), 233-276.

(52) M. S.Tung and T. J.O'Farrell, The Effect of Ethanol on the Solubility of Dicalcium Phosphate Dihydrate in the System $\mathrm{Ca}(\mathrm{OH})_{2}-\mathrm{H}_{3} \mathrm{PO}_{4}-\mathrm{H}_{2} \mathrm{O}$ at $37{ }^{\circ} \mathrm{C}$, J. Mol. Liq. 1993, 56, 237-243.

(53) Andrés-Vergés, M.; Fernández-González, C.; Martínez-Gallego, M. Hydrothermal Synthesis of Calcium Deficient Hydroxyapatites with Controlled Size and Homogeneous Morphology. J. Eur. Ceram. Soc. 1998, 18 (9), 1245-1250.

(54) Vallet-Regí, M.; Rodríguez-Lorenzo, L. M.; Salinas, A. J. Synthesis and Characterisation of Calcium Deficient Apatite. Solid State Ion. 1997, 101-103, 1279-1285.

(55) Rodríguez-Lorenzo, L. M.; Vallet-Regí, M. Controlled Crystallization of Calcium Phosphate Apatites. Chem. Mater. 2000, 12 (8), 2460-2465.

(56) Berry, E. E. The Structure and Composition of Some Calcium-Deficient Apatites. J. Inorg. Nucl. Chem. 1967, 29 (2), 317-327. 
(57) Gebauer, D.; Kellermeier, M.; Gale, J. D.; Bergström, L.; Cölfen, H. Pre-Nucleation Clusters as Solute Precursors in Crystallisation. Chem. Soc. Rev. 2014, 43 (7), 2348-2371.

(58) Chughtai, A. R.; Marshall, R.; Nancollas, G. H. Complexes in Calcium Phosphate Solutions. J. Phys. Chem. 1968, 72 (1), 208-211.

(59) Kleeberg, R.; Monecke, T.; Hillier, S. Preferred Orientation of Mineral Grains in Sample Mounts for Quantitative XRD Measurements: How Random Are Powder Samples? Clays Clay Miner. 2008, 56 (4), 404-415.

(60) Ishikawa, K.; Eanes, E. D. The Hydrolysis of Anhydrous Dicalcium Phosphate into Hydroxyapatite. J. Dent. Res. 1993, 72 (2), 474-480.

(61) Arellano-Jiménez, M. J.; García-García, R.; Reyes-Gasga, J. Synthesis and Hydrolysis of Octacalcium Phosphate and Its Characterization by Electron Microscopy and X-Ray Diffraction. J. Phys. Chem. Solids 2009, 70 (2), 390-395.

(62) Diallo-Garcia, S.; Ben Osman, M.; Krafft, J.-M.; Casale, S.; Thomas, C.; Kubo, J.; Costentin, G. Identification of Surface Basic Sites and Acid-Base Pairs of Hydroxyapatite. J. Phys. Chem. C 2014, 118 (24), 12744-12757.

(63) Ye, W.; Wang, X.-X. Ribbon-like and Rod-like Hydroxyapatite Crystals Deposited on Titanium Surface with Electrochemical Method. Mater. Lett. 2007, 61 (19), 4062-4065.

(64) Zhang, H. G.; Zhu, Q. Glutamic Acid-Mediated Synthesis of Ultralong Hydroxyapatite Nanoribbons under Hydrothermal Conditions. Chem. Lett. 2005, 34 (6), 788-789.

(65) Habraken, W. J. E. M.; Tao, J.; Brylka, L. J.; Friedrich, H.; Bertinetti, L.; Schenk, A. S.; Verch, A.; Dmitrovic, V.; Bomans, P. H. H.; Frederik, P. M.; Laven, J.; van der Schoot, P.; Aichmayer, B.; de With, G.; DeYoreo, J. J.; Sommerdijk, N. A. J. M. Ion-Association Complexes Unite Classical and Non-Classical Theories for the Biomimetic Nucleation of Calcium Phosphate. Nat. Commun. 2013, 4 (1), 1507.

(66) Ostwald, W. Studien Über Die Bildung Und Umwandlung Fester Körper. Z. Für Phys. Chem. 1897, 22, 289-330. 
(67) Tseng, Y.-H.; Mou, C.-Y.; Chan, J. C. C. Solid-State NMR Study of the Transformation of Octacalcium Phosphate to Hydroxyapatite: A Mechanistic Model for Central Dark Line Formation. J. Am. Chem. Soc. 2006, 128 (21), 6909-6918

(68) Graham, S.; Brown, P. W. Reactions of Octacalcium Phosphate to Form Hydroxyapatite. $J$. Cryst. Growth 1996, 165 (1), 106-115.

(69) Kobayashi, T.; Ono, S.; Hirakura, S.; Oaki, Y.; Imai, H. Morphological Variation of Hydroxyapatite Grown in Aqueous Solution Based on Simulated Body Fluid. CrystEngComm 2012, 14 (3), 1143-1149.

(70) May, H. M.; Klnniburgh, D. G.; Helmke, P. A.; Jackson, M. L. Aqueous Dissolution, Solubilities and Thermodynamic Stabilities of Common Aluminosilicate Clay Minerals: Kaolinite and Smectites. Geochim. Cosmochim. Acta 1986, 50 (8), 1667-1677. 


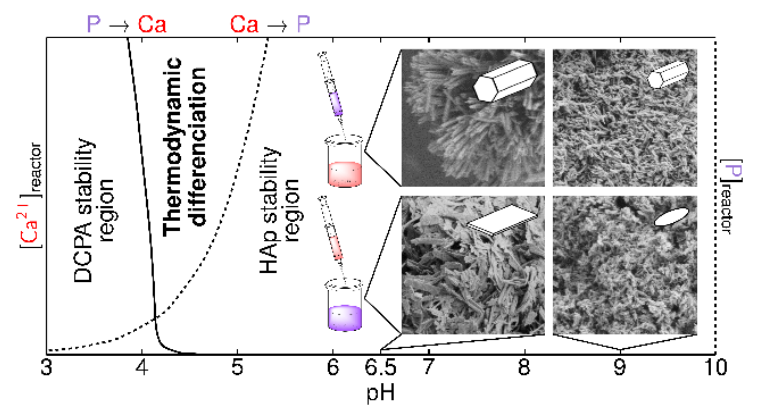

Thermodynamics of the precipitation of calcium phosphates shows the importance of the $\mathrm{pH}$ medium and the order of introduction of the precursor ions on the textural (morphology, surface area) and structural (defects) properties of hydroxyapatites. 


\section{Supplementary Information for}

\section{Development of a thermodynamic approach to assist the control of the precipitation of hydroxyapatites and associated calcium phosphates in open systems}

Corentin Reynaud, ${ }^{1}$ Cyril Thomas, ${ }^{1}$ Sandra Casale, ${ }^{1}$ Sophie Nowak ${ }^{2}$ and Guylène Costentin ${ }^{1 *}$

${ }^{1}$ Sorbonne Université, CNRS, Laboratoire de Réactivité de Surface (LRS), 4 place Jussieu, 75005 Paris, France

${ }^{2}$ Plateforme Rayons X, UFR de Chimie, Université Paris Diderot, Paris, France

*E-mail: guylene.costentin@sorbonne-universite.fr

This document includes:

S1 - $\mathrm{pH}$ control 44

$\mathrm{pH}$ meter operation

Figure S1A

Synthesis $\mathrm{pH}$ profile

Figure S1B

Figure S1C

S2 - Indexation of the XRD lines and Raman bands of CaPs

Table S2A

Table S2B

S3 - XRF calibration traces

Figure S3

S4 - Apparent solubility of CaPs

Figure S4 
S5 - Precipitation conditions of CaPs for the $\mathbf{C a} \rightarrow \mathbf{P}$ and $\mathbf{P} \rightarrow$ Ca synthesis routes

Figure S5A

Figure S5B

S6 - Low-angle diffractograms of HAp samples prepared at pH 6.5

Figure S6.

S7 - DCPA hydrolysis into CDHAp during the washing step

Figure S7

S8 - Sample 1365

Figure S8

S9 - High magnification images of rod-like and platelet/ribbon-like crystallites

Figure S9

S10 - Hexagonal section of samples 2 and 5

Figure S10

\section{S1 - pH control}

pH meter operation. The syntheses were carried out using an automated reactor controlling the $\mathrm{pH}$ during the addition step. In order to check the correct operation of the $\mathrm{pH}$ probe, the $\mathrm{pH}$ of the medium was modelled during the temperature rise step for the $\mathrm{P} \rightarrow$ Ca synthesis. The reactor initially at $20{ }^{\circ} \mathrm{C}$ contained, $200 \mathrm{~mL}$ of a calcium solution $(0.22 \mathrm{~mol} / \mathrm{L})$ adjusted to about $\mathrm{pH} 10$ by adding a few drops of concentrated ammonia $\left(C_{0} \approx 0.002 \mathrm{~mol} / \mathrm{L}\right.$ in the reactor). This solution was heated up to $80{ }^{\circ} \mathrm{C}$ under stirring (400 rpm) and a significant decrease in pH of about 1.5 unit was observed (Figure S1A). The acid-base reaction which imposes the $\mathrm{pH}$ during this temperature rise step is:

$$
\mathrm{NH}_{3(\mathrm{aq})}+\mathrm{H}_{2} \mathrm{O}_{(\mathrm{l})}=\mathrm{NH}_{4(\mathrm{aq})}^{+}+\mathrm{OH}_{(\mathrm{aq})}^{-}
$$

associated with the following equilibrium constant:

$$
K^{o}=\frac{K_{w}}{K_{a}\left(\mathrm{NH}_{4}^{+} / \mathrm{NH}_{3}\right)}
$$

with $K_{w}$ the autoprotolysis equilibrium constant of water and $K_{a}\left(\mathrm{NH}_{4}^{+} / \mathrm{NH}_{3}\right)$ the acidity constant associated with the $\mathrm{NH}_{4}^{+} / \mathrm{NH}_{3}$ acid-base couple The $\mathrm{pH}$ of the medium can be expressed as a function of the equilibrium constants $K_{w}$ and $K_{a}\left(\mathrm{NH}_{4}^{+} / \mathrm{NH}_{3}\right)$ as well as the $C_{0}$ ammonia 
concentration in the reactor initially introduced at $20^{\circ} \mathrm{C}$. The change in $\mathrm{pH}$ during the temperature rise results from the temperature dependence of the equilibrium constants. ${ }^{1,2}$ The theoretical model was found to fit reasonably well the experimental data, thus confirming the correct operation of the $\mathrm{pH}$ meter at $80{ }^{\circ} \mathrm{C}($ Figure $\mathrm{S} 1 \mathrm{~A})$.

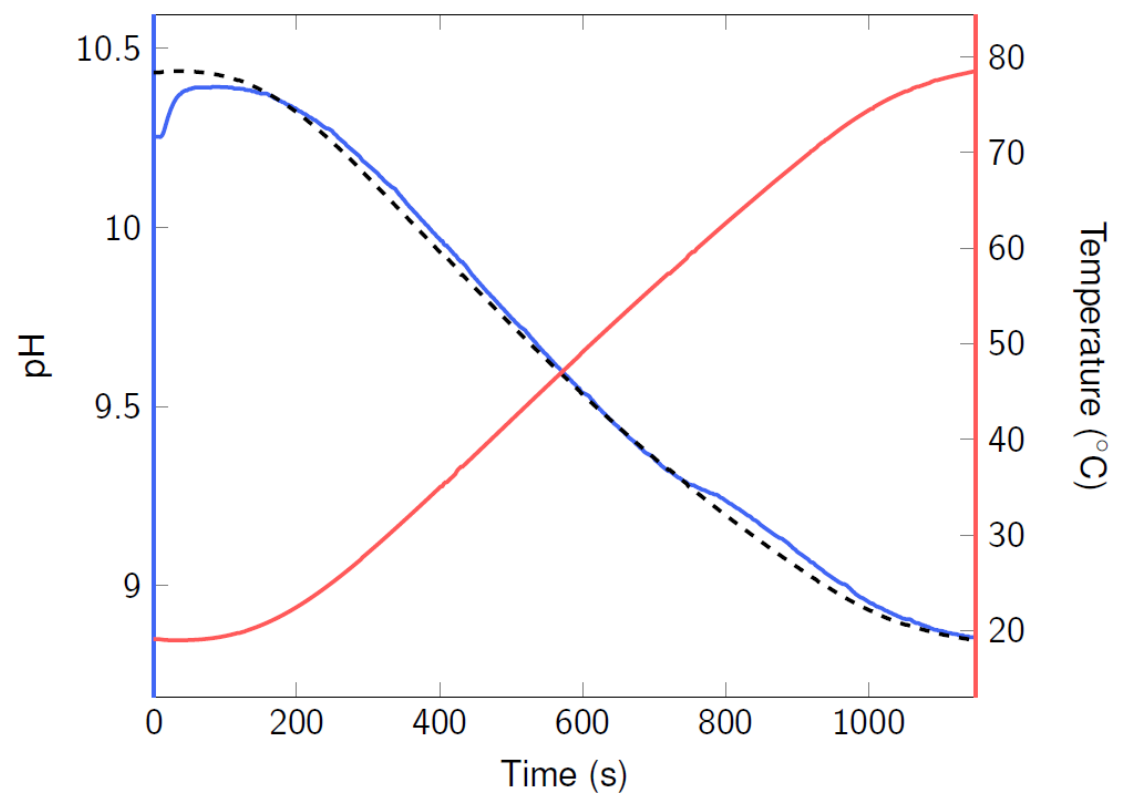

Figure S1A. Experimental (blue trace) and modelled (dashed black trace) $\mathrm{pH}$ evolution in the reactor during the temperature rise step from 20 to $80{ }^{\circ} \mathrm{C}$ (orange trace) (Table 2, sample 1).

Synthesis $\mathrm{pH}$ profile. The synthesis of calcium phosphates is particularly sensitive to the $\mathrm{pH}$ of the reaction medium. The automated reactor allows for the control of this parameter, as illustrated in Figure S1B showing a characteristic $\mathrm{pH}$ profile recorded for an experiment carried out at $\mathrm{pH} 9.0$ and $80^{\circ} \mathrm{C}$. During the temperature rise (Figure S1B, step A), the $\mathrm{pH}$ was found to decrease because of the influence of the temperature on the acid base equilibrium ( $\mathrm{pH}$ meter operation section). The $\mathrm{pH}$ was then rapidly readjusted to $\mathrm{pH} 9.0$ by adding concentrated ammonia drop by drop (Figure S1B, step B). The calcium or phosphate solution is then gradually added into the reactor. The $\mathrm{pH}$ could be reasonably kept constant by the addition of concentrated ammonia controlled by the automated reactor (Figure S1B, step C and Figure S1C) in the course of the addition of the solutions of phosphate or calcium precursors. A white precipitate is instantaneously formed during that step as the first drops of solutions of precursors are added for all experiments performed at pH 9.0 and 6.5, whereas the formation of such a precipitate was slightly delayed for the syntheses performed at $\mathrm{pH} 4.2$ (Table 2). These observations are in line with the minimal concentrations 
$\left[\mathrm{Ca}^{2+}\right]_{\min }$ and $[\mathrm{P}]_{\min }$ calculated from the methodology developed in this study implying that, at $\mathrm{pH} 4.2$, the concentration of $\mathrm{Ca}^{2+}(\mathrm{Ca} \rightarrow \mathrm{P})$ or $\mathrm{H}_{x} \mathrm{PO}_{4}^{(3-x)-}(\mathrm{P} \rightarrow \mathrm{Ca})$ ions into the reactor by one drop, is not sufficient to induce the precipitation of any CaP contrary to what occurs for the syntheses performed at pH 6.5 and 9.0 (Figure 3 A, B). For the synthesis performed at pH 9.0 and $80{ }^{\circ} \mathrm{C}$ (Table 2, sample 1), once the precipitation step was completed, few amounts (approximately $1 \mathrm{~mL}$ ) of ammonia were required to keep the $\mathrm{pH}$ constant due to the need in counterbalancing the gaseous $\mathrm{NH}_{3}$ released during the maturation step.

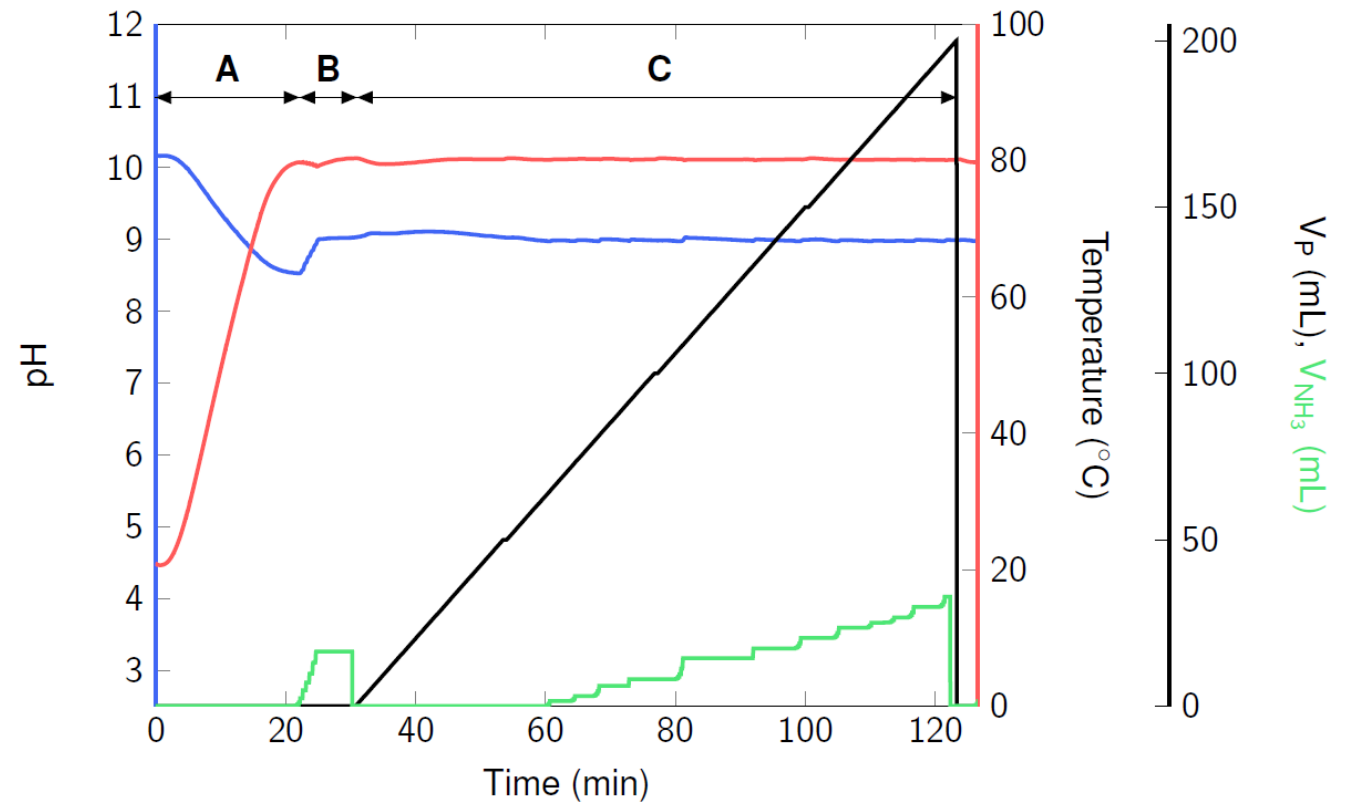

Figure S1B. Temperature profile (red trace), pH profile (blue trace) and volumes added of phosphate precursor (black trace) and ammonia (green trace) solutions into the reactor in the case of a $\mathrm{P} \rightarrow \mathrm{Ca}$ synthesis performed at $80^{\circ} \mathrm{C}$ at $\mathrm{pH} 9.0$ (Table 2, samples 2). 

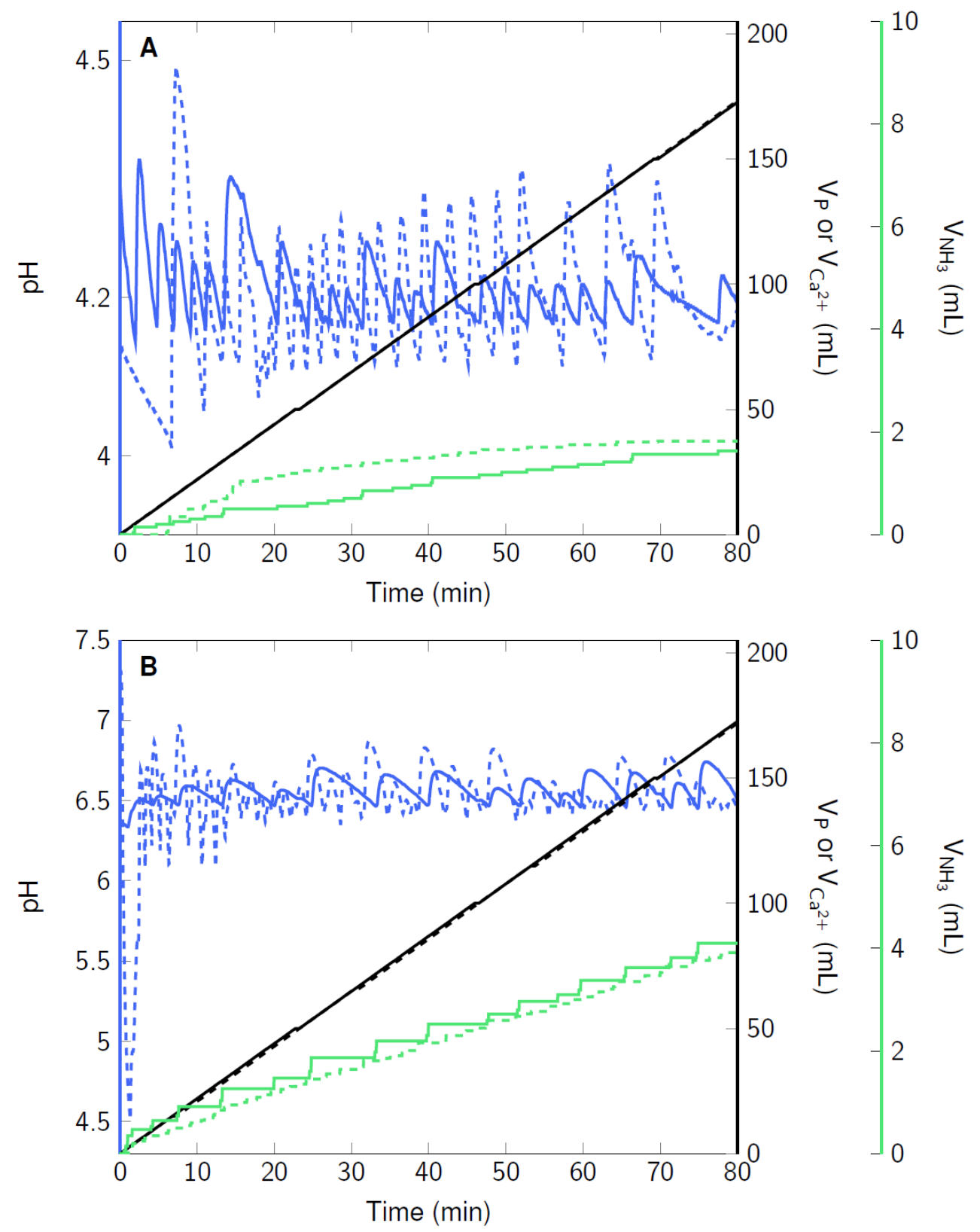

Figure S1C. Comparison of the $\mathrm{pH}$ stability (blue traces) in the reactor during the addition step at $80{ }^{\circ} \mathrm{C}$ and pH 4.2 (A) or 6.5 (B) between the $\mathrm{P} \rightarrow \mathrm{Ca}$ (Table 2, sample 5, dashed line) and $\mathrm{Ca} \rightarrow \mathrm{P}$ (Table 2, sample 7 , solid line) synthesis routes. The $\mathrm{pH}$ control parameters are: mixing time $=12 \mathrm{~s}$, minimum $\mathrm{pH}$ deviation $=0.02$ and maximum $\mathrm{pH}$ rate $=0.3 \mathrm{pH}$ unit $/ \mathrm{min}$. Note that the $\mathrm{pH}$ is easier to maintain constant when the calcium solution is added gradually into the reactor $(\mathrm{Ca} \rightarrow \mathrm{P}$ route) compared to that of the phosphate solution ( $\mathrm{P} \rightarrow$ Ca route). 


\section{S2 - Indexation of the XRD lines and Raman bands of CaPs}

Both XRD and Raman spectroscopy techniques were complementary used to identify the nature of calcium phosphate(s) obtained after washing/drying steps as well as their crystallinity and the origins of the substoichiometry of HAp (Tables S2A and S2B).

Table S2A. XRD assignment of the diffraction lines below $40^{\circ}$ for crystalline calcium phosphates: HAp (reference card $\mathrm{n}^{\circ} 00-009-0432$, ICDD), OCP (reference card ${ }^{\circ}$ 00-026-1056, ICDD), DCPD (reference card $n^{\circ} 00-009-0077$ ) and DCPA (reference card $n^{\circ} 00-009-0080$ ). The relative intensity (Int.) of each $(\mathrm{h} \mathrm{kl})$ diffraction line is indicated as a percentage of the most intense diffraction line.

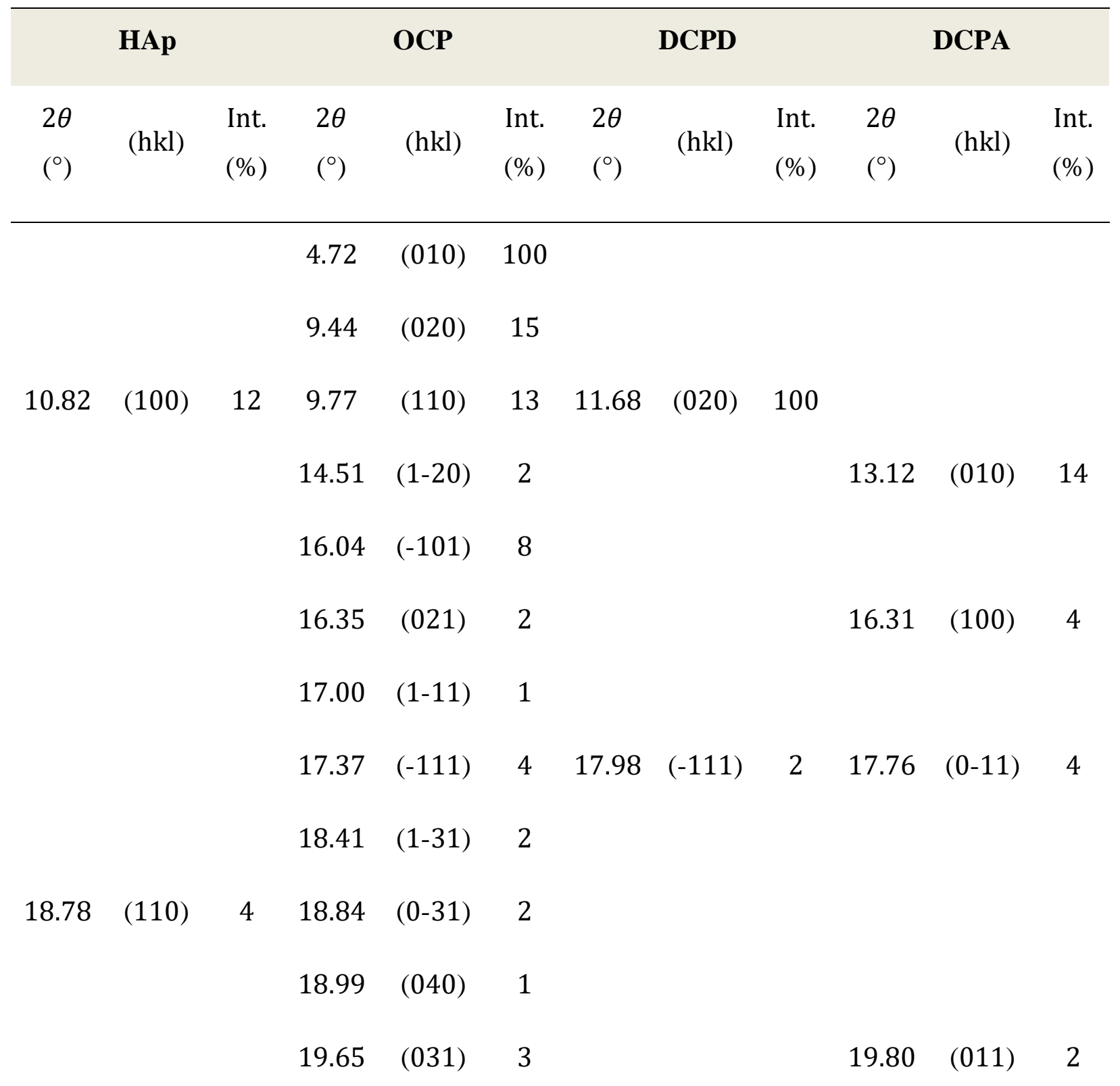




\begin{tabular}{|c|c|c|c|c|c|c|c|c|c|c|c|}
\hline & & & 19.75 & $(-121)$ & 3 & & & & 20.26 & $(-101)$ & 4 \\
\hline & & & 20.67 & (131) & 2 & 20.93 & $(021)$ & 100 & 20.79 & $(1-20)$ & 4 \\
\hline \multirow[t]{2}{*}{21.82} & $(200)$ & 10 & 21.60 & (230) & 2 & & & & & & \\
\hline & & & 22.67 & $(1-40)$ & 5 & & & & 22.04 & (101) & 4 \\
\hline \multirow[t]{5}{*}{22.90} & (111) & 10 & 22.91 & (201) & 4 & & & & & & \\
\hline & & & 23.01 & $(-201)$ & 3 & & & & & & \\
\hline & & & 23.48 & $(041)$ & 3 & 23.39 & $(040)$ & 8 & & & \\
\hline & & & 23.74 & (221) & 5 & 23.71 & (130) & $<1$ & & & \\
\hline & & & 24.30 & $(-211)$ & 10 & 24.50 & $(-131)$ & 2 & 24.03 & $(1-21)$ & 4 \\
\hline 25.35 & (201) & 2 & 25.49 & $(231)$ & 8 & & & & 25.58 & $(-121)$ & 14 \\
\hline \multirow[t]{6}{*}{25.88} & $(002)$ & 40 & 25.87 & $(2-21)$ & 17 & & & & & & \\
\hline & & & 26.00 & $(002)$ & 20 & & & & 26.43 & $(020)$ & 70 \\
\hline & & & 26.36 & $(-221)$ & 6 & & & & 26.59 & $(2-20)$ & 75 \\
\hline & & & 26.91 & $(-1-51)$ & 8 & & & & 26.75 & $(2-10)$ & 16 \\
\hline & & & 27.18 & $(1-50)$ & 8 & & & & 27.00 & $(002)$ & 10 \\
\hline & & & 27.78 & (250) & 3 & & & & & & \\
\hline
\end{tabular}

$28.13 \quad(102) \quad 12 \quad 28.04 \quad(241) \quad 2$

$28.47 \quad(-1-22) \quad 5$

$28.49 \quad \begin{array}{ll}(-1- \\ 21)\end{array}$

$28.97 \quad(201) \quad 18 \quad 28.61 \quad(-112) \quad 3$

$28.77 \quad(0-12) \quad 6$

$\begin{array}{lllllllll}29.21 & (0-32) & 5 & 29.26 & (041) & 75 & 29.90 & (-221) & 2\end{array}$ 


\begin{tabular}{|c|c|c|c|c|c|c|c|c|c|c|c|}
\hline & & & 29.60 & (330) & 3 & & & & 30.19 & $(-112)$ & 100 \\
\hline & & & 30.31 & $(-122)$ & 5 & & & & 30.41 & $(-102)$ & 35 \\
\hline & & & 30.66 & $(-151)$ & 4 & 30.51 & $(-221)$ & 50 & 30.68 & $(2-11)$ & 4 \\
\hline & & & 31.10 & (251) & 10 & & & & 31.02 & (021) & 8 \\
\hline & & & 31.55 & (260) & 33 & 31.30 & $(-112)$ & 10 & 31.17 & (111) & 4 \\
\hline 31.77 & (211) & 100 & 31.70 & $(2-41)$ & 32 & 31.97 & (200) & 2 & 31.44 & (012) & 2 \\
\hline 32.20 & (112) & 60 & 32.18 & $(-1-42)$ & 15 & & & & 32.38 & $(1-30)$ & 10 \\
\hline & & & 32.59 & (331) & 12 & & & & 32.48 & $(2-30)$ & 20 \\
\hline 32.90 & (300) & 60 & 33.06 & (042) & 8 & & & & 32.89 & (102) & 35 \\
\hline & & & 33.52 & $(070)$ & 17 & 33.54 & $(150)$ & 4 & & & \\
\hline 34.05 & (202) & 25 & 33.97 & $(1-61)$ & 12 & 33.82 & $(131)$ & 4 & & & \\
\hline & & & 34.24 & $(3-30)$ & 7 & 34.15 & $(220)$ & 50 & & & \\
\hline & & & 34.38 & $(2-22)$ & 7 & 34.43 & $(-202)$ & 30 & & & \\
\hline & & & 34.92 & $(-161)$ & 5 & 35.11 & $(002)$ & 4 & 34.73 & $(2-31)$ & 4 \\
\hline 35.48 & $(301)$ & 6 & 35.25 & $(-1-71)$ & 4 & 35.42 & $(060)$ & 2 & 35.42 & $(-122)$ & 4 \\
\hline & & & 36.10 & $(-2-51)$ & 2 & 35.60 & $(-132)$ & 4 & 35.91 & $(0-22)$ & 16 \\
\hline & & & 36.27 & (052) & 3 & & & & 36.06 & $\begin{array}{l}(-1- \\
12)\end{array}$ & 2 \\
\hline & & & 36.53 & $(1-70)$ & 2 & 36.90 & $(-241)$ & 14 & 36.76 & (201) & 2 \\
\hline & & & 38.02 & (180) & 2 & 37.10 & (022) & 16 & 37.26 & $(-212)$ & 2 \\
\hline & & & 38.52 & (271) & 3 & & & & 38.25 & $(2-22)$ & 4 \\
\hline
\end{tabular}




\begin{tabular}{|c|c|c|c|c|c|c|c|c|c|c|}
\hline \multirow[t]{3}{*}{39.20} & $(212)$ & 8 & 39.06 & $(-302)$ & 2 & & & & 39.04 & $(120)$ \\
\hline & & & 39.65 & $(361)$ & 2 & & & & 39.37 & $(2-12)$ \\
\hline & & & 39.76 & $(-1-81)$ & 2 & 39.71 & $(061)$ & 4 & & \\
\hline 39.82 & (310) & 20 & 39.89 & $(062)$ & 2 & & & & & \\
\hline
\end{tabular}


Table S2B. Raman shift $\left(\mathrm{cm}^{-1}\right)$ of $\mathrm{PO}_{4}^{3-}$ and $\mathrm{HPO}_{4}^{2-}$ groups of (CD)HAp, ACP, OCP, DCPD and DCPA reported in earlier works. ${ }^{3-6}$

\begin{tabular}{|c|c|c|c|c|c|}
\hline & (CD)HAp & $\mathrm{ACP}$ & ОСР & DCPD & DCPA \\
\hline $\begin{array}{c}v_{3}\left(\mathrm{PO}_{4}\right) \\
\text { or } \\
v_{3}\left(\mathrm{HPO}_{4}\right) \\
\text { stretch }\end{array}$ & $\begin{array}{l}1077 \\
1064 \\
1057 \\
1048 \\
1041 \\
1034 \\
1029\end{array}$ & 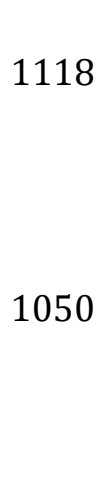 & $\begin{array}{c}1112\left(\mathrm{HPO}_{4}^{2-} \text { hydrated layer }\right) \\
1079\left(\mathrm{PO}_{4}^{3-} \text { and } \mathrm{HPO}_{4}^{2-}\right) \\
1052\left(\mathrm{PO}_{4}^{3-}\right) \\
1048\left(\mathrm{PO}_{4}^{3-}\right) \\
1036\left(\mathrm{PO}_{4}^{3-}\right) \\
1027\left(\mathrm{PO}_{4}^{3-}\right)\end{array}$ & $\begin{array}{l}1132 \\
1119 \\
1079 \\
1061\end{array}$ & $\begin{array}{l}1131 \\
1094\end{array}$ \\
\hline $\begin{array}{c}v_{1}\left(\mathrm{PO}_{4}\right) \\
\text { or } \\
v_{1}\left(\mathrm{HPO}_{4}\right) \\
\text { stretch }\end{array}$ & $\begin{array}{c}1011\left(\mathrm{HPO}_{4}^{2-} \mathrm{CDHAp}\right) \\
941-961\end{array}$ & . & $\begin{array}{c}1011\left(\mathrm{HPO}_{4}^{2-}\right) \\
1005\left(\mathrm{HPO}_{4}^{2-}\right) \\
966\left(\mathrm{PO}_{4}^{3-}\right) \\
959\left(\mathrm{PO}_{4}^{3-}\right)\end{array}$ & 986 & 988 \\
\hline $\begin{array}{c}v(\mathrm{P}-\mathrm{OH}) \\
\text { stretch }\end{array}$ & $\begin{array}{l}920 \text { (CDHAp) } \\
879 \text { (CDHAp) }\end{array}$ & & $\begin{array}{l}916 \text { (apatite layer) } \\
874 \text { (hydrated layer) }\end{array}$ & 878 & 900 \\
\hline $\begin{array}{c}v_{4}\left(\mathrm{PO}_{4}\right) \\
\text { or } \\
v_{4}\left(\mathrm{HPO}_{4}\right) \\
\text { stretch }\end{array}$ & $\begin{array}{l}614 \\
607 \\
591 \\
580\end{array}$ & 594 & $\begin{array}{c}619\left(\mathrm{PO}_{4}^{3-}\right) \\
609\left(\mathrm{PO}_{4}^{3-}\right) \\
591\left(\mathrm{PO}_{4}^{3-} \text { and } \mathrm{HPO}_{4}^{2-}\right) \\
577\left(\mathrm{PO}_{4}^{3-} \text { and } \mathrm{HPO}_{4}^{2-}\right) \\
556\left(\mathrm{PO}_{4}^{3-}\right) \\
523\left(\mathrm{PO}_{4}^{3-}\right)\end{array}$ & $\begin{array}{l}588 \\
525\end{array}$ & $\begin{array}{l}588 \\
574 \\
563\end{array}$ \\
\hline $\begin{array}{c}v_{2}\left(\mathrm{PO}_{4}\right) \\
\text { or } \\
v_{2}\left(\mathrm{HPO}_{4}\right) \\
\text { stretch }\end{array}$ & $\begin{array}{l}448 \\
433\end{array}$ & $\begin{array}{l}451 \\
419\end{array}$ & $\begin{array}{c}451\left(\mathrm{PO}_{4}^{3-}\right) \\
427\left(\mathrm{PO}_{4}^{3-}\right) \\
409\left(\mathrm{HPO}_{4}^{3-}\right) \\
353\left(\mathrm{HPO}_{4}^{2-} \text { hydrated layer }\right)\end{array}$ & $\begin{array}{l}411 \\
381\end{array}$ & 420 \\
\hline
\end{tabular}




\section{S3 - XRF calibration traces}

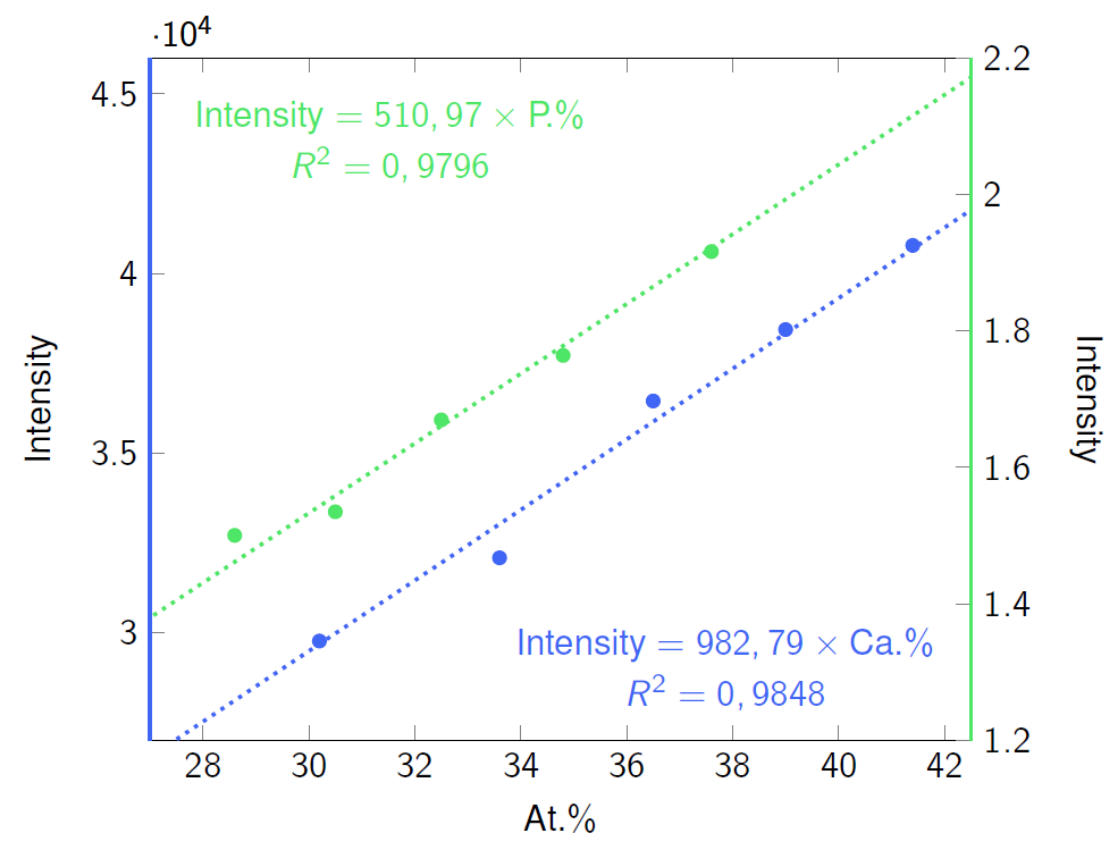

Figure S3. XRF calibration traces for the quantification of calcium (blue) and phosphorous (green). The dots represent the results of XRF analyses on beads of mechanical reference mixtures (see Materials and Methods). The dotted lines are the linear regressions used in the study to determine the Ca/P ratios of the synthesized CaPs.

\section{S4 - Apparent solubility of CaPs}

The phosphate and hydrogen phosphate groups constitutive of CaPs confer them a solubility in aqueous medium that is greatly influenced by the $\mathrm{pH}$ of the latter. The apparent solubility product $K_{S, a p p}^{C a P}$ associated with each calcium phosphate mineral is considered in order to analyze the influence of the acid-base equilibria on their dissolution in water. This temperature-dependent parameter is expressed from the solubility constants $K_{S}^{C a P}$ of the CaPs and the acidity constants $K_{a i}$ associated with the various phosphate species (Table 1).

In the case of the HAp crystalline phase, the dissolution-precipitation equilibrium in a buffered medium can be defined as:

$$
\begin{aligned}
& \mathrm{Ca}_{5}\left(\mathrm{PO}_{4}\right)_{3} \mathrm{OH}_{(\mathrm{s})}+(9 x+6 y+3 z+q) \mathrm{H}_{3} \mathrm{O}_{(\mathrm{aq})}^{+}=5 \mathrm{Ca}_{(\mathrm{aq})}^{2+}+3 x \mathrm{H}_{3} \mathrm{PO}_{4(\mathrm{aq})}+3 y \mathrm{H}_{2} \mathrm{PO}_{4(\mathrm{aq})}^{-} \\
& +3 z \mathrm{HPO}_{4(\mathrm{aq})}^{2-}+3 n \mathrm{PO}_{4(\mathrm{aq})}^{3-}+(1-q) \mathrm{HO}_{(\mathrm{aq})}^{-}+(9 x+6 y+3 z+2 q) \mathrm{H}_{2} \mathrm{O}_{(\mathrm{l})}
\end{aligned}
$$

where $x, y, z$ and $n$ stand for the molar fractions associated with $\mathrm{H}_{3} \mathrm{PO}_{4}, \mathrm{H}_{2} \mathrm{PO}_{4}^{-}, \mathrm{HPO}_{4}^{2-}$ and $\mathrm{PO}_{4}^{3-}$ entities, respectively, and $q$ and $1-q$ the molar fractions of oxonium and hydroxide ions, 
respectively. The dissolution equilibrium is associated with an apparent equilibrium constant $K_{s, a p p}^{H A p}$ which can be expressed according to:

$$
K_{s, a p p}^{H A p}=\frac{K_{s}^{H A p}}{K_{a 1}^{3 x} K_{a 2}^{3(x+y)} K_{a 3}^{3(x+y+z)} K_{w}^{q}}
$$

where $K_{w}$ is the autoprotolysis constant of water. Detailed demonstration for obtention of Eq. S4 is provided below. Due to the dependence of the molar fractions $x, y, z, n$ and $q$ on the $\mathrm{pH}$ at the equilibrium (Figure S4A and Eqs. S16-S19), the apparent solubility product is also a function of the latter, i.e. $K_{s, a p p}^{H A p}=f\left(\mathrm{pH}_{e q}\right)$. Hence, as commonly written in a strongly basic medium where $x \simeq y \simeq z \simeq q \simeq 0$ and $n \simeq 1$ (Figure S4A and Figure S4B), the dissolution equilibrium comes down to:

$$
\mathrm{Ca}_{5}\left(\mathrm{PO}_{4}\right)_{3} \mathrm{OH}_{(\mathrm{s})}=5 \mathrm{Ca}_{(\mathrm{aq})}^{2+}+3 \mathrm{PO}_{4(\mathrm{aq})}^{3-}+\mathrm{HO}_{(\mathrm{aq})}^{-}
$$

with

$$
K_{s, a p p}^{H A p}=K_{s}^{H A p}=a\left(\mathrm{Ca}^{2+}\right)_{e q}^{5} a\left(\mathrm{PO}_{4}^{3-}\right)_{e q}^{3} a\left(\mathrm{HO}^{-}\right)_{e q}
$$

where $a(\mathrm{i})_{e q}$ is the activity of the species $\mathrm{i}$ at the equilibrium and $K_{s}^{H A p}=10^{-58.6}$ at $37^{\circ} \mathrm{C} .^{7}$ Likewise, the $\mathrm{pH}$ dependence of the apparent solubility product can be expressed for each CaPs as developed below. For all of them, it appears that the lower the $\mathrm{pH}$ of the medium solution at the equilibrium, the higher the apparent solubility (Figure S4A). Such a significant increase in the solubility of CaPs in an acidic medium is accounted for by the speciation diagram of the phosphate species in solution. As the $\mathrm{pH}$ decreases, the protonation of the $\mathrm{PO}_{4}^{3-}$ and $\mathrm{HPO}_{4}^{2-}$ groups of the CaPs, into $\mathrm{HPO}_{4}^{2-}, \mathrm{H}_{2} \mathrm{PO}_{4}^{-}$and $\mathrm{H}_{3} \mathrm{PO}_{4}$ species, leads to a shift of the dissolution-precipitation equilibria towards the dissolution of the CaPs (Figure S4A). Although the $K_{s, a p p}^{H A p}$ parameter is dependent on the temperature of the medium (Table 1), its evolution as a function of the $\mathrm{pH}_{e q}$, is only slightly influenced in the $37-80^{\circ} \mathrm{C}$ temperature range at atmospheric pressure (Figures S4A and S4B). This result reflects the weak influence of this parameter on the stability of CaPs in aqueous solution. 


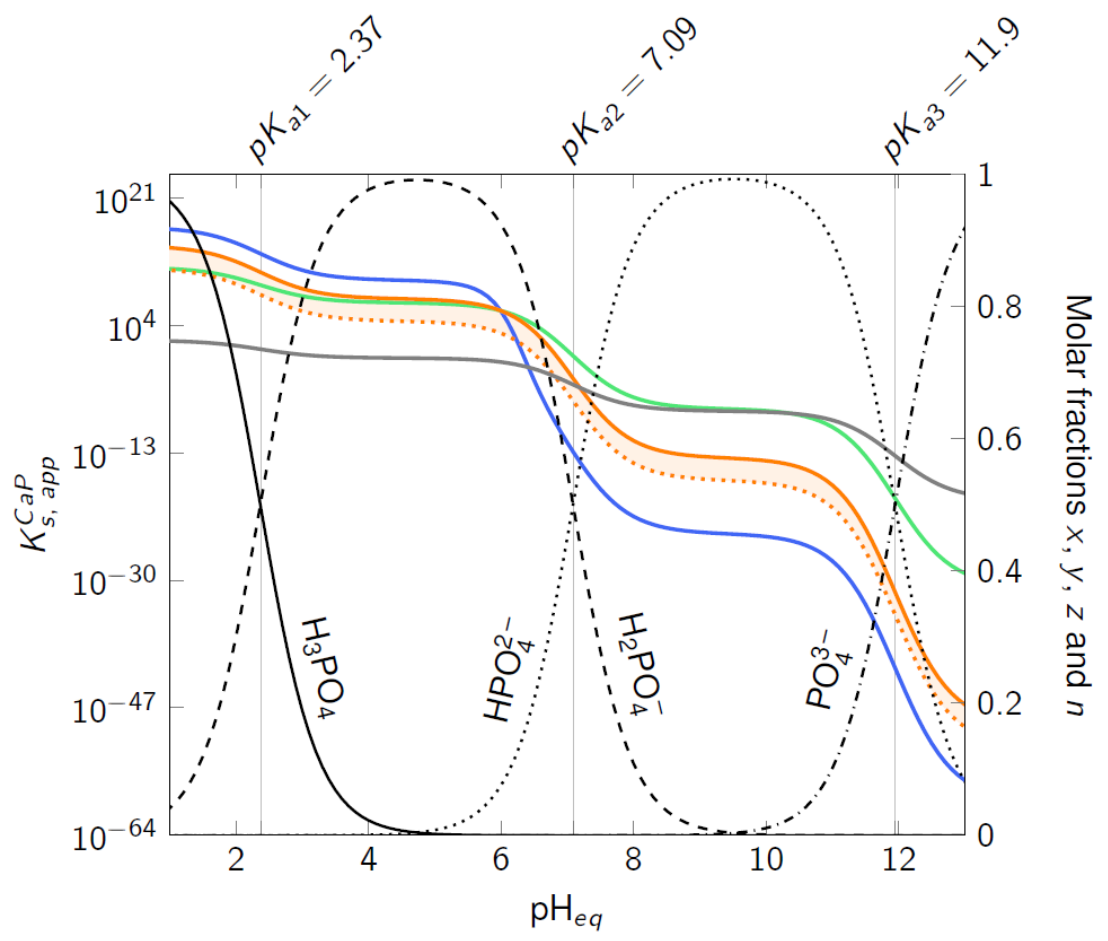

Figure S4A. Evolution of the apparent solubility product $K_{S, a p p}^{C a P}$ of HAp, ACP, OCP and DCPA as a function of the $\mathrm{pH}$ at the equilibrium at $80{ }^{\circ} \mathrm{C}$. As the DCPD trace is almost superimposed with that of DCPA, it is not plotted in the figure for a readability reason. For OCP, due to the important uncertainty on the value of its solubility product at $80{ }^{\circ} \mathrm{C}$ (Table 1), the corresponding domain is highlighted in orange. The speciation of the phosphate species in aqueous solution at $80{ }^{\circ} \mathrm{C}: \mathrm{H}_{3} \mathrm{PO}_{4}$ ( $x$, solid line), $\mathrm{H}_{2} \mathrm{PO}_{4}^{-}(y$, dashed line), $\mathrm{HPO}_{4}^{2-}(z$, dotted line $)$ and $\mathrm{PO}_{4}^{3-}(n$, dotdashed line).

In the acidic domain, the DCPA mineral is the CaP with the lowest apparent solubility product, whereas HAp has the highest one (Figure S4A). The reverse situation is observed in the alkaline domain, with DCPA and HAp becoming the most and the least soluble CaPs, respectively. These observations are fully consistent with the numerous protocols reported in the literature that report on the formation of DCPA and HAp under acidic and neutral/basic conditions, respectively. ${ }^{8,9}$ However, the $K_{s, a p p}^{C a P}$ parameter is not fully relevant to predict which $\mathrm{CaP}$ mineral will thermodynamically precipitate first under realistic operating synthesis conditions. In that respect, at a given $\mathrm{pH}$ in open systems (see Materials and Methods), the $\mathrm{Ca} / \mathrm{P}$ ratio of these compounds (Table 1), varying from 1.00 (DCPD and DCPA) to 1.67 (HAp), needs to be taken into account.

The apparent solubility product $K_{S, a p p}^{C a P}$ of a specified CaP mineral was determined based on its solubility constant $K_{s}^{C a P}$ and the equilibrium constants involving phosphate species $\left(K_{a i}\right)$ and 
water $\left(K_{w}\right)$ defined on Table 1. The computational method used is detailed in the case of hydroxyapatite. This mineral solubilizes in water according to Eq. S5.

Phosphate ions $\mathrm{PO}_{4}^{3-}$ are involved in the acid-base equilibrium:

$$
\mathrm{HPO}_{4(\mathrm{aq})}^{2-}+\mathrm{H}_{2} \mathrm{O}_{(\mathrm{l})}=\mathrm{PO}_{4(\mathrm{aq})}^{3-}+\mathrm{H}_{3} \mathrm{O}_{(\mathrm{aq})}^{+}
$$

with

$$
K_{a 3}=\frac{a\left(\mathrm{PO}_{4}^{3-}\right)_{e q} a\left(\mathrm{H}_{3} \mathrm{O}^{+}\right)_{e q}}{a\left(\mathrm{HPO}_{4}^{2-}\right)_{e q}}
$$

The protonation of $\mathrm{PO}_{4}{ }^{3-}$ ions allows the involvement of two other acid-base equilibria:

$$
\mathrm{H}_{2} \mathrm{PO}_{4(\mathrm{aq})}^{-}+\mathrm{H}_{2} \mathrm{O}_{(\mathrm{l})}=\mathrm{HPO}_{4(\mathrm{aq})}^{2-}+\mathrm{H}_{3} \mathrm{O}_{(\mathrm{aq})}^{+}
$$

with

$$
K_{a 2}=\frac{a\left(\mathrm{HPO}_{4}^{2-}\right)_{e q} a\left(\mathrm{H}_{3} \mathrm{O}^{+}\right)_{e q}}{a\left(\mathrm{H}_{2} \mathrm{PO}_{4}^{-}\right)_{e q}}
$$

and

$$
\mathrm{H}_{3} \mathrm{PO}_{4(\mathrm{aq})}+\mathrm{H}_{2} \mathrm{O}_{(\mathrm{l})}=\mathrm{H}_{2} \mathrm{PO}_{4(\mathrm{aq})}^{-}+\mathrm{H}_{3} \mathrm{O}_{(\mathrm{aq})}^{+}
$$

with

$$
K_{a 1}=\frac{a\left(\mathrm{H}_{2} \mathrm{PO}_{4}^{-}\right)_{e q} a\left(\mathrm{H}_{3} \mathrm{O}^{+}\right)_{e q}}{a\left(\mathrm{H}_{3} \mathrm{PO}_{4}\right)_{e q}}
$$

Hydroxide ions are involved in the autoprotolysis equilibrium of water:

$$
2 \mathrm{H}_{2} \mathrm{O}_{(\mathrm{l})}=\mathrm{HO}_{(\mathrm{aq})}^{-}+\mathrm{H}_{3} \mathrm{O}_{(\mathrm{aq})}^{+}
$$

with

$$
K_{w}=a\left(\mathrm{H}_{3} \mathrm{O}^{+}\right)_{e q} a\left(\mathrm{HO}^{-}\right)_{e q}
$$

No acid-base/complexation equilibrium involving $\mathrm{Ca}^{2+}$ cations was considered.

The apparent equilibrium constant $K_{s, a p p}^{H A p}$ can be expressed based on Eq.S4 as a function of the activity of the different species: 


$$
\begin{gathered}
K_{s, a p p}^{H A p}=\frac{a\left(\mathrm{Ca}^{2+}\right)_{e q}^{5} a\left(\mathrm{PO}_{4}^{3-}\right)_{e q}^{3} a\left(\mathrm{HO}^{-}\right)_{e q}}{K_{a 1}^{3 x} K_{a 2}^{3(x+y)}\left(\frac{a\left(\mathrm{PO}_{4}^{3-}\right)_{e q} a\left(\mathrm{H}_{3} \mathrm{O}^{+}\right)_{e q}}{a\left(\mathrm{HPO}_{4}^{2-}\right)_{e q}}\right)^{3(x+y+z)}\left(a\left(\mathrm{H}_{3} \mathrm{O}^{+}\right)_{e q} a\left(\mathrm{HO}^{-}\right)_{e q}\right)^{q}} \\
K_{s, a p p}^{H A p}=\frac{a\left(\mathrm{Ca}^{2+}\right)_{e q}^{5} a\left(\mathrm{PO}_{4}^{3-}\right)_{e q}^{3} a\left(\mathrm{HO}^{-}\right)_{e q}^{1-q}}{K_{a 1}^{3 x}\left(\frac{a\left(\mathrm{HPO}_{4}^{2-}\right)_{e q} a\left(\mathrm{H}_{3} \mathrm{O}^{+}\right)_{e q}}{a\left(\mathrm{H}_{2} \mathrm{PO}_{4}^{-}\right)_{e q}}\right)^{3(x+y)}\left(\frac{a\left(\mathrm{PO}_{4}^{3-}\right)_{e q}}{a\left(\mathrm{HPO}_{4}^{2-}\right)_{e q}}\right)^{3(x+y+z)} a\left(\mathrm{H}_{3} \mathrm{O}^{+}\right)_{e q}^{q+3(x+y+z)}} \\
K_{s, a p p}^{H A p}=\frac{a\left(\mathrm{Ca}^{2+}\right)_{e q}^{5} a\left(\mathrm{PO}_{4}^{3-}\right)_{e q}^{3} a\left(\mathrm{HO}^{-}\right)_{e q}^{1-q} a\left(\mathrm{HPO}_{4}^{2-}\right)_{e q}^{3 z}}{K_{a 1}^{3 x}\left(\frac{1}{a\left(\mathrm{H}_{2} \mathrm{PO}_{4}^{-}\right)_{e q}}\right)^{3(x+y)} a\left(\mathrm{PO}_{4}^{3-}\right)_{e q}^{3(x+y+z)} a\left(\mathrm{H}_{3} \mathrm{O}^{+}\right)_{e q}^{q+6(x+y)+3 z}}
\end{gathered}
$$

The speciation of phosphate species (Figures S4A and S4B) implies that at any pH the relation $x+y+z+n=1$ is verified. The last equation simplifies as:

$$
\begin{gathered}
K_{s, a p p}^{H A p}=\frac{a\left(\mathrm{Ca}^{2+}\right)_{e q}^{5} a\left(\mathrm{HO}^{-}\right)_{e q}^{1-q} a\left(\mathrm{PO}_{4}^{3-}\right)_{e q}^{3 n} a\left(\mathrm{HPO}_{4}^{2-}\right)_{e q}^{3 z}}{\left(\frac{a\left(\mathrm{H}_{2} \mathrm{PO}_{4}^{-}\right)_{e q} a\left(\mathrm{H}_{3} \mathrm{O}^{+}\right)_{e q}}{a\left(\mathrm{H}_{3} \mathrm{PO}_{4}\right)_{e q}}\right)^{3 x}\left(\frac{1}{a\left(\mathrm{H}_{2} \mathrm{PO}_{4}^{-}\right)_{e q}}\right)^{3(x+y)} a\left(\mathrm{H}_{3} \mathrm{O}^{+}\right)_{e q}^{q+6(x+y)+3 z}} \\
K_{s, a p p}^{\mathrm{HAp}}=\frac{a\left(\mathrm{Ca}^{2+}\right)_{e q}^{5} a\left(\mathrm{HO}^{-}\right)_{e q}^{1-q} a\left(\mathrm{PO}_{4}^{3-}\right)_{e q}^{3 n} a\left(\mathrm{HPO}_{4}^{2-}\right)_{e q}^{3 z} a\left(\mathrm{H}_{2} \mathrm{PO}_{4}^{-}\right)_{e q}^{3 y}}{\left(\frac{1}{a\left(\mathrm{H}_{3} \mathrm{PO}_{4}\right)_{e q}}\right)^{3 x} a\left(\mathrm{H}_{3} \mathrm{O}^{+}\right)_{e q}^{q+9 x+6 y+3 z}}
\end{gathered}
$$

Finally, the following equation is obtained:

$$
K_{s, a p p}^{H A p}=\frac{a\left(\mathrm{Ca}^{2+}\right)_{e q}^{5} a\left(\mathrm{HO}^{-}\right)_{e q}^{1-q} a\left(\mathrm{PO}_{4}^{3-}\right)_{e q}^{3 n} a\left(\mathrm{HPO}_{4}^{2-}\right)_{e q}^{3 z} a\left(\mathrm{H}_{2} \mathrm{PO}_{4}^{-}\right)_{e q}^{3 y} a\left(\mathrm{H}_{3} \mathrm{PO}_{4}^{-}\right)_{e q}^{3 x}}{a\left(\mathrm{H}_{3} \mathrm{O}^{+}\right)_{e q}^{q+9 x+6 y+3 z}}
$$

which accounts for the general dissolution equilibrium of HAp in a buffered medium (Eq. S3).

The parameters $x, y, z, n$ and $q$ are dependent on the $\mathrm{pH}$ at the equilibrium (Figures $\mathrm{S} 4 \mathrm{~A}$ and S4B) according to:

$$
\begin{gathered}
x=\frac{\left[\mathrm{H}_{3} \mathrm{PO}_{4}\right]_{e q}}{[\mathrm{P}]_{t o t}} \frac{1}{1+\frac{K_{a 1}}{10^{-\mathrm{pH}_{e q}}}+\frac{K_{a 1} K_{a 2}}{10^{-2 \mathrm{pH}_{e q}}+\frac{K_{a 1} K_{a 2} K_{a 3}}{10^{-3 \mathrm{pH}}}}} \\
y=\frac{\left[\mathrm{H}_{2} \mathrm{PO}_{4}^{-}\right]_{e q}}{[\mathrm{P}]_{t o t}}=\frac{\frac{K_{a 1}}{10^{-\mathrm{pH}_{e q}}}}{1+\frac{K_{a 1}}{10^{-\mathrm{pH}_{e q}}}+\frac{K_{a 1} K_{a 2}}{10^{-2 \mathrm{pH}}+\frac{K_{a 1} K_{a 2} K_{a 3}}{10^{-3 \mathrm{pH}}}}}
\end{gathered}
$$




$$
\begin{aligned}
& z=\frac{\left[\mathrm{HPO}_{4}^{2-}\right]_{e q}}{[\mathrm{P}]_{t o t}}=\frac{\frac{K_{a 1} K_{a 2}}{10^{-2 \mathrm{pH}} \mathrm{H}_{e q}}}{1+\frac{K_{a 1}}{10^{-\mathrm{pH}_{e q}}}+\frac{K_{a 1} K_{a 2}}{10^{-2 \mathrm{pH}_{e q}}}+\frac{K_{a 1} K_{a 2} K_{a 3}}{10^{-3 \mathrm{pH}}}} \\
& n=\frac{\left[\mathrm{PO}_{4}^{3-}\right]_{e q}}{[\mathrm{P}]_{t o t}}=\frac{\frac{K_{a 1} K_{a 2} K_{a 3}}{10^{-3 \mathrm{pH}} e q}}{1+\frac{K_{a 1}}{10^{-\mathrm{pH}_{e q}}}+\frac{K_{a 1} K_{a 2}}{10^{-2 \mathrm{pH}_{e q}}}+\frac{K_{a 1} K_{a 2} K_{a 3}}{10^{-3 \mathrm{pH} \mathrm{H}_{e q}}}} \\
& q=\frac{10^{-\mathrm{pH}_{e q}}}{10^{-\mathrm{pH}_{e q}}+10^{\mathrm{pH}_{e q}+\mathrm{p} K_{w}}}
\end{aligned}
$$

with $[\mathrm{P}]_{\text {tot }}=\left[\mathrm{H}_{3} \mathrm{PO}_{4}\right]_{e q}+\left[\mathrm{H}_{2} \mathrm{PO}_{4}^{-}\right]_{e q}+\left[\mathrm{HPO}_{4}^{2-}\right]_{e q}+\left[\mathrm{PO}_{4}^{3-}\right]_{e q}$ the total concentration in phosphate species.

The calculation of the apparent solubility product associated with the HAp mineral accounts for the influence of the $\mathrm{pH}$ on its solubility as $K_{s, a p p}^{H A p}=f(x, y, z, n, q)=f\left(\mathrm{pH}_{e q}\right)$.

Similarly, the apparent solubility products associated with the other calcium phosphates (ACP, OCP, DCPD and DCPA) were determined. In the case of ACP, the dissolution equilibrium in a buffered medium is defined as:

$$
\begin{gathered}
\mathrm{Ca}_{3}\left(\mathrm{PO}_{4}\right)_{2(\mathrm{~s})}+(6 x+4 y+2 z) \mathrm{H}_{3} \mathrm{O}_{(\mathrm{aq})}^{+}=3 \mathrm{Ca}_{(\mathrm{aq})}^{2+}+2 x \mathrm{H}_{3} \mathrm{PO}_{4(\mathrm{aq})}+2 y \mathrm{H}_{2} \mathrm{PO}_{4(\mathrm{aq})}^{-} \\
+2 z \mathrm{HPO}_{4(\mathrm{aq})}^{2-}+2 n \mathrm{PO}_{4(\mathrm{aq})}^{3-}+(6 x+4 y+2 z) \mathrm{H}_{2} \mathrm{O}_{(\mathrm{l})}
\end{gathered}
$$

It is associated with an apparent equilibrium constant $K_{s, a p p}^{A C P}$ :

$$
K_{s, a p p}^{A C P}=\frac{K_{s}^{A C P}}{K_{a 1}^{2 x} K_{a 2}^{2(x+y)} K_{a 3}^{2(x+y+z)}}
$$

In the case of OCP, the dissolution equilibrium in a buffered medium is defined as:

$$
\begin{aligned}
& \mathrm{Ca}_{4} \mathrm{HPO}_{4}\left(\mathrm{PO}_{4}\right)_{2} \cdot \frac{5}{2} \mathrm{H}_{2} \mathrm{O}_{(\mathrm{s})}+(9 x+6 y+3 z-1) \mathrm{H}_{3} \mathrm{O}_{(\mathrm{aq})}^{+}=4 \mathrm{Ca}_{(\mathrm{aq})}^{2+}+3 x \mathrm{H}_{3} \mathrm{PO}_{4(\mathrm{aq})} \\
& +3 y \mathrm{H}_{2} \mathrm{PO}_{4(\mathrm{aq})}^{-}+3 z \mathrm{HPO}_{4(\mathrm{aq})}^{2-}+3 n \mathrm{PO}_{4(\mathrm{aq})}^{3-}+\left(9 x+6 y+3 z+\frac{3}{2}\right) \mathrm{H}_{2} \mathrm{O}_{(\mathrm{l})}
\end{aligned}
$$

It is associated with an apparent equilibrium constant $K_{S, a p p}^{O C P}$ : 


$$
K_{s, a p p}^{O C P}=\frac{K_{s}^{O C P}}{K_{a 1}^{3 x} K_{a 2}^{3(x+y)} K_{a 3}^{3(x+y+z-1)}}
$$

In the case of DCPD, the dissolution equilibrium in a buffered medium is defined as:

$$
\begin{aligned}
& \mathrm{CaHPO}_{4} \cdot 2 \mathrm{H}_{2} \mathrm{O}_{(\mathrm{s})}+(2 x+y-\mathrm{n}-1) \mathrm{H}_{3} \mathrm{O}_{(\mathrm{aq})}^{+}=\mathrm{Ca}_{(\mathrm{aq})}^{2+}+x \mathrm{H}_{3} \mathrm{PO}_{4(\mathrm{aq})} \\
& +y \mathrm{H}_{2} \mathrm{PO}_{4(\mathrm{aq})}^{-}+z \mathrm{HPO}_{4(\mathrm{aq})}^{2-}+n \mathrm{PO}_{4(\mathrm{aq})}^{3-}+(2 x+y-\mathrm{n}+2) \mathrm{H}_{2} \mathrm{O}_{(\mathrm{l})}
\end{aligned}
$$

It is associated with an apparent equilibrium constant $K_{s, a p p}^{D C P D}$ :

$$
K_{s, a p p}^{D C P D}=\frac{K_{s}^{D C P D} K_{a 3}^{n}}{K_{a 1}^{x} K_{a 2}^{x+y}}
$$

Finally, in the case of DCPA, the dissolution equilibrium in a buffered medium is defined as:

$$
\begin{aligned}
& \mathrm{CaHPO}_{4(\mathrm{~s})}+(2 x+y-\mathrm{n}-1) \mathrm{H}_{3} \mathrm{O}_{(\mathrm{aq})}^{+}=\mathrm{Ca}_{(\mathrm{aq})}^{2+}+x \mathrm{H}_{3} \mathrm{PO}_{4(\mathrm{aq})} \\
& +y \mathrm{H}_{2} \mathrm{PO}_{4(\mathrm{aq})}^{-}+z \mathrm{HPO}_{4(\mathrm{aq})}^{2-}+n \mathrm{PO}_{4(\mathrm{aq})}^{3-}+(2 x+y-\mathrm{n}) \mathrm{H}_{2} \mathrm{O}_{(\mathrm{l})}
\end{aligned}
$$

It is associated with an apparent equilibrium constant $K_{s, a p p}^{D C P A}$ :

$$
K_{s, a p p}^{D C P A}=\frac{K_{s}^{D C P A} K_{a 3}^{n}}{K_{a 1}^{x} K_{a 2}^{x+y}}
$$




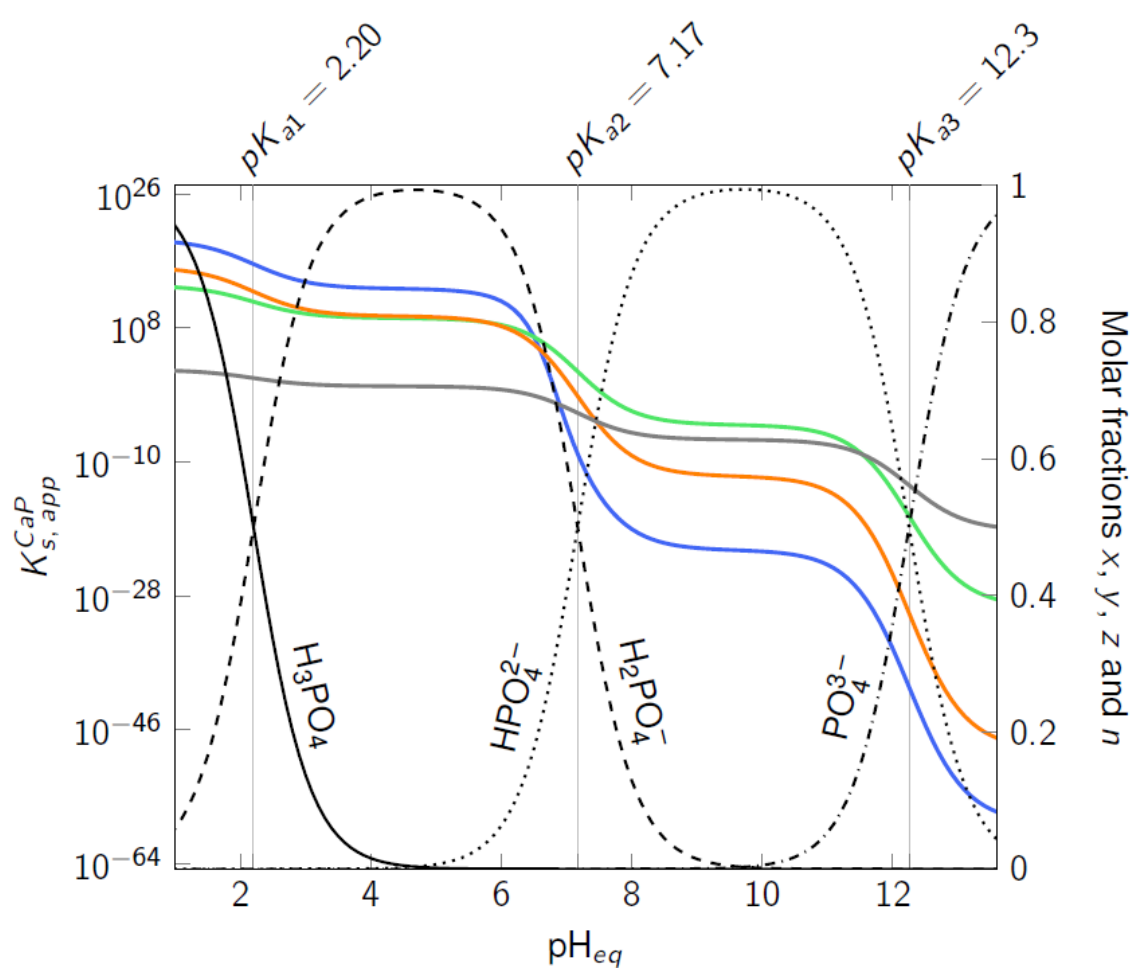

Figure S4B. Evolution of the apparent solubility product $K_{s, a p p}^{C a P}$ of HAp, ACP, OCP and DCPA as a function of the $\mathrm{pH}_{e q}$ at $37^{\circ} \mathrm{C}$. As the DCPD trace is almost superimposed with that of DCPA, it has not been plotted for a readability reason. Speciation of phosphate species in aqueous solution at $37{ }^{\circ} \mathrm{C}: \mathrm{H}_{3} \mathrm{PO}_{4}$ ( $x$, solid line), $\mathrm{H}_{2} \mathrm{PO}_{4}^{-}(y$, dashed line $), \mathrm{HPO}_{4}^{2-}(z$, dotted line $)$ and $\mathrm{PO}_{4}^{3-}(n$, dotdashed line $)$.

\section{S5 - Precipitation conditions of CaPs for the $\mathrm{Ca} \rightarrow \mathrm{P}$ and $\mathrm{P} \rightarrow \mathrm{Ca}$ synthesis routes}

The thermodynamic approach developed in section I Thermodynamic modelling of the precipitation of calcium phosphates in open systems for the HAp material has been applied to predict the conditions for the precipitation of ACP, OCP, DCPD and DCPA. Note that the criterion $Q \geq K_{s}$ (thermodynamic driving force) that was taken to estimate the precipitation conditions is the same as that commonly reported as $S \geq 1$, where $S$ is the supersaturation of the solution. Indeed, for an ionic solid of stoichiometry $v$, these different parameters are linked according to equation S29:

$$
S=\left(\frac{Q}{K_{S}}\right)^{\frac{1}{v}}
$$

Following the $\mathrm{Ca} \rightarrow \mathrm{P}$ synthesis route, the different $\mathrm{CaPs}$ precipitate spontaneously at the beginning of the addition step if the concentration $\left[\mathrm{Ca}^{2+}\right]_{\min }^{\mathrm{CaP}}$ introduced into the reactor verifies: 


$$
\begin{gathered}
{\left[\mathrm{Ca}^{2+}\right]_{\min }^{A C P}=\frac{1}{\gamma_{2 \pm}}\left(\frac{K_{s}^{A C P}\left(c^{\circ}\right)^{5}}{\gamma_{3 \pm}^{2}\left[\mathrm{PO}_{4}^{3-}\right]_{r}^{2}}\right)^{\frac{1}{3}}} \\
{\left[\mathrm{Ca}^{2+}\right]_{\min }^{O C P}=\frac{1}{\gamma_{2 \pm}}\left(\frac{K_{s}^{O C P}\left(c^{\circ}\right)^{8}}{\gamma_{3 \pm}^{3}\left[\mathrm{PO}_{4}^{3-}\right]_{r}^{3} \gamma_{ \pm}\left[\mathrm{H}_{3} \mathrm{O}^{+}\right]_{r}}\right)^{\frac{1}{4}}} \\
{\left[\mathrm{Ca}^{2+}\right]_{\min }^{D C P D}=\frac{K_{s}^{D C P D}\left(c^{\circ}\right)^{2}}{\gamma_{2 \pm}^{2}\left[\mathrm{HPO}_{4}^{2-}\right]_{r}}} \\
{\left[\mathrm{Ca}^{2+}\right]_{\min }^{D C P A}=\frac{K_{s}^{D C P D}\left(c^{\circ}\right)^{2}}{\gamma_{2 \pm}^{2}\left[\mathrm{HPO}_{4}^{2-}\right]_{r}}}
\end{gathered}
$$

Following the $\mathrm{P} \rightarrow \mathrm{Ca}$ synthesis route, the different $\mathrm{CaPs}$ precipitate spontaneously at the beginning of the addition step if the concentration $[\mathrm{P}]_{\min }^{\mathrm{CaP}}$ introduced into the reactor verifies:

$$
\begin{gathered}
{[\mathrm{P}]_{\min }^{A C P}=\frac{1}{n \gamma_{3 \pm}}\left(\frac{K_{s}^{A C P}\left(c^{\circ}\right)^{5}}{\gamma_{2 \pm}^{3}\left[\mathrm{Ca}^{2+}\right]_{r}^{3}}\right)^{\frac{1}{2}}} \\
{[\mathrm{P}]_{\min }^{O C P}=\frac{1}{n \gamma_{3 \pm}}\left(\frac{K_{s}^{O C P}\left(c^{\circ}\right)^{8}}{\gamma_{2 \pm}^{3}\left[\mathrm{Ca}^{2+}\right]_{r}^{4} \gamma_{ \pm}\left[\mathrm{H}_{3} \mathrm{O}^{+}\right]_{r}}\right)^{\frac{1}{3}}} \\
{[\mathrm{P}]_{\min }^{D C P D}=\frac{K_{s}^{D C P D}\left(c^{\circ}\right)^{2}}{z \gamma_{2 \pm}^{2}\left[\mathrm{Ca}^{2+}\right]_{r}}} \\
{[\mathrm{P}]_{\min }^{D C P A}=\frac{K_{s}^{D C P A}\left(c^{\circ}\right)^{2}}{z \gamma_{2 \pm}^{2}\left[\mathrm{Ca}^{2+}\right]_{r}}}
\end{gathered}
$$



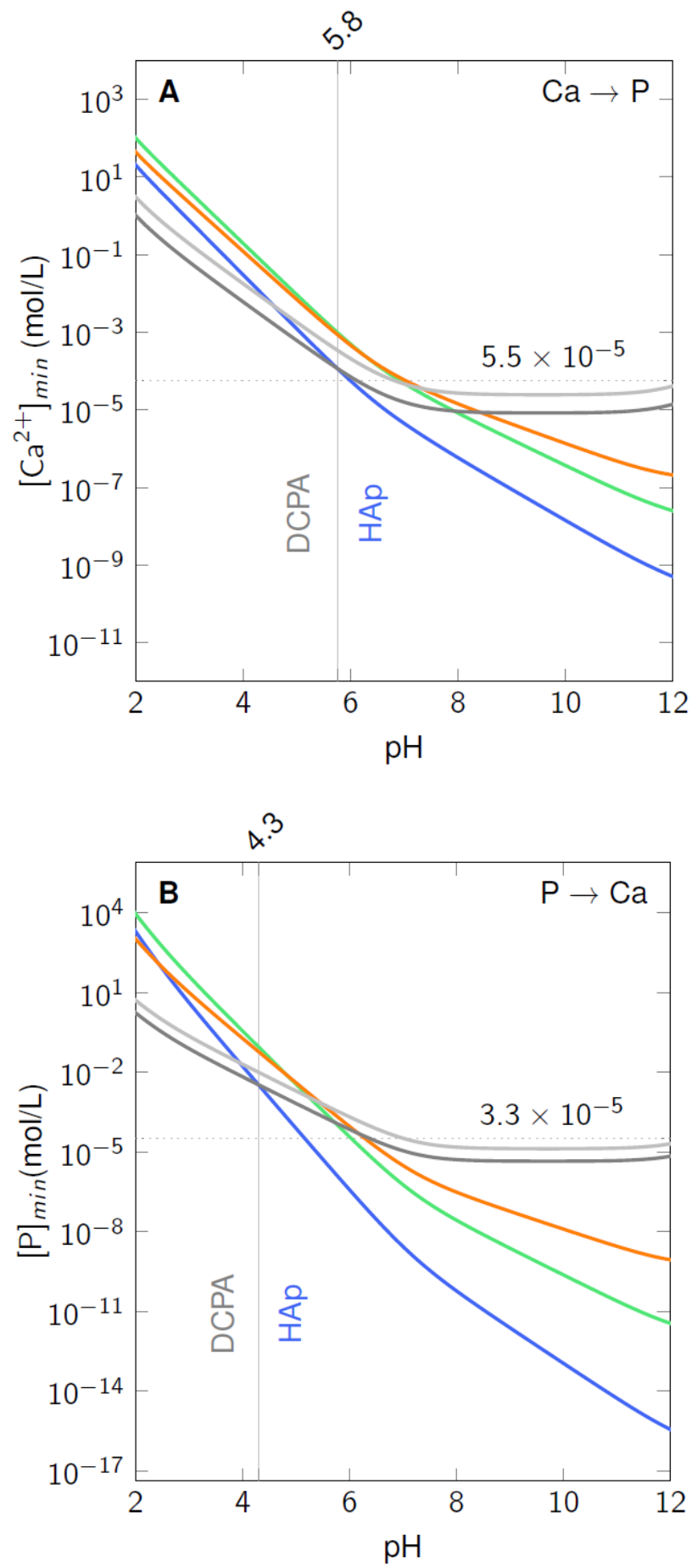

Figure S5A. Thermodynamic traces predicting the minimum concentration in precursor to be initially introduced into the reactor for both $\mathrm{Ca} \rightarrow \mathrm{P}(\mathbf{A})$ and $\mathrm{P} \rightarrow \mathrm{Ca}(\mathbf{B})$ routes in order to precipitate the different calcium phosphates HAp, ACP, OCP, DCPD and DCPA at $37{ }^{\circ} \mathrm{C}$ (modelling parameters: $[\mathrm{P}]_{r}=0.13$ $\mathrm{mol} / \mathrm{L}$, and $\left.\left[\mathrm{Ca}^{2+}\right]_{r}=0.22 \mathrm{~mol} / \mathrm{L}\right)$. Specified concentrations of $\left[\mathrm{Ca}^{2+}\right]=5.5 \times 10^{-5} \mathrm{~mol} / \mathrm{L}$ and $[\mathrm{P}]=$ $3.3 \times 10^{-5} \mathrm{~mol} / \mathrm{L}$ are those estimated in the reactor after one drop of the corresponding precursor is added (see Materials and Methods). 


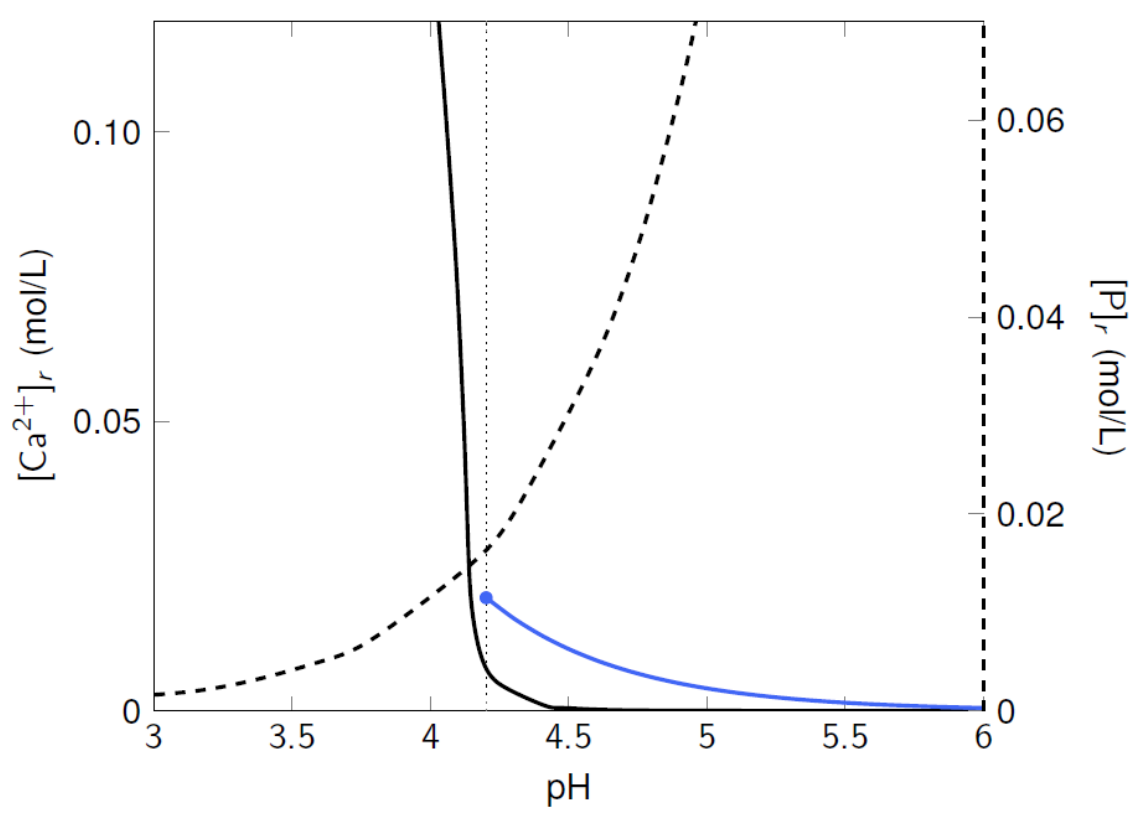

Figure S5B. Magnification of Figure 5 showing in blue, the concentrations in calcium ions and phosphate species at the end of the addition step considering a targeted final ratio $\left[\mathrm{Ca}^{2+}\right] /[\mathrm{P}]$ of 1.67 and assuming that the thermodynamic equilibrium is achieved. Note that the more acidic the reaction medium at the equilibrium, the greater the concentration of $\mathrm{Ca}^{2+}$ and $\mathrm{H}_{x} \mathrm{PO}_{4}^{(3-x)-}$ ions as discussed in Section $\mathrm{I}$.

S6 - Low-angle diffractograms of HAp samples prepared at pH $\mathbf{6 . 5}$ The diffractograms of the samples prepared at $\mathrm{pH} 6.5$ were acquired at low-angles to ascertain the absence of OCP in the corresponding samples (Figure S6).

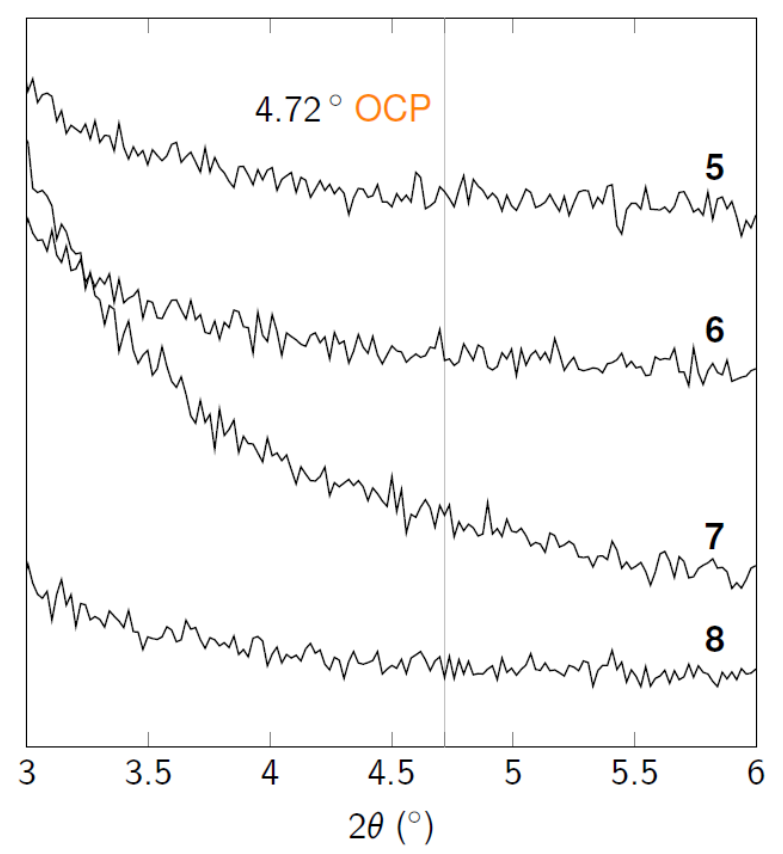

Figure S6. Low-angle XRD patterns of samples 5, 6, 7 and 8 prepared at pH 6.5 (Table 2). 


\section{S7 - DCPA hydrolysis into CDHAp during the washing step}

Due to the slight acidity of the distilled water $(\mathrm{pH} \approx 6.5)$ and the absence of phosphate ions, the DCPA formed in the reactor is susceptible to be hydrolyzed into HAp during the washing step (Figure S7). In that respect, the impact of the exposure time of DCPA to distilled water was investigated by comparing two procedures: centrifugation (precipitates exposed for $\approx 1 \mathrm{~h}$ to distilled water) and filtration on Büchner (precipitates exposed for $\approx 5$ min to distilled water).

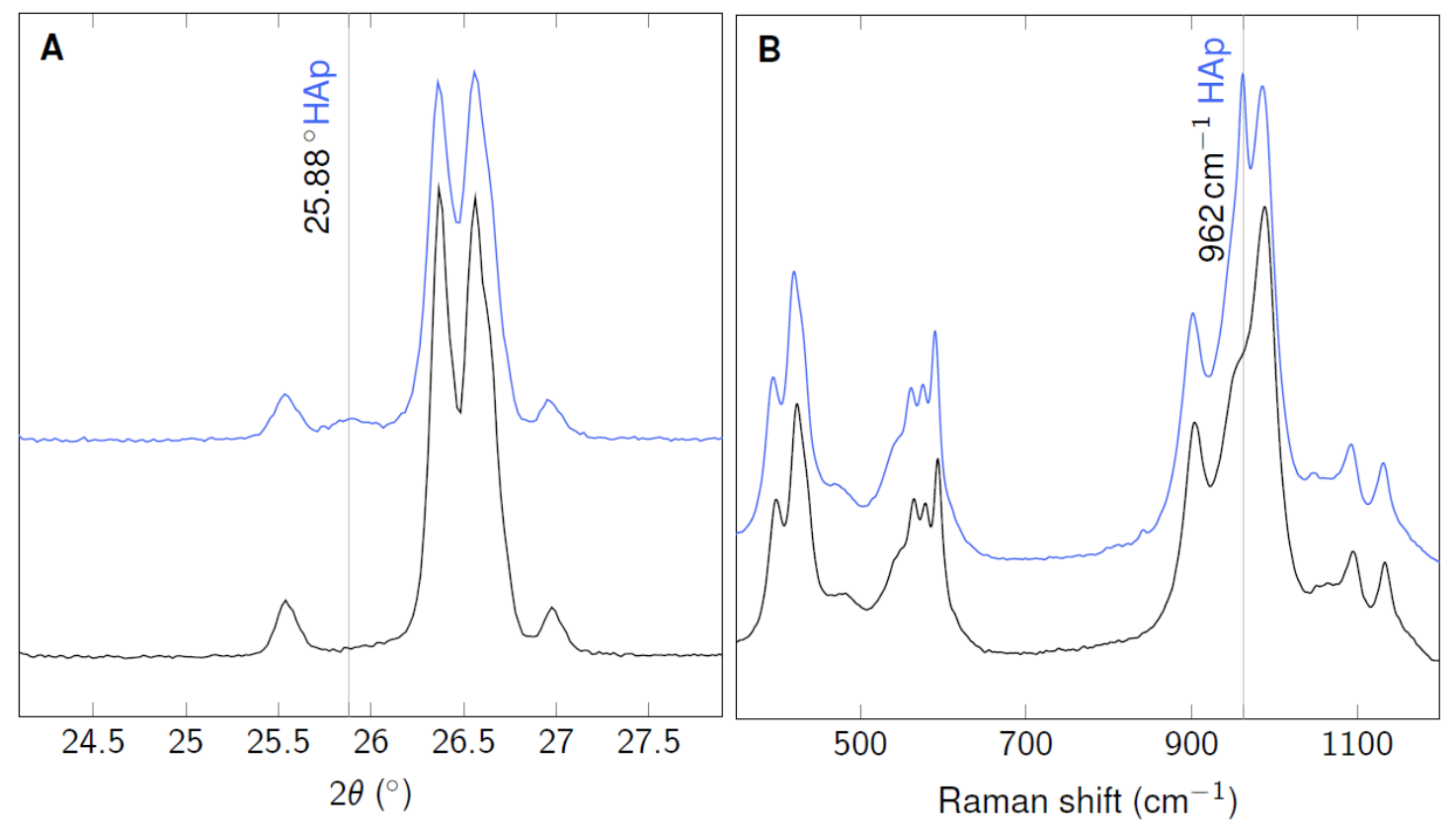

Figure S7. XRD patterns (A) and Raman spectra (B) of the samples prepared at $\mathrm{pH} 4.2$ and $80{ }^{\circ} \mathrm{C}$ following the $\mathrm{P} \rightarrow$ Ca route after recovering and washing promptly with distilled water on Büchner (black line) or by centrifugation (blue line, sample 11). The longer exposure of the sample in a slightly acidic medium when recovered by centrifugation compared to filtration on Büchner allow for more pronounced hydrolysis of DCPA into (CD)HAp in the precipitates. 
S8 - Sample 13

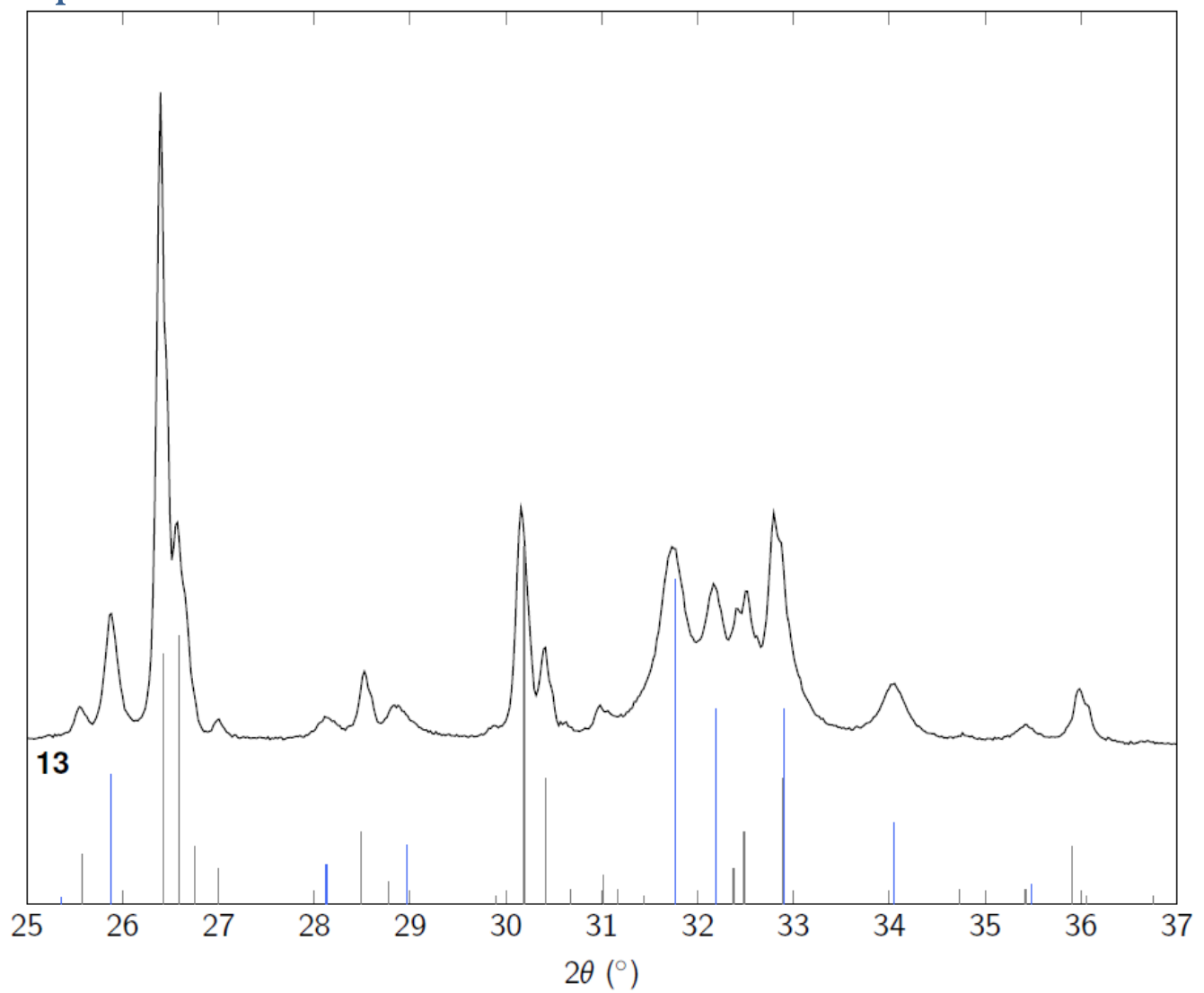

Figure S8. XRD patterns of the sample 13 prepared at $\mathrm{pH} 4.2$ and $80{ }^{\circ} \mathrm{C}$ following the $\mathrm{Ca} \rightarrow \mathrm{P}$ synthesis route (Table 2) and position of the diffraction lines expected for DCPA (grey, ICDD reference card $\mathrm{n}^{\circ} 00$ 009-0080) and for HAp (blue, ICDD reference card n ${ }^{\circ}$ 00-009-043).

S9 - High magnification images of rod-like and platelet/ribbon-like crystallites
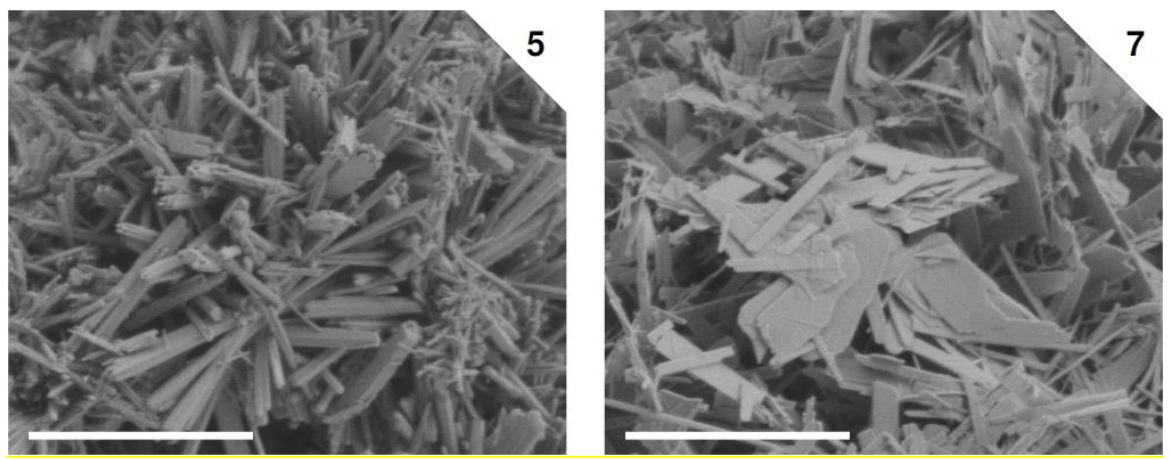

Figure S9. Scanning electron microscopy images of samples 5 and 7 prepared at $\mathrm{pH} 6.5$ following the $\mathrm{Ca} \rightarrow$ $\mathrm{P}$ and $\mathrm{P} \rightarrow$ Ca routes, respectively. The numbers indicated on the top right corners of the images refer to as the sample references listed in Table 2. Scale bars: $2 \mu \mathrm{m}$. 


\section{S10 - Hexagonal section of samples 2 and 5}

Transmission electron microscopy (TEM) observations were done on ultrathin cuttings of crystallites in order to visualize hexagonal sections of few rods (Table 2, samples 2 and 5). The sections were prepared as follows: a few milligrams of powder were embedding in a resin. Polymerization of the resin took place at $70^{\circ} \mathrm{C}$ for $48 \mathrm{~h}$, then the polymerized blocks were cut with a diamond knife in slices (around $70 \mathrm{~nm}$ in thickness). These slices were then deposited on copper grids covered with a carbon membrane layer. TEM images were taken on a JEOLJEM2100Plus electron microscope operating at $200 \mathrm{keV}$ ( $\mathrm{LaB}_{6}$ gun). For samples 2 and 5, crystallites with a more or less distorted hexagonal section are observed (Figure S10).
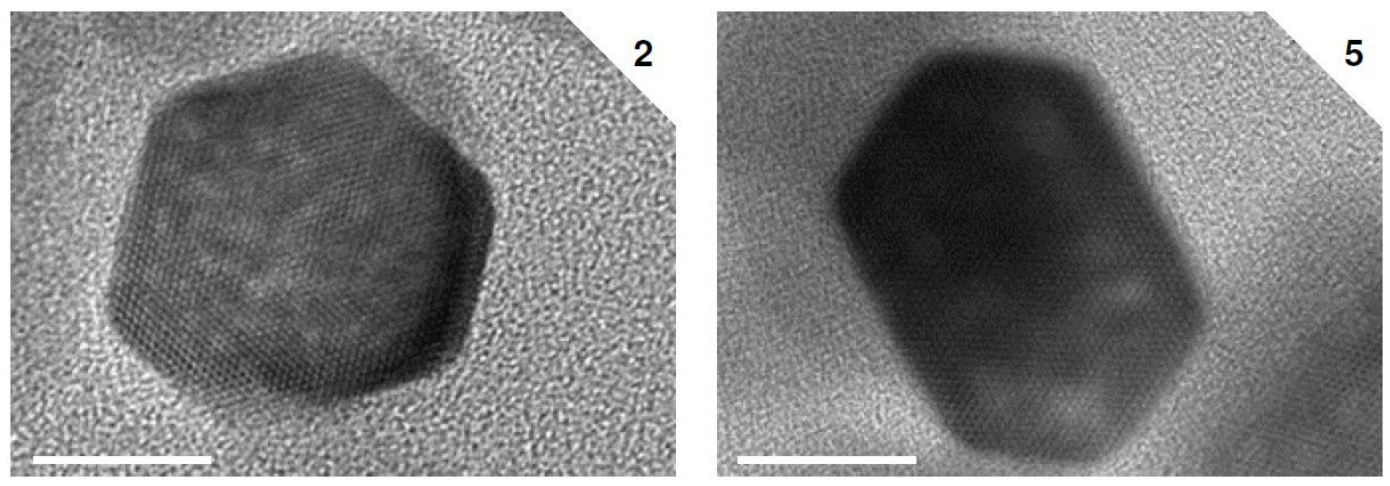

Figure S10. TEM images of hexagonal sections of rods from samples 2 and 5 prepared according to the $\mathrm{P} \rightarrow \mathrm{Ca}$ route at $\mathrm{pH} 9.0$ and 6.5, respectively. The numbers indicated on the top right corners of the images refer to as the sample references listed in Table 2. Scale bars: $20 \mathrm{~nm}$.

\section{References}

(1) Bandura, A. V.; Lvov, S. N. The Ionization Constant of Water over Wide Ranges of Temperature and Density. J. Phys. Chem. Ref. Data 2005, 35, 15-30.

(2) Emerson, K.; Russo, R. C.; Lund, R. E.; Thurston, R. V. Aqueous Ammonia Equilibrium Calculations: Effect of $\mathrm{pH}$ and Temperature. J. Fish. Board Can. 2011.

(3) Blakeslee, K. C.; Condrate, R. A. Vibrational Spectra of Hydrothermally Prepared Hydroxyapatites. J. Am. Ceram. Soc. 1971, 54, 559-563.

(4) Stammeier, J. A.; Purgstaller, B.; Hippler, D.; Mavromatis, V.; Dietzel, M. In-Situ Raman Spectroscopy of Amorphous Calcium Phosphate to Crystalline Hydroxyapatite Transformation. MethodsX 2018, 5, 1241-1250.

(5) Fowler, B. O.; Marković, M.; Brown, W. Octacalcium Phosphate. 3. Infrared and Raman Vibrational Spectra. Chem. Mater. 1993, 5, 1417-1423. 
(6) Xu, J.; Butler, I. S.; Gilson, D. F. R. FT-Raman and High-Pressure Infrared Spectroscopic Studies of Dicalcium Phosphate Dihydrate (CaHPO 4.2H 2O) and Anhydrous Dicalcium Phosphate (CaHPO 4). Spectrochim. Acta Part Mol. Spectrosc. 1999, 55, 2801-2809.

(7) McDowell, H.; Gregory, T. M.; Brown, W. E. Solubility of $\mathrm{Ca}_{5}\left(\mathrm{PO}_{4}\right)_{3} \mathrm{OH}$ in the System $\mathrm{Ca}(\mathrm{OH})_{2}-\mathrm{H}_{3} \mathrm{PO}_{4}-\mathrm{H}_{2} \mathrm{O}$ at 5, 15, 25, and $37{ }^{\circ} \mathrm{C}$. J. Res. Natl. Bur. Stand. Sect. Phys. Chem. 1977, 81A, 273-281.

(8) Suchanek, K.; Bartkowiak, A.; Perzanowski, M.; Marszałek, M. From Monetite Plate to Hydroxyapatite Nanofibers by Monoethanolamine Assisted Hydrothermal Approach. Sci. Rep. 2018, 8 .

(9) Chen, S.; Krumova, M.; Cölfen, H.; Sturm, E. V. Synthesis of Fiber-like Monetite without Organic Additives and Its Transformation to Hydroxyapatite. Chem. Mater. 2019, 31 (5), $1543-1551$. 
